\title{
A Comprehensive Review on Pharmacotherapeutics of Herbal Bioenhancers
}

\author{
Ghanshyam B. Dudhatra, Shailesh K. Mody, Madhavi M. Awale, Hitesh B. Patel, \\ Chirag M. Modi, Avinash Kumar, Divyesh R. Kamani, and Bhavesh N. Chauhan
} Department of Pharmacology \& Toxicology, College of Veterinary Science \& Animal Husbandry, Sardarkrushinagar Dantiwada
Agricultural University, Sardarkrushinagar 385506, Gujarat, India

Correspondence should be addressed to Ghanshyam B. Dudhatra, drgvets@gmail.com

Received 24 June 2012; Accepted 9 August 2012

Academic Editors: K. Ebihara and F. Song

Copyright (C) 2012 Ghanshyam B. Dudhatra et al. This is an open access article distributed under the Creative Commons Attribution License, which permits unrestricted use, distribution, and reproduction in any medium, provided the original work is properly cited.

\begin{abstract}
In India, Ayurveda has made a major contribution to the drug discovery process with new means of identifying active compounds. Recent advancement in bioavailability enhancement of drugs by compounds of herbal origin has produced a revolutionary shift in the way of therapeutics. Thus, bibliographic investigation was carried out by analyzing classical text books and peerreviewed papers, consulting worldwide-accepted scientific databases from last 30 years. Herbal bioenhancers have been shown to enhance bioavailability and bioefficacy of different classes of drugs, such as antibiotics, antituberculosis, antiviral, antifungal, and anticancerous drugs at low doses. They have also improved oral absorption of nutraceuticals like vitamins, minerals, amino acids, and certain herbal compounds. Their mechanism of action is mainly through absorption process, drug metabolism, and action on drug target. This paper clearly indicates that scientific researchers and pharmaceutical industries have to give emphasis on experimental studies to find out novel active principles from such a vast array of unexploited plants having a role as a bioavailability and bioefficacy enhancer. Also, the mechanisms of action by which bioenhancer compounds exert bioenhancing effects remain to be explored.
\end{abstract}

\section{Introduction}

Modern pharmaceutical research is concerned with all aspects of identifying new chemical substances with new modes of action. Particularly, economics of treatment linked to drug dosage has led to new drug development technologies. As a result, treatments are now becoming more affordable for wide sections of society, including the financially challenged. One way to achieve reduction in drug dosage, and therefore drug toxicity and cost, is to increase drug bioavailability [1]. The consumption of antibiotics and drugs by man is increasing at an alarming rate. Out of the total drugs and chemicals, $20-50 \%$ of that use is unnecessary depending on the class of antibiotic. In addition, indiscriminate use of antibiotics promotes antibiotic resistance leading to multiple drug resistance and makes it difficult to control the diseases. The infected individuals have to consume more amount of antibiotics; this may be due to (1) reduced absorption in gut membrane when taken orally,
(2) restrictive uptake by target microbe, and (3) operation of efflux pump leading to indiscriminate extrusion of the antibiotics or therapeutic molecules. So, the major amount of the applied drug is wasted and only a minor amount is being targeted to the site of infection [2].

In addition, the unutilized drug/antibiotics amount remains as a load in the body and environment acting as a selection pressure facilitating emergence of drug resistance, ultimately leading to failure of antibiotics against resistant infections. This is also responsible for side effects, illness, and reduction in life expectancy. One of the possible ways to reduce drug dosage is synergism between two therapeutic agents, that is, combination therapy. However, if both drugs used concurrently have antimicrobial property, the problem of selection pressure and drug toxicity will continue. Thus, there is need of molecules, which are not antimicrobial or target drugs but enhance activity and availability of main drugs in combination therapy, that is, bioenhancers. These molecules by their presence will not exert any selection 
pressure for mutants to emerge resistant against them and on that their ill effects can be minimized. The resistance development process will be substantially delayed, ultimately leading to enhanced life-span of the novel and existing antibiotics. Such drugs/molecule facilitators should have novel properties such as (1) nontoxic to humans or animals, (2) they should be effective at a very low concentration in a combination, (3) they should be easy to formulate, and (4) most importantly enhance uptake/absorption and activity of the drug molecules. This can lead to developing judicious and strategic concentrations of antibiotic with specific bioenhancers to improve availability of the drug for controlling the infectious organisms effectively [2].

Herbal bioenhancer is an agent of herbal origin or any phytomolecule, which is capable of enhancing bioavailability and bioefficacy of a particular drug or nutrient with which it is combined, without any typical pharmacological activity of its own at the dose used. In the 1920's, Bose, an acknowledged author of "Pharmacographia Indica," reported an enhanced antiasthmatic effect of an Ayurvedic formula containing vasaka (Adhatoda vasica) when administered with long pepper [3]. The term bioavailability enhancer was first coined by Indian Scientists at the Regional Research laboratory, Jammu (RRL, now known as Indian Institute of Integrative Medicine) discovered and scientifically validated piperine as the world's first bioavailability enhancer in 1979 [4].

The concept of bioenhancers of herbal origin can be tracked back from the ancient knowledge of Ayurveda system of medicine. Use of ayurvedic preparation "Trikatu" from the period between the 7th century B.C. and the 6th century A.D., which is a Sanskrit, word meaning three acrids. It refers to a combination of black pepper (Piper nigrum Linn.), long pepper (Piper longum Linn.), and ginger (Zingiber officinale Rosc.), which contains active component piperine, which enhances the bioavailability of drugs, nutrients, and vitamins $[2]$.

\section{Bioavailability/Bioefficacy-Enhancing Activity}

The term bioavailability or bioenhancing activity is defined as "a substance at a lower dosage level, which in combination with a drug or nutrient provides more availability of the drug by reducing the consumption of the drug or nutrient resulting in enhanced efficacy of the drugs."

The great interests for the improvement of bioavailability of a large number of drugs are (1) poorly available, (2) administered for long periods, (3) toxic, and (4) expensive. Maximizing bioavailability is therapeutically important because the extent of bioavailability directly influences plasma concentrations and consequently therapeutic efficacy. Bioavailability enhancement can make the expensive drugs affordable and reduce the toxic effects by reducing the required dose of drugs.

Poorly bioavailable drugs remain subtherapeutic because a major portion of a dose never reaches the plasma or exerts its pharmacological effect unless and until very large doses are given which may lead to serious side effects. Any significant improvement in bioavailability will result in lowering the dose or the dose frequency of that particular drug. Intersubject variability is particularly of concern for a drug with a narrow safety margin. Incomplete oral bioavailability includes poor dissolution or low aqueous solubility, poor intestinal membrane permeation, degradation of the drug in gastric or intestinal fluids, and presystemic intestinal or hepatic metabolism. Many therapeutic treatments are also accompanied by loss of essential nutraceuticals in the course of therapy. The bioenhancers improve nutritional status by increasing bioavailability/bioefficacy of various nutraceuticals including metals and vitamins [5].

Bioavailability enhancement can be done by the following [5].

(a) Promoting the absorption of the drugs from GIT.

(b) Inhibiting or reducing the rate of biotransformation of drugs in the liver or intestines.

(c) Modifying the immune system in such a way that the overall requirement of the drug is reduced substantially.

(d) Increasing the penetration or the entry into the pathogens even where they become persistors within the macrophages such as for Mycobacterium tuberculosis and such others. This eventually ensures the enhanced killing of these organisms is well secured within the places otherwise inaccessible to the active drug.

(e) Inhibiting the capability of pathogens or abnormal tissue to reject the drug, for example, efflux mechanisms frequently encountered with antimalarial, anticancer and antimicrobial drugs.

(f) Modifying the signaling process between host and pathogen ensuring increased accessibility of the drugs to the pathogens.

(g) Enhancing the binding of the drug with the target sites such as receptors, proteins, DNA, RNA, and the like in the pathogen, thus potentiating and prolonging its effect leading to enhanced antibiotic activity against pathogens.

(h) Besides above mode of action, the bioenhancer agents may also be useful for promoting the transport of nutrients and the drugs across the blood brain barrier, which could be of immense help in the control of diseases like cerebral infections, epilepsy, and other CNS problems.

Modern drug development processes achieve oral bioavailability enhancement by a number of approaches.

(a) Increasing the polarity of the drug through chemical modification.

(b) Salt preparation or complexation.

(c) Prodrug formation.

(d) Micronization and nanonization. 
TABLE 1: Mechanisms of action of herbal bioenhancers.

\begin{tabular}{|c|c|}
\hline Mechanisms of action & References \\
\hline Bioenergetic properties & Reanmongkol et al. [9], Jamwal and Singh [10] \\
\hline Increases gastrointestinal blood supply and reduces hydrochloric acid secretion & Annamalai and Manavalan [11] \\
\hline $\begin{array}{l}\text { Stimulation of } \gamma \text {-glutamyl transpeptidase (GGT) activity which enhances uptake of } \\
\text { amino acids }\end{array}$ & Johri et al. [12] \\
\hline Cholagogues effect & Majeed et al. [13] \\
\hline Thermogenic and bioenergetics properties & Majeed et al. [13] \\
\hline Inhibition of gastric emptying time, gastrointestinal transit & Bajad et al. [14] \\
\hline Inhibition of drug metabolizing enzymes and suppression of first pass metabolism & $\begin{array}{l}\text { Atal et al. [15], Reen et al. [16], and Bhardwaj } \\
\text { et al. [17] }\end{array}$ \\
\hline Modifications in GIT epithelial cell membrane permeability & Khajuria et al. [18] \\
\hline
\end{tabular}

(e) Specific polymorphic form selection.

(f) Targeted delivery of the drug to the site of action.

(g) Controlled drug delivery through film coating.

(h) Sustained drug release through polymorphic matrices formation.

(i) Liposomal microencapsulation and so forth.

(j) Application of P-glycoprotein inhibitors [6, 7].

However, bioavailability enhancement through the supplementation of the main therapeutic agent with a secondary agent gained wide popularity since the traditional times. However, based on Ayurvedic literature, a new approach is increasing bioavailability of drugs including poorly bioavailable drugs by using herbal bioenhancers [5].

Major categories of drugs that have shown increased bioenhancement include cardiovascular, respiratory, CNS, GIT, antibiotics, and anticancerous. Some examples include tetracyclines, sulfadiazine, vasicine, rifampicin, pyrazinamide, ethambutol, phenytoin, phenobarbitone, carbamazepine, nimesulide, indomethacin $\beta$-carotene, coenzyme $Q_{10}$, ciprofloxacin, curcumin, dapsone, amino acids, glucose, and several other classes of drugs [8].

\section{Mechanisms of Action}

Herbal bioenhancers act through several mechanisms of action. Different herbal bioenhancers may have same or different mechanisms of action. They increase bioavailability of nutraceuticals by acting on gastrointestinal tract to enhance absorption, whereas they increase bioavailability of drugs by acting on drug metabolism process. Various mechanisms of action postulated for herbal bioenhancers are shown in Table 1.

They cause inhibition of gastric emptying (GE) of solids/liquids in rats and gastrointestinal transit (GT) in mice in a dose- and time-dependent manners was studied. It significantly inhibited GE of solids and GT at the doses extrapolated from humans $(1 \mathrm{mg} / \mathrm{kg}$ and $1.3 \mathrm{mg} / \mathrm{kg}$ p.o. in rats and mice, resp.). However, at the same dose the effect was insignificant for GE of liquids. One-week oral treatment of $1 \mathrm{mg} / \mathrm{kg}$ and $1.3 \mathrm{mg} / \mathrm{kg}$ in rats and mice, respectively, did not produce a significant change in activity as compared to single-dose administration. GE inhibitory activity is independent of gastric acid and pepsin secretion [14].

Thermogenic and bioenergetic mechanisms are believed to be triggered by activation of thermoreceptors and release of catecholamines and/or direct action as beta 1, 2, 3adrenoceptor agonist. Secretion of catecholamines can also be mediated by ATP via $\mathrm{P}_{2}$-type purinergic receptors and through a direct or indirect stimulation by the compositions of the invention of dopaminergic and serotinergic systems. It is known that stimulation of $\beta-3$ adrenoceptors results in increased thermogenesis, decrease in the amount of white adipose tissue without food intake being affected, increased levels of insulin receptors, and decreased levels of serum insulin and blood glucose. This may possess antiobesity and antidiabetic effects, which by themselves contribute to the mechanism of thermogenesis and the increase in lean body mass. The thermogenic effect may also be mediated by an increase in the activity of thyroid peroxidase, an important enzyme in thyroid hormone synthesis, an increase in the plasma levels of triiodothyronine $\left(\mathrm{T}_{3}\right)$ and thyroxine $\left(\mathrm{T}_{4}\right)$ with simultaneous increase in tissue oxygen uptake, and increase in thermogenesis [19].

Piperine mediated changes in the permeability of rat intestinal epithelial cells: the status of $\gamma$-glutamyl transpeptidase activity, uptake of amino acids, and lipid peroxidation was studied. The effect of piperine on the absorptive function of the intestine were studied. In vitro experiments showed that piperine $(25-100 \mu \mathrm{M})$ significantly stimulated $\gamma$-glutamyl transpeptidase activity, enhanced the uptake of radiolabelled l-leucine, l-isoleucine, and l-valine, and increased lipid peroxidation in freshly isolated epithelial cells of rat jejunum. In the presence of benzyl alcohol, an enhanced $\gamma$-glutamyl transpeptidase activity due to piperine was maintained. These results suggested that piperine may interact with the lipid environment to produce effects which lead to increased permeability of the intestinal cells [12].

\section{Herbal Bioenhancers}

4.1. Piperine. Piperine, the major plant alkaloid present in $P$. nigrum Linn (Black pepper) and P. longum Linn (Long 
pepper), has bioavailability enhancing activity for some nutritional substances and for some drugs [20]. It has been used extensively as a condiment and flavoring for all types of savory dishes. Piper species have been used in folklore medicine for the treatment of various diseases, including seizure disorders [21]. Piperine is known to exhibit a variety of biological activities which include anti-inflammatory activity [22, 23], antipyretic activity [24], fertility enhancement [25], antifungal activity [26], antidiarrhoeal activity [27], antioxidant activity [28-33], antimetastatic activity [34], antithyroid activity [35, 36], antimutagenic activity [37-40], antitumor activity [39, 41, 42], antidepressant activity [43-45], antiplatelet activity [46], analgesic activity [47], hepatoprotective activity [48], antihypertensive activity [49], and antiasthmatic activity [50]. Piperine exhibits a toxic effect against hepatocytes [51] and cultured hippocampal neurons [52], reproductive toxicity in swiss albino mice [53], and immunotoxicity [54].

Piperine reduces the aflatoxin $\mathrm{B}_{1}$-induced cytotoxicity and micronuclei formation in rat hepatoma cells in concentration-dependent manner. It is capable of counteracting aflatoxin $\mathrm{B}_{1}$ toxicity by suppressing cytochromes P450-mediated bioactivation of the mycotoxin [55]. Inhibition of aflatoxin $\mathrm{B}_{1}$-induced cytotoxicity and genotoxicity in chinese hamster cells by piperine was reported by Reen et al. [56]. A significant suppression (33.9-66.5\%) in the micronuclei formation induced by benzo(a)pyrene and cyclophosphamide was reduced following oral administration of piperine at doses of 25,50 , and $75 \mathrm{mg} / \mathrm{kg}$ in mice [32].

Piperine modulates the oxidative changes by inhibiting lipid peroxidation and mediating enhanced synthesis or transport of glutathione thereby replenishing thiol redox [57]. Simultaneous supplementation with black pepper or piperine in rats fed high fat diet lowered thiobarbituric acid reactive substances (TBARS) and conjugated dienes levels and maintained superoxide dismutase (SOD), catalase (CAT), glutathione peroxidase (GPX), glutathione-Stransferase (GST), and glutathione (GSH) levels close to controls in rats [30]. Piperine could effectively inhibit benzo(a)pyrene-induced lung carcinogenesis in albino mice by offering protection from protein damage and also by suppressing cell proliferation [58]. It produces chemopreventive effect by modulating lipid peroxidation and augmenting antioxidant defense system [59, 60]. Supplementation of piperine causes inhibition of Phase I and II enzymes, elevation of glutathione metabolizing enzymes, reduction in DNA damage, and DNA protein cross-links in benzo(a)pyreneinduced lung carcinogenesis in mice $[38,61]$.

The antiapoptotic efficacy of piperine has been demonstrated against cisplatin-induced apoptosis via heme oxygenase- 1 induction in auditory cells [62]. Piperine can reverse the corticosterone induced reduction of brainderived neurotrophic factor mRNA expression in cultured hippocampal neurons [44]. Gallic acid exerts a synergistic effect when administered with piperine and provides a more pronounced therapeutic potential in reducing beryllium-induced hepatorenal dysfunction and oxidative stress consequences [63]. Piperine contains pentacyclic oxindole group which is effective for immunomodulation.
This immunomodulation activity is due to its multifaceted activities such as antioxidative, antiapoptotic, and restorative ability against cell proliferative mitogenic response, thymic and splenic cell population, and cytokine release [64].

Daily supplement taken with a nutrient or nutrients by an average healthy adult, piperine is effective and safe in a broad dose range. A preferred effective dose range of piperine for oral use to enhance gastrointestinal nutrient absorption is $0.0004-0.15 \mathrm{mg} / \mathrm{kg} / \mathrm{day}$. The recommended dose of piperine for a healthy individual for oral use is approximately $5 \mathrm{mg} /$ person/day. Black pepper contains approximately 59\% piperine, listed by the Food and Drug Administration (FDA) as an herb which is generally recognized as safe (GRAS) for its intended use as spice, seasoning, or flavoring. The bioenhancing dose of piperine is approximately $15 \mathrm{mg} /$ person/day and no more than $20 \mathrm{mg} /$ day in divided doses, which corresponds to from several thousands to up to 40,000 times less than the $\mathrm{LD}_{50}$ dose of piperine, as established in various experiments on rodents. The effective bioenhancing dose of piperine for drug compounds varies, but the prior art studies indicated that a dose of approximately $10 \%(\mathrm{w} / \mathrm{w})$ of the active drug could be regarded as an appropriate bioenhancing dose for most drugs [19]. $\mathrm{LD}_{50}$ of piperine has been found to be 330 and $514 \mathrm{mg} / \mathrm{kg}$ in mice and rats, respectively. In subacute toxicity tests, piperine in a dosage of $100 \mathrm{mg} / \mathrm{kg}$ was found to be nontoxic [65].

There are two possible explanations for the role of piperine in drug bioavailability: (a) nonspecific mechanisms mainly promoting rapid absorption of drugs and nutrients, for example, increased blood supply to the gastrointestinal tract, decreased hydrochloric acid secretion which prevents breakdown of some drugs, increased emulsifying content of the gut, and increased enzymes like $\gamma$-glutamyl transpeptidase which participate in active and passive transport of nutrients to the intestinal cells, and (b) nonspecific mechanisms inhibiting enzymes participating in biotransformation of drugs, preventing their inactivation and elimination [19].

\subsubsection{Drug Metabolizing Enzymes Inhibited by Piperine} (Shown in Table 2). The interaction of piperine with enzymatic drug biotransforming reactions in hepatic tissue has been studied in vitro and in vivo. Piperine inhibited arylhydrocarbon hydroxylation, ethylmorphine-Ndemethylation, 7-ethoxycoumarin-O-deethylation, and 3hydroxy-benzo(a)pyrene glucuronidation in rat postmitochondrial supernatant in vitro in a dose-dependent manner. Piperine inhibition of these reactions in postmitochondrial supernatant from 3-methylcholanthrene and phenobarbital treated rats was similar to the controls. Inhibition by piperine of arylhydrocarbon hydroxylase (AHH) from 3methylcholanthrene treated rats was comparable to that observed with 7, 8-benzoflavone. Piperine caused noncompetitive inhibition of hepatic microsomal $\mathrm{AHH}$ from the untreated and 3-methylcholanthrene-treated rats with a $K_{i}=30 \mu \mathrm{M}$ which was close to the apparent $K_{m}$ of $\mathrm{AHH}$ observed in the controls. Similarly, the kinetics of inhibition of ethylmorphine- $\mathrm{N}$-demethylase from control rat liver microsomes exhibited noncompetitive inhibition with an 
TABLe 2: Drug metabolizing enzymes inhibited by piperine.

\begin{tabular}{ll}
\hline Drug metabolizing enzymes & References \\
\hline Arylhydrocarbon hydroxylase (AHH) & $\begin{array}{l}\text { Atal et al. [15], } \\
\text { Singh et al. [66] }\end{array}$ \\
Uridine diphosphate- (UDP-) glucuronyl & Atal et al. [15], \\
transferase & Singh et al. [66] \\
Ethylmorphine-N-demethylase & Atal et al. [15], \\
& Singh et al. [66] \\
7-Ethoxycoumarin-O-deethylase & Atal et al. [15], \\
& Singh et al. [66] \\
3-Hydroxy-benzo(a)pyrene glucuronidation & Atal et al. [15], \\
& Singh et al. [66] \\
UDP-glucose dehydrogenase (UDP-GDH) & Reen et al. [16] \\
5-lipoxygenase & Stöhr et al. [67] \\
Cyclooxygenase-1 & Stöhr et al. [67] \\
& Atal et al. [15], \\
Cytochrome P450 & Singh et al. [66], \\
& Bhardwaj et al. [17] \\
\hline
\end{tabular}

apparent $K_{m}=0.8 \mathrm{mM}$ and $K_{i}=35 \mu \mathrm{M}$. These studies demonstrated that piperine is a nonspecific inhibitor of drug metabolism. Oral administration of piperine in rats strongly inhibited the hepatic AHH and Uridine diphosphate-(UDP-) glucuronyltransferase (UGT) activities. The maximal inhibition of $\mathrm{AHH}$ observed within $1 \mathrm{~h}$ restored to normal value in $6 \mathrm{~h}$. These results demonstrate that piperine is a potent inhibitor of drug metabolism [15]. Piperine modified the rate of glucuronidation by lowering the endogenous UDPglucuronic acid (UDP-GA) content and also by inhibiting the transferase activity [66].

The effects of piperine on UDP-glucose dehydrogenase (UDP-GDH) and glucuronidation potentials of rat and guinea pig liver and intestine were studied in vitro. Piperine caused a concentration-related strong inhibition of UDPGDH $(50 \%$ at $10 \mu \mathrm{M})$ reversibly and equipotently, in both tissues. Partially purified rat liver UDP-GDH was used to obtain the kinetic values at $\mathrm{pH}$ optima of 9.4 and 8.6. At $\mathrm{pH}$ 9.4, $K_{m}=15 \mu \mathrm{M}, V_{\max }=5.2 \mathrm{nmol}$, with $\mathrm{NADH}-$ $K_{i}=6 \mu \mathrm{M}$, with $\mathrm{NAD}-K_{i}=16 \mu \mathrm{M}$ were obtained. At pH 8.6, $K_{m}=35 \mu \mathrm{M}, V_{\max }=7.5 \mathrm{nmol}$, and $K_{i}=$ $15 \mu \mathrm{M}$. In all of these cases, piperine caused noncompetitive inhibition. Data from structure activity comparisons of piperine analogs indicated that the presence of conjugated double bonds in the side chain of the molecule is a factor in piperine inhibition. However, the UDP-GA contents were decreased less effectively by piperine in isolated rat hepatocytes compared with enterocytes of guinea pig small intestine. Piperine at $50 \mu \mathrm{M}$ caused a marginal decrease of UDP-GA in hepatocytes when the rate of glucuronidation of 3-hydroxybenzo(a)pyrene (3-OH-BP) decreased by about $40 \%$. The decrease obtained at $10 \mu \mathrm{M}$ piperine in intestinal cells was comparable to that obtained at $50-100 \mu \mathrm{M}$ in hepatocytes. UGT activities towards 3-OH-BP (UGT1A1) and 4OH-biphenyl (UGT2B1) were also determined. Piperine did not affect the rate of glucuronidation of 4-OH-biphenyl in rat liver, whereas that of 3-OH-BP was impaired significantly. In guinea pig small intestine, both these activities were inhibited significantly requiring less than $25 \mu \mathrm{M}$ piperine to produce more than $50 \%$ inhibition of UGT(s). The results suggested that (i) piperine is a potent inhibitor of UDPGDH, (ii) inhibition is offered exclusively by the conjugated double bonds of the molecule, and (iii) piperine exerts stronger effects on intestinal glucuronidation than in rat liver [16].

Piperine inhibits human P-glycoprotein and CYP3A4 (CYP: Cytochrome P450). Both the proteins are expressed in enterocytes and hepatocytes and contribute to a major extent to first-pass elimination of many drugs. This indicates that dietary piperine could affect plasma concentrations of P-glycoprotein and CYP3A4 substrates in humans, in particular if these drugs are administered orally. Some of the metabolizing enzymes inhibited or induced by piperine include CYP1A1, CYP1B1, CYP1B2, CYP2E1, and CYP3A4. Most of the drugs metabolized by these enzymes will therefore be influenced by bioenhancers [17].

4.1.2. Drugs/Nutraceuticals Bioenhanced by Piperine. Piperine acts as an antimicrobial bioenhancer which enhances bioavailability and bioefficacy of drugs by acting on drug metabolism. It also acts as a nutritional bioenhancer which enhances bioavailability and absorption of nutrients by acting on gastrointestinal tract. Allameh et al. [68] reported that piperine enhances bioavailability of aflatoxin $B_{1}$ in rat tissues. A $10 \mathrm{mg}$ dose of piperine causes a marked increase in serum gonadotropins and a decrease in intratesticular testosterone concentration, despite normal serum testosterone titres in adult male albino rats [69]. However, some of the experimental findings also indicated the ability to decrease the bioavailability of drugs, like rifampicin $[70,71]$, isoniazid [72], and Diclofenac sodium [73].

Piperine has been shown to inhibit several cytochrome P450-mediated pathways and phase II reactions in animal models. Piperine, or mixtures containing piperine, has been shown to increase the bioavailability, blood levels, and efficacy of many of drugs (Table 3 ) and nutraceuticals (Table 4). Administration of piperinesignificantly increased plasma concentrations of rifampicin,phenytoin, spartein, sulfadiazine, tetracycline, propranolol, and theophylline in humans.

Piperine and Phenytoin. Effect of piperine on pharmacokinetics of phenytoin was studied in healthy volunteers. In a crossover study, five volunteers received either a single oral dose $(300 \mathrm{mg})$ of phenytoin alone or in combination with multiple doses of piperine $(20 \mathrm{mg} \times 7$ days) followed by an oral dose of phenytoin. Blood samples were collected at $0.5,1,2,3,4,8,12,24$, and $48 \mathrm{~h}$ after drug administration and analyzed for phenytoin by the enzymemultiplied immunoassay technique. The results showed that a single daily dose of piperine for 7 days decreased the $t_{1 / 2 \alpha}$ $(P<0.05)$, prolonged the $t_{1 / 2}(P<0.01)$, and produced a higher AUC $(P<0.05)$ in comparison to phenytoin alone. It is therefore concluded that piperine on multiple-dose administration alters the pharmacokinetic parameters of the antiepileptic [76]. 
TABLE 3: Drugs bioenhanced by piperine.

\begin{tabular}{|c|c|c|}
\hline Drugs & Experimental model & References \\
\hline Vasicine & Rats & Zutshi and Kaul [74] \\
\hline Pyrazinamide & In vitro & Zutshi [75] \\
\hline $\begin{array}{l}\text { Phenytoin, propranolol, theophyllin, spartein, } \\
\text { sulphadiazine, and tetracycline }\end{array}$ & Human volunteers & Bano et al. $[76,77]$ \\
\hline Pentobarbitone & Human volunteers & Mujumdar et al. [78] \\
\hline \multirow{3}{*}{ Curcumin } & Human volunteers and rats & Shoba et al. [79] \\
\hline & In vivo & Shaikh et al. [80] \\
\hline & Rats & Suresh and Srinivasan $[81]$ \\
\hline Nimesulide & Mice & Gupta et al. [82] \\
\hline Indomethacin & Rabbits & Karan et al. [83] \\
\hline Oxyphenylbutazone & Rats & Mujumdar et al. [84] \\
\hline Phenytoin & Human volunteers & Velpandian et al. [85], Pattanaik et al. [86] \\
\hline \multirow{2}{*}{ Rifampicin } & Human & Zutshi et al. [87] \\
\hline & In vitro & Balakrishnan et al. [88] \\
\hline Amoxycillin trihydrate and cefotaxime & Rats & Hiwale et al. [89] \\
\hline EGCG [(-)-epigallocatechin-3-gallate] & Mice & Lambert et al. [90] \\
\hline Oxytetracycline & WLH hens & Singh et al. [91] \\
\hline \multirow{2}{*}{ Ciprofloxacin } & Rabbits & Balkrishna and Yogesh [92] \\
\hline & In vitro & Khan et al. [8] \\
\hline Nevirapine & Human & Kasibhatta and Naidu [93] \\
\hline Diclofenac sodium and pentazocine & Albino mice & Pooja et al. [47] \\
\hline Pefloxacin & Gaddi goats & Dama et al. [94] \\
\hline Ampcilllin and norloxacin & Rabbits & Janakiraman and Manavalan [95] \\
\hline Carbamazepine & In vitro & Pattanaik et al. [96] \\
\hline Fexofenadine & Rats & Jin and Han [97] \\
\hline Metronidazole & Rabbits & Singh et al. [98] \\
\hline Ampicillin trihydrate & Human & Janakiraman and Manavalan [99] \\
\hline Resveratrol & Mice & Johnson et al. [100] \\
\hline \multirow{2}{*}{ Gatifloxacin } & Layer birds & Patel et al. [101] \\
\hline & Broiler birds & Devada et al. [102] \\
\hline Atenolol & Rats & Singh and Chand [103] \\
\hline Ibuprofen & In vitro & Venkatesh et al. [104] \\
\hline Losartan potassium & Rats & Singh et al. [105] \\
\hline
\end{tabular}

A preliminary pharmacokinetic study was carried out in mice by administering phenytoin $(10 \mathrm{mg})$ orally, with or without piperine $(0.6 \mathrm{mg})$. Subsequently, oral pharmacokinetics of phenytoin was carried out in six healthy volunteers in a crossover design. Phenytoin tablet (300 mg) was given 30 minutes after ingestion of a soup (Melahu rasam) with or without black pepper. A further study of intravenous pharmacokinetics of phenytoin $(1 \mathrm{mg})$ in rats with or without oral pretreatment with piperine $(10 \mathrm{mg})$ was also conducted. The phenytoin concentration in the serum was analyzed by HPLC. The study showed a significant increase in the kinetic estimates of $K_{a}, \mathrm{AUC}_{0-10}$ and $\mathrm{AUC}_{0-\infty}$ in the piperine fed mice. Similarly, in human volunteers piperine increased $K_{a}, \mathrm{AUC}_{0-48}, \mathrm{AUC}_{0-\infty}$ and delayed elimination of phenytoin. Intravenous phenytoin in the oral piperinetreated rat group showed a significant alteration in the elimination phase indicating its metabolic blockade [85].

The effect of piperine on oral bioavailability of phenytoin was studied in human volunteers. The objective of this study was to explore the effect of a single dose of piperine in patients with uncontrolled epilepsy on the steady-state pharmacokinetics of phenytoin. Two groups of 10 patients each receiving either a $150 \mathrm{mg}$ or $200 \mathrm{mg}$ twice daily dose of phenytoin were selected. $12 \mathrm{~h}$ after the night dose, venous blood samples were collected at $0,0.5,1,2,4,6,9$, and $12 \mathrm{~h}$ after administration of phenytoin. On the next study day, piperine $20 \mathrm{mg}$ was administered along with phenytoin and samples were collected similarly. There was a significant increase in $\mathrm{AUC}_{0-12 \mathrm{~h}}(P<0.01), C_{\max }(P<0.001)$, and $K_{a}(P<0.05)$, whereas the changes in $K_{\mathrm{el}}$ and $t_{\max }$ were not significant. The results showed that piperine enhanced the bioavailability of phenytoin significantly, possibly by increasing the absorption [86].

Piperine and Pentobarbitone. Effect of piperine on pentobarbitone-induced hypnosis in rats was studied. Piperine treatment in rats, treated chronically with phenobarbitone, significantly potentiated pentobarbitone sleeping time, as compared to the controls. There was no alteration in barbital sodium sleeping time. It is possible 
TABLE 4: Nutraceuticals bioenhanced by piperine $[13,19]$.

\begin{tabular}{|c|c|}
\hline Class & Examples \\
\hline Water soluble vitamins & $\begin{array}{l}\text { Vitamin } B_{1} \text {, Vitamin } B_{2} \text {, niacinamide, } \\
\text { Vitamin } B_{6} \text {, Vitamin } B_{12} \text {, folic acid, } \\
\text { and Vitamin } C\end{array}$ \\
\hline Fat soluble vitamins & $\begin{array}{l}\text { Vitamin A, } \beta \text {-carotene (provitamin), } \\
\text { Vitamin } D \text {, Vitamin } \mathrm{E} \text {, and Vitamin } \mathrm{K}\end{array}$ \\
\hline Amino acids & $\begin{array}{l}\text { Lysine, isoleucine, leucine, threonine, } \\
\text { valine, tryptophan, phenylalanine, and } \\
\text { methionine }\end{array}$ \\
\hline Minerals & $\begin{array}{l}\text { Iodine, calcium, iron, zinc, copper, } \\
\text { selenium, magnesium, potassium, and } \\
\text { manganese }\end{array}$ \\
\hline Herbal compounds & $\begin{array}{l}\text { Boswellic acid (Boswellia serrata), } \\
\text { Ginsenosides (Gingko biloba), } \\
\text { Withanaloids (Withania somnifera), } \\
\text { Curcuminoides (Curcuma longa), and } \\
\text { Pycnogenol (Pinus pinaster) }\end{array}$ \\
\hline
\end{tabular}

that piperine inhibits liver microsomal enzyme system and thereby potentiates the pentobarbitone sleeping time [78].

Piperine with Propranolol and Theophylline. The effects of piperine on the bioavailability and pharmacokinetics of propranolol and theophylline were studied. Six subjects in each group received a single oral dose of propranolol ( $40 \mathrm{mg}$ ) or theophylline $(150 \mathrm{mg})$ alone or in combination with piperine $\left(20 \mathrm{mg}\right.$ ) daily for 7 days. An earlier $t_{\max }$ and a higher $C_{\max }$ and AUC were observed in the subjects who received piperine and propranolol. It produced a higher $C_{\max }$, longer $t_{1 / 2}$, and a higher AUC with theophylline. In clinical practice, the enhanced systemic availability of oral propranolol and theophylline could be exploited to achieve better therapeutic control and improved patient compliance [77].

Piperine and Nimesulide. Influence of piperine on nimesulide-induced antinociception was studied in mice. The plasma concentration after oral administration of nimesulide $(10 \mathrm{mg} / \mathrm{kg})$ alone was $8.03 \pm 0.99 \mu \mathrm{g} / \mathrm{mL}$. However, when it was administered with piperine $(10 \mathrm{mg} / \mathrm{kg})$, the plasma concentration of nimesulide increased to $11.9 \pm 0.23 \mu \mathrm{g} / \mathrm{mL}$. This indicates that piperine inhibits the biotransformation and metabolism of nimesulide leading to significantly $(P<$ $0.05)$ higher levels of drug in the systemic circulation. The findings of this study suggest that piperine could be used as a biological enhancer when coadministered with nimesulide [82].

Piperine and Curcumin. Influence of piperine on the pharmacokinetics of curcumin in animals and human volunteers was studied. The medicinal properties of curcumin obtained from Curcuma longa Linn. cannot be utilized because of poor bioavailability due to its rapid metabolism in the liver and intestinal wall. The effect of combining piperine, a known inhibitor of hepatic and intestinal glucuronidation, was evaluated on the bioavailability of curcumin in rats and healthy human volunteers. When curcumin was given alone,
TABLE 5: Comparative pharmacokinetic parameters after oral supplementation of curcumin and curcumin + piperine in human volunteers [79].

\begin{tabular}{lcc}
\hline Parameters & $\begin{array}{c}\text { Curcumin } \\
(2 \mathrm{~g} / \mathrm{kg})\end{array}$ & $\begin{array}{c}\text { Curcumin }(2 \mathrm{~g} / \mathrm{kg})+\text { piperine } \\
(20 \mathrm{mg} / \mathrm{kg})\end{array}$ \\
\hline$C_{\max }(\mu \mathrm{g} / \mathrm{mL})$ & $1.35 \pm 0.23$ & $1.80 \pm 0.16$ \\
$t_{\max }(\mathrm{h})$ & $0.83 \pm 0.05$ & $1.29 \pm 0.23$ \\
$t_{1 / 2}(\mathrm{~h})$ & $1.70 \pm 0.58$ & $1.05 \pm 0.18$ \\
$\mathrm{AUC}(\mu \mathrm{g} \cdot \mathrm{h} / \mathrm{mL})$ & $2.36 \pm 0.28$ & $3.64 \pm 0.31$ \\
$\mathrm{Cl}_{B}(\mathrm{~L} / \mathrm{h})$ & $713 \pm 12$ & $495.90 \pm 193.90$ \\
\hline
\end{tabular}

at dose $2 \mathrm{~g} / \mathrm{kg}$ to rats, moderate serum concentrations were achieved over a period of $4 \mathrm{~h}$. Concomitant administration of piperine $20 \mathrm{mg} / \mathrm{kg}$ increased the serum concentration of curcumin for a short period of $1-2 \mathrm{~h}$ after drug. $t_{\max }$ was significantly increased $(P<0.02)$ while $t_{1 / 2}$ and $\mathrm{Cl}_{B}$ significantly decreased $(P<0.02)$, and the bioavailability was increased by $154 \%$. On the other hand, in humans after a dose of $2 \mathrm{~g}$ curcumin alone, serum levels were either undetectable or very low (Table 5). Concomitant administration of piperine $20 \mathrm{mg}$ produced much higher concentrations from 0.25 to $1 \mathrm{~h}$ after $\operatorname{drug}(P<0.01$ at 0.25 and $0.5 \mathrm{~h} ; P<0.001$ at $1 \mathrm{~h}$ ); the increase in bioavailability was $200 \%$. The study shows that in the dosages used, piperine enhances the serum concentration, extent of absorption, and bioavailability of curcumin in both rats and humans with no adverse effects [79].

Piperine and $\beta$-Carotene. The effectiveness of piperine was evaluated for its ability to improve serum response of $\beta$ carotene during oral supplementation using a double-blind, crossover study design. Subjects were randomly selected to ingest a daily $\beta$-carotene dose $(15 \mathrm{mg})$ either with $5 \mathrm{mg}$ of piperine or placebo during each of two 14-day supplementation periods. Intersubject variability in presupplementation serum $\beta$-carotene levels was minimized by limiting the selection of volunteers to healthy, adult males with fasting serum $\beta$-carotene values $<20 \mathrm{pg} / \mathrm{dL}$. The results indicate that significantly greater increases $(P<0.0001)$ in serum $\beta$ carotene occurred during supplementation with $\beta$-carotene plus piperine $(49.8 \pm 9.6 \mathrm{pg} / \mathrm{dL}$ versus $30.9 \pm 5.4 \mathrm{pg} / \mathrm{dL})$ compared to $\beta$-carotene plus placebo. Supplementation with betacarotene plus piperine for 14 days produced a $60 \%$ greater increase AUC than was observed during supplementation with $\beta$-carotene plus placebo (Table 6). Study suggests that the serum response during oral $\beta$-carotene supplementation is improved through the nonspecific, thermogenic property of piperine, described in this paper as thermonutrient in action [20].

Piperine and Coenzyme $Q_{10}$. An extract from the fruits of black pepper consisting of a minimum of $98 \%$ pure piperine was evaluated in a clinical study using a doubleblind design. The relative bioavailability of $90 \mathrm{mg}$ and $120 \mathrm{mg}$ of coenzyme $Q_{10}$ administered in a single-dose experiment or in separate experiments for 14 and 21 days 
TABLE 6: Effect of piperine on the serum $\beta$-carotene levels during a 14-day supplementation in human volunteers [20].

\begin{tabular}{lcccr}
\hline Treatment $(n=6)$ & & $\beta$-carotene $(\mu \mathrm{g} / \mathrm{dL})$ & Change & AUC $(\mu \mathrm{g} / \mathrm{dL}) \times($ time in days $)$ \\
\hline$\beta$-carotene + placebo & $16.3 \pm 2.6$ & Day 14 & $30.9 \pm 5.4$ & $272 \pm 47.6$ \\
$\beta$-carotene + piperine & $16.0 \pm 3.1$ & $47.2 \pm 6.4$ & $49.8 \pm 9.6$ & $435 \pm 74.2$ \\
\hline
\end{tabular}

TABLE 7: Effect of piperine on pharmacokinetics of rifampicin, isoniazid, and pyrazinamide combination in human volunteers [107, 108].

\begin{tabular}{|c|c|c|c|c|c|c|}
\hline \multirow{2}{*}{ Kinetic parameters } & \multicolumn{3}{|c|}{ Formulation A } & \multicolumn{3}{|c|}{ Formulation B } \\
\hline & Rifampicin & Isoniazid & Pyrazinamide & Rifampicin** & Isoniazid** & Pyrazinamide** \\
\hline$t_{1 / 2}(\mathrm{~h})$ & $0.67 \pm 0.008$ & $0.64 \pm 0.01$ & $0.60 \pm 0.03$ & $0.40 \pm 0.04$ & $0.42 \pm 0.04$ & $0.37 \pm 0.008$ \\
\hline$t_{1 / 2(\mathrm{el})}(\mathrm{h})$ & $8.40 \pm 0.06$ & $7.90 \pm 0.10$ & $9.50 \pm 0.14$ & $11.1 \pm 0.18$ & $8.15 \pm 0.26^{*}$ & $11.0 \pm 0.17$ \\
\hline$C_{\max }(\mu \mathrm{g} / \mathrm{mL})$ & $8.20 \pm 0.46$ & $2.56 \pm 0.17$ & $27.0 \pm 2.0$ & $17.6 \pm 1.09$ & $10.07 \pm 0.90$ & $40.0 \pm 1.64$ \\
\hline $\mathrm{AUC}_{0-\infty}(\mu \mathrm{g} \cdot \mathrm{h} / \mathrm{mL})$ & $104.6 \pm 4.38$ & $41.0 \pm 1.72$ & $318.6 \pm 8.05$ & $143.95 \pm 5.85$ & $94.95 \pm 3.98$ & $435.41 \pm 9.7$ \\
\hline
\end{tabular}

${ }^{*}$ Not significant $(P>0.05),{ }^{* *}$ highly significant $(P<0.001)$.

Formulation A: rifampicin— $450 \mathrm{mg}$, isoniazid—300 $\mathrm{mg}$, pyrazinamide— $1500 \mathrm{mg}$.

Formulation B: rifampicin—450 mg, isoniazid-300 mg, pyrazinamide—1500 mg, piperine—20 mg.

with placebo or with $5 \mathrm{mg}$ of piperine was determined by comparing measured changes in plasma concentration. The intersubject variability was minimized by limiting the selection of individuals to healthy adult male volunteers with (presupplementation) fasting coenzyme $Q_{10}$ values between 0.30 and $0.60 \mathrm{mg} / \mathrm{L}$. The results of the single-dose study and the 14-day study indicate smaller, but not significant, increases in plasma concentrations of coenzyme $Q_{10}$ in the control group compared with the group receiving coenzyme $Q_{10}$ with a supplement of piperine. Supplementation of $120 \mathrm{mg}$ coenzyme $Q_{10}$ with piperine for 21 days produced approximately $30 \%$ greater AUC than was observed during supplementation with coenzyme $Q_{10}$ plus placebo. It is postulated that the bioenhancing mechanism of piperine to increase plasma levels of supplemental coenzyme $Q_{10}$ is nonspecific and possibly based on its description in the literature as a thermonutrient [106].

Piperine and Rifampicin. Piperine augments transcription inhibitory activity of rifampicin by several folds against Mycobacterium smegmatis. A 24:1 (w/w) mixture of antibiotic rifampicin and piperine shows remarkable growth inhibitory effect on M. smegmatis, and this inhibition is higher than that of rifampicin alone. Interestingly, piperine alone, even at higher concentration, does not inhibit the growth of Mycobacterium. As RNA polymerase is the site of action of rifampicin, the enzyme was purified from $M$. smegmatis and the mixture of rifampicin and piperine was found to abrogate nonspecific transcription catalyzed by M. smegmatis RNA polymerase. The effect is higher than rifampicin alone and piperine shows no effect independently. When RNA polymerase was purified from a rifampicinresistant strain of $M$. smegmatis, the enzymatic activity, otherwise resistant to rifampicin, significantly decreases in the presence of piperine along with rifampicin. Piperine enhances the binding ability of rifampicin to RNA polymerase [88].

The amount of piperine used in the range of $0.4-0.9 \%$ by weight of the antituberculosis and antileprosy drugs.
Antituberculosis composition contains rifampicin (100$300 \mathrm{mg}$ ), isoniazid (100-300 mg) and pyrazinamide (500$1000 \mathrm{mg}$ ) (combination of any two), and piperine (5-29 mg). Antileprosy composition contains rifampicin (100-300 mg), dapsone (50-100 mg), and piperine (5-20 mg). Effect of piperine on pharmacokinetic parameters of rifampicin, isoniazid, and pyrazinamide combination was studied in human volunteers. The results from Table 7 indicate that piperine significantly increases the bioavailability of antituberculosis drugs like rifampicin, isoniazid, and pyrazinamide $[107,108]$.

Risorine is a formulation developed by the Indian Institute of Integrative Medicine, Jammu, and marketed in India in November 2009 in public-private partnership with Cadila Pharmaceutical Ltd, Ahmedabad. Risorine has been approved for marketing by Drug Controller General of India, after successful completion of all the phased clinical trials. It contains rifampicin $(200 \mathrm{mg})$, isoniazid $(300 \mathrm{mg})$, and piperine $(10 \mathrm{mg})$. It has been found to be bioequivalent with commercially available rifampicin preparations. This is due to enhanced uptake of the drug by body cells, and also because the drug remains available in blood for longer durations. Combining piperine with rifampicin decreases the dose of rifampicin from 450 to $200 \mathrm{mg}$ [109].

Piperine with Amoxicillin Trihydrate and Cefotaxime. Effect of coadministration of piperine on pharmacokinetics of $\beta$ lactam antibiotics was studied in rats. Coadministration of piperine enhanced bioavailability of $\beta$-lactam antibiotics like amoxicillin trihydrate and cefotaxime sodium significantly in rats. The improved bioavailability is reflected in various pharmacokinetic parameters, namely $t_{\max }, C_{\max }, t_{1 / 2}$, and AUC of these antibiotics. The increased bioavailability could be attributed to the effect of piperine on microsomal metabolizing enzymes or enzymes system [89].

Piperine and Epigallocatechin Gallate (EGCG). Piperine enhanced the bioavailability of the tea polyphenol EGCG in Mice. EGCG, from green tea (Camellia sinensis), has 
TABLE 8: Comparison of mean plasma levels of oxytetracycline $(\mu \mathrm{g} / \mathrm{mL})$ at different time intervals following oral administration in control and P. longum-treated WLH birds [91].

\begin{tabular}{lcc}
\hline Time (Min) & Control & Treated \\
\hline 15 & $0.23 \pm 0.024$ & $0.30 \pm 0.022^{*}$ \\
30 & $0.34 \pm 0.025$ & $0.45 \pm 0.029^{* *}$ \\
60 & $0.72 \pm 0.051$ & $0.77 \pm 0.046$ \\
120 & $0.58 \pm 0.037$ & $0.63 \pm 0.030$ \\
240 & $0.37 \pm 0.015$ & $0.47 \pm 0.034^{* *}$ \\
360 & $0.26 \pm 0.017$ & $0.38 \pm 0.021^{* * * *}$ \\
480 & $0.23 \pm 0.015$ & $0.31 \pm 0.019^{* * *}$ \\
600 & $0.19 \pm 0.005$ & $0.25 \pm 0.015^{* * *}$ \\
\hline
\end{tabular}

$n=8$, mean $\pm \mathrm{SE} ;{ }^{*} P<0.1,{ }^{* *} P<0.05,{ }^{* * *} P<0.01,{ }^{* * * *} P<0.001$.

demonstrated chemopreventive activity in animal models of carcinogenesis. Cotreatment with piperine enhanced the bioavailability of EGCG in mice. Intragastric coadministration of $163.8 \mu \mathrm{mol} / \mathrm{kg}$ EGCG and $70.2 \mu \mathrm{mol} / \mathrm{kg}$ piperine to male CF- 1 mice increased the plasma $C_{\max }$ and AUC by 1.3-fold compared to mice treated with EGCG only. Piperine appeared to increase EGCG bioavailability by inhibiting glucuronidation and gastrointestinal transit. Piperine $(100 \mu \mathrm{mol} / \mathrm{L})$ inhibited EGCG glucuronidation in mouse small intestine (by $40 \%$ ) but not in hepatic microsomes. Piperine $(20 \mu \mathrm{mol} / \mathrm{L})$ also inhibited production of EGCG$3^{\prime \prime}$-glucuronide in human HT-29 colon adenocarcinoma cells. Small intestinal EGCG levels in CF-1 mice following treatment with EGCG alone had a $C_{\max }=37.50 \pm$ $22.50 \mathrm{nmol} / \mathrm{g}$ at $60 \mathrm{~min}$ that then decreased to $5.14 \pm$ $1.65 \mathrm{nmol} / \mathrm{g}$ at $90 \mathrm{~min}$; however, cotreatment with piperine resulted in a $C_{\max }=31.60 \pm 15.08 \mathrm{nmol} / \mathrm{g}$ at $90 \mathrm{~min}$, and levels were maintained above $20 \mathrm{nmol} / \mathrm{g}$ until $180 \mathrm{~min}$. This resulted in a significant increase in the small intestine EGCG AUC $(4621.80 \pm 1958.72 \mathrm{nmol} / \mathrm{g} / \mathrm{min}$ versus $1686.50 \pm$ $757.07 \mathrm{nmol} / \mathrm{g} / \mathrm{min})$. EGCG appearance in the colon and the feces of piperine-cotreated mice was slower than in mice treated with EGCG alone [90].

Piperine and Oxytetracycline (OTC). The pharmacokinetic profile of orally administered oxytetracycline $(10 \mathrm{mg} / \mathrm{kg}$ body weight) was studied 7 days after oral treatment of $P$. longum $(15 \mathrm{mg}$ equivalent $/ \mathrm{kg})$ in White Leghorn birds (WLH) $(2.0$ $2.8 \mathrm{~kg}$ ). On day 8 , oxytetracycline (OTC) was administered orally and blood samples were collected from the wing vein in heparinized vials for plasma separation at 0 (before treatment), 15, 30, 60, 120,240,360,480, and $600 \mathrm{~min}$ after OTC administration. Plasma OTC concentrations were determined by microbial assay technique using Bacillus cereus var. mycoides (ATCC 11778) as test organism. The plasma levels of OTC against time were adequately described by one compartment open model (Table 8 ). The pharmacokinetic data (Table 9) revealed that $P$. longum-treated animals had significantly higher AUC, AUMC, and MRT. Prior treatment of $P$. longum significantly reduced $\beta$ and increased $t_{1 / 2}$. The $\mathrm{Cl}_{B}$ reduced by $21 \%$, whereas $t_{d}$ increased by $29 \%$. The treatment with $P$. longum reduced loading and maintenance dose by $33.3 \%$ and $39 \%$, respectively [91].
TABle 9: Comparative pharmacokinetic parameters of oxytetracycline administered orally $(10 \mathrm{mg} / \mathrm{kg})$ in control and P. longum treated birds [91].

\begin{tabular}{lcc}
\hline Parameters & Control OTC & Treated OTC + piperine \\
\hline$\beta(/ \mathrm{h})$ & $0.147 \pm 0.011$ & $0.112 \pm 0.006^{*}$ \\
$t_{1 / 2 \beta}(\mathrm{h})$ & $4.934 \pm 0.422$ & $6.370 \pm 0.438^{* *}$ \\
$\mathrm{AUC}(\mu \mathrm{g} \cdot \mathrm{h} / \mathrm{mL})$ & $5.055 \pm 0.689$ & $6.417 \pm 0.317^{*}$ \\
$\mathrm{AUMC}\left(\mu \mathrm{g} \cdot \mathrm{h}^{2} / \mathrm{mL}\right)$ & $43.62 \pm 11.15$ & $63.58 \pm 7.042^{*}$ \\
$\mathrm{MRT}(\mathrm{h})$ & $7.98 \pm 0.744$ & $9.77 \pm 0.644^{* *}$ \\
$t_{d}(\mathrm{~h})$ & $16.38 \pm 1.4$ & $21.142 \pm 1.453^{* *}$ \\
$\mathrm{Cl}_{B}(\mathrm{~mL} / \mathrm{kg} / \mathrm{h})$ & $184.63 \pm 7.7$ & $145.97 \pm 14.42^{* *}$ \\
\hline
\end{tabular}

$n=8$, mean $\pm \mathrm{SE} ;{ }^{*} P<0.01, * * P<0.05$.

TABle 10: MIC of ciprofloxacin for S. aureus ATCC 29213 at different concentrations of piperine [8].

\begin{tabular}{lc}
$\begin{array}{l}\text { Piperine conc. } \\
(\mu \mathrm{g} / \mathrm{mL})\end{array}$ & $\begin{array}{c}\text { MIC }(\mu \mathrm{g}) \text { of ciprofloxacin for S. aureus } \\
\text { ATCC } 29213\end{array}$ \\
\hline 0.0 & 0.25 \\
12.5 & 0.12 \\
25 & 0.12 \\
50 & 0.06 \\
\hline
\end{tabular}

Piperine and Ciprofloxacin. The influence of coadministration of piperine on pharmacokinetic profile of ciprofloxacin in rabbits was studied. The study reveals that piperine has affected statically to the pharmacokinetics of the ciprofloxacin which is significant with change in $C_{\max }, t_{\max }$, AUC, and $K_{\mathrm{el}}$. The results obtained are the combined effect of piperine on the absorption kinetics and the inhibition of the metabolism of the ciprofloxacin. This leads to increase bioavailability of ciprofloxacin when administered with piperine [92].

The potentiating effect of piperine with ciprofloxacin in in vitro combination against Staphylococcus aureus ATCC 29213 was studied and its suggestive role as an efflux pumps inhibitor. Piperine, in combination with ciprofloxacin, markedly reduced the MIC and mutation prevention concentration of ciprofloxacin for S. aureus, including methicillin resistant $S$. aureus. In vitro combination studies, the final concentrations ranged from 0.03 to $64 \mu \mathrm{g} / \mathrm{mL}$ for ciprofloxacin and from 0.8 to $50 \mu \mathrm{g} / \mathrm{mL}$ for piperine. The final bacterial inoculum in each well was $5 \times 105 \mathrm{CFU} / \mathrm{mL}$. The plates were incubated at $37^{\circ} \mathrm{C}$ for $24 \mathrm{~h}$. Piperine did not show any antibacterial activity when tested up to $100 \mu \mathrm{g} / \mathrm{mL}$. Table 10 is showing that there was a 2 -fold reduction in the MIC of ciprofloxacin (from 0.25 to $0.12 \mu \mathrm{g} / \mathrm{mL}$ ) for S. aureus ATCC 29213 when tested in combination with piperine at 12.5 and $25 \mu \mathrm{g} / \mathrm{mL}$. The MIC was further reduced to 4 -fold with $50 \mu \mathrm{g} / \mathrm{mL}$ piperine [8]. Piperine inhibits the efflux of ethidium bromide and ciprofloxacin from bacterial cells (Table 11). It is a P-glycoprotein inhibitor that inhibits ciprofloxacin efflux [8].

Piperine and Nevirapine. Influence of piperine on the pharmacokinetics of nevirapine under fasting conditions was 
TABle 11: Drug susceptibilities of S. aureus ATCC 29213 and the ciprofloxacin selected mutant $\left(\mathrm{CIP}^{\mathrm{r}}{ }_{-1}\right)$ [8].

\begin{tabular}{|c|c|c|}
\hline \multirow{2}{*}{ Compound } & \multicolumn{2}{|l|}{$\mathrm{MIC}(\mu \mathrm{g} / \mathrm{mL})$} \\
\hline & S. aureus ATCC 29213 & $\mathrm{CIP}^{\mathrm{r}}-1$ \\
\hline Ethidium bromide & 4 & 8 \\
\hline Ethidium bromide + piperine & 1 & 2 \\
\hline Ciprofloxacin & 0.25 & 128 \\
\hline Ciprofloxacin + piperine & 0.12 & 8 \\
\hline
\end{tabular}

studied. This was a crossover, placebo-controlled pilot study conducted in a total of eight healthy adult males aged 20-40 years. Subjects were randomly assigned to receive piperine $20 \mathrm{mg}$ or placebo each morning for 6 days, and on day 7 , nevirapine $(200 \mathrm{mg})$ plus piperine $(20 \mathrm{mg})$ or nevirapine plus placebo in a crossover fashion. Blood samples were collected from $1-144 \mathrm{~h}$ after dose for pharmacokinetic analysis. Mean $C_{\max }, \mathrm{AUC}_{t}, \mathrm{AUC}_{0-\infty}$, and $C_{\text {last }}$ values of nevirapine were increased by approximately 120\%, 167\%, 170\%, and $146 \%$, respectively, when coadministered with piperine. This pilot study provided evidence for enhanced bioavailability of nevirapine when administered with piperine [93].

Piperine with Diclofenac Sodium and Pentazocine. The analgesic activity of $P$. nigrum extract per se and its interaction with diclofenac sodium and pentazocine in albino mice was studied. Healthy albino mice of either sex weighing 25-30 grams were taken and divided into 4 groups of 8 animals each. Peripheral analgesic activity was evaluated by acetic acid-induced writhing test, using diclofenac sodium $(5 \mathrm{mg} / \mathrm{kg})$, P. nigrum extract $(10 \mathrm{mg} / \mathrm{kg})$, and their combination $(5+10 \mathrm{mg} / \mathrm{kg})$ orally. Similarly central analgesic activity was studied using tail flick method and pentazocine $(5 \mathrm{mg} / \mathrm{kg})$ orally was used instead of diclofenac sodium. $P$. nigrum extract alone did not show any significant analgesic activity in tail flick and writhing methods. However, results of acetic acid-induced writhing model showed that diclofenac sodium reduces writhing $54.90 \%$ with respect to control when administered alone, but showed significant decrease in writhes $78.43 \%$ with respect to control when $P$. nigrum extract was coadministered with diclofenac sodium. When $P$. nigrum extract combined with pentazocine showed significant increase in tail flick latency in comparison with pentazocine alone and control group $(P<0.05)$, the results suggest that the $P$. nigrum extract significantly increased the analgesic activity of diclofenac sodium and pentazocine [47].

Piperine and Pefloxacin. The pharmacokinetics of orally administered pefloxacin were studied to evaluate the bioenhancing effect of the herbal bioenhancer, trikatu, in mountain Gaddi goats $(n=6)$. The findings of the study revealed a decreased plasma concentration $(P>0.05)$ of pefloxacin following trikatu administration during the absorption phase (10, 15, and $20 \mathrm{~min}$ after pefloxacin administration). In contrast, the plasma concentrations of pefloxacin were significantly higher at 4, 6, 8, and $12 \mathrm{~h}$ (during the elimination phase) of the pefloxacin administration. The findings of the investigation revealed higher values for AUC, AUMC, MRT,
TABLE 12: Effect of piperine on plasma concentration of ampicillin in rabbits [95].

\begin{tabular}{lcc}
\hline Time $(\mathrm{h})$ & Ampicillin $(\mu \mathrm{g} / \mathrm{mL})$ & Ampicillin + piperine $(\mu \mathrm{g} / \mathrm{mL})$ \\
\hline 0.0 & 0 & 0 \\
0.5 & $30.584 \pm 0.38$ & $35.481 \pm 0.26$ \\
1.0 & $44.668 \pm 0.32$ & $251.188 \pm 0.27$ \\
1.5 & $31.672 \pm 0.49$ & $188.364 \pm 0.31$ \\
2.0 & $26.607 \pm 0.37$ & $66.139 \pm 0.31$ \\
2.5 & $18.836 \pm 0.38$ & $35.481 \pm 0.26$ \\
3.0 & $17.782 \pm 0.32$ & $33.496 \pm 0.26$ \\
3.5 & $12.589 \pm 0.31$ & $26.607 \pm 0.27$ \\
4.0 & $12.589 \pm 0.32$ & $26.607 \pm 0.27$ \\
4.5 & $9.441 \pm 0.26$ &
\end{tabular}

$n=6$, mean \pm SD, $P<0.05$.

TABLE 13: Effect of piperine on plasma concentration of norfloxacin in rabbits [95].

\begin{tabular}{lcc}
\hline Time $(\mathrm{h})$ & Norfloxacin $(\mu \mathrm{g} / \mathrm{mL})$ & Norfloxacin + piperine $(\mu \mathrm{g} / \mathrm{mL})$ \\
\hline 0.0 & 0 & 0 \\
1.0 & $10.593 \pm 0.26$ & $14.125 \pm 0.27$ \\
2.0 & $7.079 \pm 0.26$ & $17.783 \pm 0.32$ \\
3.0 & $5.623 \pm 0.32$ & $14.963 \pm 0.27$ \\
4.0 & $5.011 \pm 0.38$ & $11.885 \pm 0.32$ \\
5.0 & $4.732 \pm 0.26$ & $10.592 \pm 0.37$ \\
6.0 & $3.981 \pm 0.26$ & $8.414 \pm 0.25$ \\
7.0 & $3.548 \pm 0.21$ & $8.414 \pm 0.26$ \\
8.0 & $3.349 \pm 0.26$ & $7.079 \pm 0.26$ \\
9.0 & $3.162 \pm 0.27$ & $7.079 \pm 0.27$ \\
10.0 & $2.512 \pm 0.27$ & $5.623 \pm 0.27$ \\
11.0 & $2.238 \pm 0.26$ & $5.011 \pm 0.27$ \\
12.0 & $1.778 \pm 0.26$ & $4.467 \pm 0.27$ \\
\hline
\end{tabular}

$n=6$, mean $\pm \mathrm{SD}, P<0$.

$t_{d}$, and bioavailability. Trikatu treatment, however, significantly reduced $t_{1 / 2}$ and zero time intercept of the elimination phase. The $V_{d \text { (area) }}$ and $V_{d(B)}$ were significantly higher in trikatu-treated animals indicating a better penetration of the drug. Based on the MIC of $0.8 \mu \mathrm{g} / \mathrm{mL}$ of pefloxacin; a priming dose of $6.0 \mathrm{mg} / \mathrm{kg}$ and a maintenance dose of $2.21 \mathrm{mg} / \mathrm{kg}$ are required to be administered at $8 \mathrm{~h}$ intervals. For practical purposes in goats this would mean a priming dose of $6 \mathrm{mg} / \mathrm{kg}$ and a maintenance dose of $2 \mathrm{mg} / \mathrm{kg}$ given by the oral route to be repeated at $8 \mathrm{~h}$ intervals [94].

Piperine with Ampicillin and Norfloxacin. Effect of piperine on oral bioavailability of ampicillin and norfloxacin was studied in rabbits. Coadministration of piperine $(20 \mathrm{mg} / \mathrm{kg})$, an alkaloid from P. nigrum, enhanced oral bioavailability of ampicillin and norfloxacin in animal model. This is reflected in various pharmacokinetic measurements like $C_{\max }, t_{\max }$, AUC, and $t_{1 / 2}$ of the above antibiotics in animal model shown in Tables 12, 13, and 14 [95].

Piperine and Carbamazepine. The effect of piperine on the steady-state pharmacokinetics of a single dose of 
TABLE 14: Pharmacokinetic parameters of ampicillin, norfloxacin, and in combination with piperine after oral treatment in rabbit [95].

\begin{tabular}{lcccc}
\hline Treatment & $t_{\max }(\mathrm{h})$ & $C_{\max }(\mu \mathrm{g} / \mathrm{mL})$ & $t_{1 / 2}(\mathrm{~h})$ & $\mathrm{AUC}(\mu \mathrm{g} \cdot \mathrm{h} / \mathrm{mL})$ \\
\hline Ampicillin $(150 \mathrm{mg} / \mathrm{kg})$ & $1 \pm 0.31$ & $44.6 \pm 0.27$ & $1.3 \pm 0.46$ & $103.7 \pm 0.52$ \\
Ampicillin $(150 \mathrm{mg} / \mathrm{kg})+$ piperine $(20 \mathrm{mg} / \mathrm{kg})$ & $1.1 \pm 0.3$ & $251.2 \pm 0.28$ & $1.9 \pm 0.57$ & $350.49 \pm 0.47$ \\
Norfloxacin $(150 \mathrm{mg} / \mathrm{kg})$ & $3.1 \pm 0.32$ & $11 \pm 0.26$ & $1.75 \pm 0.38$ & $63.98 \pm 0.51$ \\
Norfloxacin $(150 \mathrm{mg} / \mathrm{kg})+$ piperine $(20 \mathrm{mg} / \mathrm{kg})$ & $3.2 \pm 0.31$ & $16.1 \pm 0.27$ & $2.97 \pm 0.38$ & $111.69 \pm 0.54$ \\
\hline
\end{tabular}

$n=6$, mean $\pm \mathrm{SD}, P<0.05$.

carbamazepine in poorly controlled epilepsy patients on carbamazepine monotherapy was studied. Patients $(n=$ 10 each) receiving either $300 \mathrm{mg}$ or $500 \mathrm{mg}$ dose of carbamazepine twice a day were selected. After administration of carbamazepine, venous blood samples were collected at $0,0.5,1,2,4,6,9$, and $12 \mathrm{~h}$. Subsequently, piperine (20 mg p.o.) was administered along with carbamazepine and samples were collected similarly. Piperine significantly increased the mean plasma concentrations of carbamazepine at most of the time points in both dose groups. There was a significant increase in $\mathrm{AUC}_{0-12 \mathrm{~h}}(P<0.001)$, average $\mathrm{C}_{\mathrm{ss}}(P<0.001), t_{1 / 2}(P<0.05)$, and a decrease in $K_{\mathrm{el}}$ $(P<0.05)$, in both the dose groups, whereas changes in $K_{a}$ and $t_{1 / 2 \alpha}$ were not significant. $C_{\max }(P<0.01)$ and $t_{\max }$ $(P<0.01)$ were increased significantly following piperine administration in the $500 \mathrm{mg}$ dose group; however, these parameters were not significant in the lower dose group. Piperine could significantly enhance the oral bioavailability of carbamazepine, possibly by decreasing the elimination or by increasing its absorption [96].

Piperine and Fexofenadine. Effect of piperine, a major component of black pepper, on the oral exposure of fexofenadine in rats was studied. Pharmacokinetic parameters of fexofenadine were determined in rats following an oral $(10 \mathrm{mg} / \mathrm{kg})$ administration of fexofenadine in the presence and absence of piperine (10 or $20 \mathrm{mg} / \mathrm{kg}$ ). Compared to the control group given fexofenadine alone, the combined use of piperine increased the AUC of fexofenadine by $180 \%$ to $190 \%$ while there was no significant change in $C_{\max }$ and $t_{1 / 2}$ of fexofenadine in rats. The bioavailability of fexofenadine was increased by approximately 2 -fold via the concomitant use of piperine. Furthermore, $t_{\max }$ tends to be increased which might be attributed to the delayed gastric emptying in the presence of piperine. In conclusion, piperine significantly enhanced the oral exposure of fexofenadine in rats likely by the inhibition of P-glycoprotein-mediated cellular efflux during the intestinal absorption, suggesting that the combined use of piperine or piperine-containing diet with fexofenadine may require close monitoring for potential drug-diet interactions [97].

Piperine and Metronidazole. Effect of piperine on bioavailability of metronidazole was studied in rabbits. Male New Zealand white rabbits $(2.0-2.5 \mathrm{~kg}$ body weight) used for pharmacokinetic and bioavailability study. Three groups of rabbits were formed from which one group was considered as control and received only vehicle (distilled water) orally. The remaining two groups were treated with metronidazole
TABLE 15: Comparative pharmacokinetic parameters after oral administration of metronidazole and in combination with piperine in rabbits [98].

\begin{tabular}{lcc}
\hline $\begin{array}{l}\text { Pharmacokinetic } \\
\text { parameters }\end{array}$ & Metronidazole & Metronidazole + piperine \\
\hline$C_{\max }(\mathrm{ng} / \mathrm{mL})$ & $3,805.89 \pm 233.8$ & $6,007.07 \pm 348.8$ \\
$\mathrm{AUC}_{0-24}(\mathrm{ng} \cdot \mathrm{h} / \mathrm{mL})$ & $45,073.75 \pm 713.7$ & $84,980.98 \pm 345.6$ \\
$t_{\max }(\mathrm{h})$ & $1.66 \pm 0.57$ & $1.66 \pm 0.57$ \\
$K_{\mathrm{el}}(\mathrm{mL} / \mathrm{h})$ & $0.06 \pm 0.02$ & $0.04 \pm 0.02$ \\
$t_{1 / 2}(\mathrm{~h})$ & $1.48 \pm 1.23$ & $12.24 \pm 1.04$ \\
$V_{d}(\mathrm{~L})$ & $2.69 \pm 0.23$ & $1.48 \pm 0.65$ \\
\hline
\end{tabular}

and combination of metronidazole and piperine, respectively. About $1 \mathrm{~mL}$ of blood sample was collected at the different time intervals and analyzed spectrophotometrically by HPLC. Different pharmacokinetic parameters have shown to enhance bioavailability of metronidazole in combination with piperine than metronidazole alone (Table 15). So, it is concluded that bioavailability of metronidazole was significantly enhanced in the presence of piperine [98].

Piperine and Resveratrol. Effect of piperine on oral bioavailability of resveratrol was studied in mice. Employing a standardized LC-MS assay, the effect of piperine coadministration with resveratrol on serum levels resveratrol and resveratrol-3-O- $\beta$-D-glucuronide in C57BL mice was determined. Mice were administered resveratrol $(100 \mathrm{mg} / \mathrm{kg})$ or resveratrol $(100 \mathrm{mg} / \mathrm{kg})+$ piperine $(10 \mathrm{mg} / \mathrm{kg})$, and the serum levels of resveratrol and resveratrol-3-O- $\beta$-Dglucuronide were analyzed at different times. The AUC to resveratrol was enhanced to $229 \%$ and the $C_{\max }$ was increased to $1544 \%$ with the addition of piperine. Study demonstrated that piperine significantly improves the in vivo bioavailability of resveratrol [100].

Piperine and Gatifloxacin. Influence of coadministration of piperine on pharmacokinetic profile of gatifloxacin was studied in layer birds. The pharmacokinetic profile (Tables 16 and 17$)$ of gatifloxacin $(10 \mathrm{mg} / \mathrm{kg}$ body weight) along with piperine coadministration $(15 \mathrm{mg} / \mathrm{kg})$ via single oral dose in layer birds showed $t_{1 / 2}, C_{\max }$, and AUC of $4.03 \pm$ $0.097 \mathrm{~h}, 2.14 \pm 0.019 \mu \mathrm{g} / \mathrm{mL}$, and $17.54 \pm 0.204 \mu \mathrm{g} \cdot \mathrm{h} / \mathrm{mL}$, respectively, which is found significantly higher than gatifloxacin alone $(3.74 \pm 0.073 \mathrm{~h}, 1.74 \pm 0.023 \mu \mathrm{g} / \mathrm{mL}$, and $15.25 \pm$ $0.219 \mu \mathrm{g} \cdot \mathrm{h} / \mathrm{mL}$, resp.). This study reveals that piperine has significant effect on the pharmacokinetics of the gatifloxacin. There is enhancement in bioavailability $(F)$ from $74.52 \pm$ $1.021 \%$ to $85.74 \pm 0.956 \%$ in piperine + gatifloxacin-treated 
TABLE 16: Comparison of plasma concentrations $(\mu \mathrm{g} / \mathrm{mL})$ of gatifloxacin- and gatifloxacin + piperine-treated birds after single oral administration $(10 \mathrm{mg} / \mathrm{kg})$ [101].

\begin{tabular}{lcc}
\hline Time $(\mathrm{h})$ & Gatifloxacin & Gatifloxacin + piperine \\
\hline 0.5 & $0.48 \pm 0.013$ & $0.53 \pm 0.009^{* *}$ \\
0.75 & $1 \pm 0.014$ & $1.16 \pm 0.029^{* *}$ \\
1 & $1.35 \pm 0.016$ & $1.46 \pm 0.021^{*}$ \\
2 & $1.74 \pm 0.023$ & $2.14 \pm 0.020$ \\
4 & $1.35 \pm 0.02$ & $1.47 \pm 0.034^{*}$ \\
8 & $0.97 \pm 0.009$ & $1.08 \pm 0.019^{* *}$ \\
12 & $0.46 \pm 0.01$ & $0.54 \pm 0.008$ \\
\hline
\end{tabular}

$n=6,{ }^{*}$ Significant at $P<0.05,{ }^{*}$ Highly significant at $P<0.01$.

TABLE 17: Comparison of pharmacokinetic parameters of gatifloxacin- and gatifloxacin + piperine-treated layer birds after single oral administration $(10 \mathrm{mg} / \mathrm{kg})$ [101].

\begin{tabular}{lcc}
\hline $\begin{array}{l}\text { Pharmacokinetic } \\
\text { parameters }\end{array}$ & Gatifloxacin & Gatifloxacin + piperine \\
\hline$C_{\max }(\mu \mathrm{g} / \mathrm{mL})$ & $1.74 \pm 0.023$ & $2.14 \pm 0.019^{*}$ \\
AUC $(\mu \mathrm{g} \cdot \mathrm{h} / \mathrm{mL})$ & $15.25 \pm 0.219$ & $17.54 \pm 0.204^{*}$ \\
$t_{\max }(\mathrm{h})$ & $2 \pm 0.0$ & $2 \pm 0.0$ \\
$t_{1 / 2}(\mathrm{~h})$ & $3.74 \pm 0.073$ & $4.03 \pm 0.097^{*}$ \\
$V_{d}(\mathrm{~L} / \mathrm{kg})$ & $3.54 \pm 0.038$ & $3.33 \pm 0.083^{*}$ \\
$F(\%)$ & $74.52 \pm 1.021$ & $85.74 \pm 0.956^{*}$ \\
\hline
\end{tabular}

$n=6$, mean \pm SE; ** Highly significant at $P<0.01$, ${ }^{*}$ Significant at $P<0.05$.

group. The results obtained are the combined effect of piperine on the absorption kinetics and the inhibition of the metabolism of gatifloxacin [101].

The influence of coadministration of piperine on pharmacokinetic profile of gatifloxacin was studied in broiler birds. The pharmacokinetic profile of gatifloxacin $(10 \mathrm{mg} / \mathrm{kg}$ body weight) along with piperine coadministration $(15 \mathrm{mg} / \mathrm{kg})$ via single dose oral administration in broiler birds showed $t_{1 / 2}, C_{\max }$, and AUC of $4.1 \pm 0.092 \mathrm{~h}, 2.14 \pm$ $0.02 \mu \mathrm{g} / \mathrm{mL}$, and $17.58 \pm 0.17 \mu \mathrm{g} \cdot \mathrm{h} / \mathrm{mL}$, respectively, which is found significantly higher than $t_{1 / 2}, C_{\max }$ and AUC of $3.81 \pm 0.07 \mathrm{~h}, 1.74 \pm 0.024 \mu \mathrm{g} / \mathrm{mL}$, and $15.24 \pm 0.23 \mu \mathrm{g} \cdot \mathrm{h} / \mathrm{mL}$, respectively, obtained after single oral administration of gatifloxacin $(10 \mathrm{mg} / \mathrm{kg}$ body weight $)$ alone. This study reveals that piperine has significant effect on the pharmacokinetics of the gatifloxacin. There is significant enhancement of bioavailability $(F)$ in piperine-treated group $(81.95 \pm 1.56 \%)$ compared to gatifloxacin alone treated group (72.96 \pm $1.10 \%)$. The results obtained are the combined effect of piperine on the absorption kinetics and the inhibition of the metabolism of gatifloxacin [102].

Piperine and Atenolol. A bioavailability of atenolol in presence of piperine was studied in male New Zealand white rats. All rats were divided in three groups. First group was considered as control and received only vehicle (distilled water) orally. The remaining two groups were treated with atenolol and combination of atenolol and piperine, respectively. About $2 \mathrm{~mL}$ of blood sample was collected at the
TABLE 18: Comparison of pharmacokinetic parameters of atenololand atenolol + piperine-treated male New Zealand white rats after single oral administration (100 mg/kg) [103].

\begin{tabular}{lcc}
\hline $\begin{array}{l}\text { Pharmacokinetic } \\
\text { parameters }\end{array}$ & Atenolol & Atenolol + piperine \\
\hline$C_{\max }(\mathrm{pg} / \mathrm{mL})$ & $22,453 \pm 233$ & $37,860 \pm 348$ \\
$\mathrm{AUC}_{0-24}(\mathrm{pg} \cdot \mathrm{h} / \mathrm{mL})$ & $1,07,189 \pm 1615$ & $1,52,011 \pm 2354$ \\
$t_{\max }(\mathrm{h})$ & $2.0 \pm 0.0$ & $2.0 \pm 0.0$ \\
$K_{\mathrm{el}}(\mathrm{mL} / \mathrm{h})$ & $0.27 \pm 0.005$ & $0.25 \pm 0.010$ \\
$t_{1 / 2}(\mathrm{~h})$ & $6.27 \pm 0.057$ & $6.72 \pm 0.100$ \\
$V_{d}(\mathrm{~L})$ & $4.54 \pm 0.786$ & $2.88 \pm 0.305$ \\
\hline
\end{tabular}

$n=3$, mean \pm SE.

different time intervals and analyzed spectrophotometrically by HPLC. The pharmacokinetic parameters obtained after administration of atenolol $(100 \mathrm{mg} / \mathrm{kg})$ and combination of atenolol $(100 \mathrm{mg} / \mathrm{kg})$ and piperine $(10 \mathrm{mg} / \mathrm{kg})$. So, from Table 18 it can be concluded that bioavailability of atenolol was significantly enhanced in presence of piperine [103].

Piperine and Ibuprofen. Influence of piperine on ibuprofeninduced antinociception and its pharmacokinetics was studied. Piperine $(10 \mathrm{mg} / \mathrm{kg})$ significantly increased the dosedependent antinociceptive activity of ibuprofen evaluated by both acetic acid writhing and formalin test, when it was administered with ibuprofen. Ibuprofen plasma concentration was also increased when it was administered with piperine. The synergistic antinociception activity of ibuprofen when administered with piperine can be attributed to increased plasma concentration of ibuprofen. From this study it can be concluded that piperine can be used as a bioenhancer along with ibuprofen [104].

Piperine and Losartan Potassium. Effect of piperine on bioavailability of losartan potassium was studied in male New Zealand white rats. All rats were divided in three groups. First group received only mineral water orally. Second group received losartan potassium $(100 \mathrm{mg} / \mathrm{kg})$. Third group received losartan potassium $(100 \mathrm{mg} / \mathrm{kg})$ and piperine $(10 \mathrm{mg} / \mathrm{kg})$. About $2 \mathrm{~mL}$ of blood sample was collected at the different time intervals and analyzed by HPLC. The pharmacokinetic parameters obtained after administration of losartan potassium $(100 \mathrm{mg} / \mathrm{kg})$ and combination of losartan potassium $(100 \mathrm{mg} / \mathrm{kg})$ and piperine $(10 \mathrm{mg} / \mathrm{kg})$. So, from Table 19 it can be concluded that bioavailability of losartan potassium was significantly enhanced in presence of piperine [105].

4.2. Zingiber officinale. The major pungent compounds in Zingiber officinale (Ginger) of rhizome extract contain potentially active gingerols, which can be converted to shogaols, zingerone, and paradol [110, 111]. The odor of ginger depends mainly on its volatile oil, the yield of which varies from 1 to $3 \%$ [112]. In laboratory animals, the gingerols increase the motility of the gastrointestinal tract and have analgesic, sedative, antipyretic, and antibacterial properties [113]. [6]-gingerol is the major pungent principle 
TABle 19: Comparison of pharmacokinetic parameters of losartan potassium- and losartan potassium + piperine-treated male New Zealand white rats after single oral administration $(100 \mathrm{mg} / \mathrm{kg})$ [105].

\begin{tabular}{lcc}
\hline $\begin{array}{l}\text { Pharmacokinetic } \\
\text { parameters }\end{array}$ & Losartan potassium & $\begin{array}{c}\text { Losartan potassium } \\
+ \text { piperine }\end{array}$ \\
\hline$C_{\max }(\mathrm{pg} / \mathrm{mL})$ & $32,461 \pm 1436$ & $48,399 \pm 6060$ \\
$\mathrm{AUC}_{0-24}(\mathrm{pg} \cdot \mathrm{h} / \mathrm{mL})$ & $1,10,441 \pm 5280$ & $1,69,924 \pm 14,343$ \\
$t_{\max }(\mathrm{h})$ & $1.0 \pm 0.0$ & $1.0 \pm 0.0$ \\
$K_{\mathrm{el}}(\mathrm{mL} / \mathrm{h})$ & $0.295 \pm 0.002$ & $0.283 \pm 0.022$ \\
$t_{1 / 2}(\mathrm{~h})$ & $2.34 \pm 0.01$ & $2.44 \pm 0.195$ \\
$V_{d}(\mathrm{~L})$ & $3.0 \pm 0.15$ & $2.0 \pm 0.25$ \\
\hline
\end{tabular}

$n=3$, mean \pm SE.

of ginger. The chemopreventive potentials of [6]-gingerol present a promising future alternative to expensive and toxic therapeutic agents [114]. Ginger exhibits activities like antiulcer activity [115, 116], antithrombotic activity [117], antimicrobial activity [118], antifungal activity [119], antiinflammatory activity [117, 120-122], antidiabetic activity [123], antiemetic activity [124, 125], anthelmintic activity [126], analgesic and antipyretic activity [121], antioxidant and antiapoptotic activity [122], and anticancer activity [127].

Ginger acts powerfully on GIT mucous membrane. The role of ginger is to regulate intestinal function to facilitate absorption. The composition containing $Z$. officinale alone provides bioavailability/bioenhancing activity in the range of $30-75 \%$, and piperine and $Z$. officinale, and provides the bioavailability of drugs in the range of $10-85 \%$. The dosage of bioenhancer from $Z$. officinale as extract is in the range of $10-30 \mathrm{mg} / \mathrm{kg}$ body weight and piperine is in the range of $4-$ $12 \mathrm{mg} / \mathrm{kg}$ body weight. The dosage of bioenhancer from $Z$. officinale as bioactive fraction is in the range of $5-15 \mathrm{mg} / \mathrm{kg}$ body weight, preferably $30 \mathrm{mg} / \mathrm{kg}$ body weight and piperine is in the range of $6-10 \mathrm{mg} / \mathrm{kg}$ body weight, preferably $8 \mathrm{mg} / \mathrm{kg}$ body weight. The extracts or its fractions either in presence or absence of piperine have been found to be highly selective in their bioavailability enhancing activity (Table 20). It varies from almost nearly significant (20\%) to highly significant $(200 \%)[128,129]$.

4.3. Niaziridin. Niaziridin is a nitrile glycoside that has been isolated from the leaves, pods, and bark of Drumstick (Moringa oleifera) [130]. M. oleifera has shown to exhibit activities like antifertility effect [131], antimicrobial activity [132], diuretic activity [133], anticancer activity [134, 135], anti-inflammatory activity $[133,135]$, hypotensive and spasmolytic activity [136], antifungal activity [137], antiulcer activity [138], antioxidant activity [139, 140], hepatoprotective activity [141], hypolipidaemic activity [142], antiteratogenic activity [143], and antiarthritic activity [144].

It enhances bioactivity of commonly used antibiotics such as rifampicin, ampicillin, tetracycline, and nalidixic acid against Gram-positive bacteria like M. smegmatis and Bacillus subtilis and Gram-negative bacteria like E. coli (Table 21). It enhances activity of commonly used antibiotics such as rifampicin, ampicillin, tetracycline, and nalidixic acids against E. coli Gram-negative bacteria. It enhances activity of rifampicin, ampicillin, tetracycline, and nalidixic acids by 1.2-19-fold against the Gram-positive strains. It enhances the activity of azole antifungal drugs such as clotrimazole against Candida albicans by 5-6-fold. However, the antifungal activity enhancement was observed only at a relatively higher concentration $(10 \mu \mathrm{g} / \mathrm{mL})$ of the compound. It also facilitates the uptake of nutrients like Vitamin $B_{12}$ through the intestinal gut membrane in combination, thus also functioning as bioavailability enhancer $[145,146]$.

4.4. Glycyrrhizin. Glycyrrhizin is a glycoside obtained from roots and stolon of Liquorice (Glycyrrhiza glabra). It has expectorant action to treat bronchitis and can also reduce inflammation, allergies, asthma, gastritis, peptic ulcers, rheumatism, and sore throat. It helps the liver to detoxify drugs and is used for treatment of liver disease. It strengthens the immune system, stimulates the adrenal gland, and is diuretic and laxative. Glycyrrhizin is 50 times sweeter than sugar. Primary uses include treatment for peptic ulcers and stomach ailments, respiratory, and intestinal passages. Glycyrrhizin exhibits activities like antihepatotoxic activity $[147,148]$, anti-inflammatory activity $[149,150]$, anticancer activity [151], and antiviral activity [152, 153].

The concentration of glycyrrhizin ranges from 0.05 to $50 \%$ of the weight of the antibacterial compounds. The concentration of glycyrrhizin ranges from 0.10 to $10 \%$ of the weight of the nutraceutical compounds. The concentration of glycyrrhizin ranges from 0.25 to $20 \%$ of the weight of the antifungal agents. The level of glycyrrhizin ranges from 10 to 10,000 -fold of the weight of the anticancer compound used $[154,155]$.

Glycyrrhizin-mediated enhancement in the cell division inhibitory action of anticancer agent "Taxol" (paclitaxel) in the animal cell culture experiments using cancerous cell line MCF-7. The anticancerous activity of Taxol in terms of inhibiting the growth and multiplication of MCF-7 cancer cells was markedly enhanced by 5 -fold. The cancerous cells growth inhibition by Taxol $(0.01 \mu \mathrm{g} / \mathrm{mL})$ in presence of glycyrrhizin $(1 \mu \mathrm{g} / \mathrm{mL})$ was higher than even the treatment with Taxol $(0.05 \mu \mathrm{g} / \mathrm{mL})$ alone $[154,155]$.

It enhances bioactivity of commonly used antibiotics such as rifampicin, ampicillin, tetracycline, and nalidixic acids against Gram-positive bacteria like M. smegmatis and Bacillus subtilis and Gram-negative bacteria like E. coli (Table 22). It enhances activity of commonly used antibiotics such as rifampicin, ampicillin, tetracycline, and nalidixic acids against E. coli Gram-negative bacteria. It enhances activity of rifampicin, tetracycline, and nalidixic acids against the Gram-positive strains. It enhances the activity of azole antifungal drugs such as clotrimazole against Candida albicans $[154,155]$.

4.5. Cuminum cyminum. The main components of $C$. cyminum oil are $p$-mentha-1,4-dien-7-al, cumin aldehyde, $\gamma$ terpinene, and $\beta$-pinene [156]. C. cyminum exhibits activities like estrogenic activity [157], hypolipidaemic activity [158], 
TABLE 20: Percent enhancement in bioavailability of different drugs/compounds by supplementation of bioactive fractions from $Z$. officinale and its combination with piperine $[128,129]$.

\begin{tabular}{|c|c|c|c|}
\hline \multirow{2}{*}{ Category } & \multirow{2}{*}{ Compound } & \multicolumn{2}{|c|}{ Percent enhancement } \\
\hline & & BE from Z. officinale & BE from $Z$. officinale + piperine \\
\hline \multirow{3}{*}{ Macrolides } & Azithromycin & 78 & 85 \\
\hline & Erythromycin & 68 & 105 \\
\hline & Roxithromycin & 72 & 93 \\
\hline \multirow{2}{*}{ Cephalosporins } & Cefalexin & 75 & 85 \\
\hline & Cefadroxil & 68 & 65 \\
\hline \multirow{2}{*}{ Penicillins } & Amoxycillin & 80 & 90 \\
\hline & Cloxacillin & 76 & 90 \\
\hline Aminoglycosides & Kanamycin & 65 & 92 \\
\hline \multirow{2}{*}{ Fluoroquinolones } & Ciprofloxacin & 68 & 70 \\
\hline & Pefloxacin & 53 & 69 \\
\hline \multirow{2}{*}{ Antifungal } & Fluconazole & 120 & 110 \\
\hline & Ketoconazole & 125 & 100 \\
\hline \multirow{2}{*}{ Antiviral } & Acyclovir & 82 & 85 \\
\hline & Zidovudine & 105 & 126 \\
\hline CNS drugs & Alprazolam & 76 & 70 \\
\hline \multirow{4}{*}{ Anticancer } & Methotrexate & 87 & 49 \\
\hline & 5-Fluorouracil & 110 & 93 \\
\hline & Doxorubicin & 72 & 75 \\
\hline & Cisplatin & 56 & 45 \\
\hline \multirow{3}{*}{ Cardiovascular } & Amlodipine & 68 & 95 \\
\hline & Propranolol & 76 & 104 \\
\hline & Lisinopril & 76 & 100 \\
\hline \multirow{3}{*}{ Anti-inflammatory/Antiarthritic } & Diclofenac & 90 & 140 \\
\hline & Nimesulide & 144 & 165 \\
\hline & Piroxicam & 86 & 134 \\
\hline \multirow{4}{*}{ Antituberculosis/Antileprosy } & Rifampicin & 65 & 98 \\
\hline & Dapsone & 46 & 55 \\
\hline & Ethionamide & 56 & 48 \\
\hline & Cycloserine & 71 & 70 \\
\hline \multirow{3}{*}{ Antihistamines } & Salbutamol & 78 & 92 \\
\hline & Theophylline & 76 & 80 \\
\hline & Bromhexine & 46 & 75 \\
\hline \multirow{2}{*}{ Corticosteroids } & Dexamethasone & 76 & 80 \\
\hline & Betamethasone & 75 & 70 \\
\hline \multirow{2}{*}{ Immunosuppressants } & Cyclosporin A & 116 & 120 \\
\hline & Tacrolimus & 75 & 117 \\
\hline \multirow{2}{*}{ Antiulcer } & Ranitidine & 147 & 165 \\
\hline & Cimetidine & 98 & 76 \\
\hline \multirow{4}{*}{ Vitamins } & Vitamin A (1 mg/kg) & 30 & 40 \\
\hline & Vitamin E (40 mg/kg) & 27 & 25 \\
\hline & Vitamin C (50 mg/kg) & 25 & 24 \\
\hline & Folic acid $(50 \mu \mathrm{g} / \mathrm{kg})$ & 34 & 35 \\
\hline \multirow{2}{*}{ Antioxidants } & $\beta$-Carotene $(15 \mathrm{mg} / \mathrm{kg})$ & 36 & 55 \\
\hline & Silymarin $(5 \mathrm{mg} / \mathrm{kg})$ & 28 & 43 \\
\hline
\end{tabular}


TABle 20: Continued.

\begin{tabular}{|c|c|c|c|}
\hline \multirow{2}{*}{ Category } & \multirow{2}{*}{ Compound } & \multicolumn{2}{|c|}{ Percent enhancement } \\
\hline & & BE from $Z$. officinale & BE from $Z$. officinale + piperine \\
\hline \multirow{2}{*}{ Herbal products } & Curcumin $(50 \mathrm{mg} / \mathrm{kg})$ & 43 & 70 \\
\hline & Rutin (40 mg/kg) & 21 & 78 \\
\hline \multirow{7}{*}{ Herbal plants } & Echinacea & 66 & 82 \\
\hline & Tinospora cordifolia & 67 & 112 \\
\hline & Picrorhiza kurroa & 56 & 87 \\
\hline & Andrographis paniculata & 55 & 70 \\
\hline & Emblica ribes & 65 & 72 \\
\hline & Asparagus racemosus & 44 & 60 \\
\hline & Withania somnifera & 64 & 48 \\
\hline \multirow{5}{*}{ Amino acids } & Methionine $(20 \mathrm{mg} / \mathrm{kg})$ & 25 & 45 \\
\hline & Lysine (40 mg/kg) & 15 & 40 \\
\hline & Leucine $(50 \mathrm{mg} / \mathrm{kg})$ & 17 & 34 \\
\hline & Valine $(25 \mathrm{mg} / \mathrm{kg})$ & 25 & 46 \\
\hline & Isoleucine $(25 \mathrm{mg} / \mathrm{kg})$ & 31 & 35 \\
\hline \multirow{2}{*}{ Essential elements } & Zinc $(0.1 \mathrm{mg} / \mathrm{kg})$ & 19 & 20 \\
\hline & Potassium $(25 \mathrm{mg} / \mathrm{kg})$ & 21 & 19 \\
\hline
\end{tabular}

antinociceptive and anti-inflammatory activity [159], anticonvulsant effect [160], anticancer activity [161], antimicrobial activity [156, 162], antitussive effect [163], antioxidant activity [164], and antifungal activity [165]. The doses of its fractions responsible for the bioavailability enhancement activity ranged from 0.5 to $25 \mathrm{mg} / \mathrm{kg}$ body weight. The dosage level of the composition comprising C. cyminum extract is in the range of $10-30 \mathrm{mg} / \mathrm{kg}$ body weight and composition comprising bioactive fraction is in the range of $2-20 \mathrm{mg} / \mathrm{kg}$ body weight. The composition contain $C$. cyminum extract or the fractions there of which provides bioavailability/bioenhancing activity in the range of 25$335 \%$ (Table 23). Polar and nonpolar extract of parts of $C$. cyminum and piperine increased bioavailability in the range of $25-435 \%[166,167]$.

4.6. Carum carvi. Carum carvi (Caraway) contains caraway oil obtained from dried and crushed seeds. Carvone and limonene are the chief constituents of the oil and its odour and flavour are mainly attributed to them [168]. C. carvi exhibits activities like antiulcer effects [169], hypoglycemic effect [170], antimicrobial activity $[156,171]$, diuretic activity [172], antioxidant activity [171, 173], antiaflatoxigenic activity [174], and antifungal activity [171]. The effective dose of the bioenhancer extract is in the range of 5$100 \mathrm{mg} / \mathrm{kg}$ body weight and the dose bioactive fraction of bioenhancer is in the range of $1-55 \mathrm{mg} / \mathrm{kg}$ body weight. It has been reported to enhance bioavailability of antibiotics, antifungal, antiviral, and anticancerous drug. The extract or its fractions were found to be $20-110 \%$ more active and when used in combination with $Z$. officinale, it was found to be more effective, in the range of $10-150 \mathrm{mg} / \mathrm{kg}$ body weight. $C$. carvi in different combinations showed pronounced activity ranging from 25 to $95 \%$ in presence of piperine and amount of piperine in formulations ranged from 3 to $15 \mathrm{mg} / \mathrm{kg}$ body weight $[5,175]$. The percent enhancement of bioavailability of different class of drugs by fractions of $C$. carvi and in combination with piperine and $Z$. officinale is shown in Table 24.

4.7. Allicin. Allicin is an allyl sulfur containing compound obtained from Garlic (Allium sativum). Allicin exhibits activities like antiplatelet activity [176], antioxidant activity [177, $178]$, antibacterial activity $[179,180]$, anticancer activity [181], Immunomodulating effect [182], antidiabetic activity [183, 184], antiparasitic activity [185], antifungal activity [186-188], antioxidant and anti-inflammatory activity [189, 190], and antiviral activity [191].

4.7.1. Allicin and $\mathrm{Cu}^{2+} \cdot \mathrm{Cu}^{2+}$ showed a dose-dependent fungicidal activity against Saccharomyces cerevisiae cells, and its lethal effect was extremely enhanced in the presence of allicin, an allyl sulfur compound from garlic. The fungicidal activity of $\mathrm{Cu}^{2+}$ was unaffected or rather attenuated by other sulfur-containing compounds such as $N$-acetyl-cysteine, 1cysteine, or dithiothreitol. $\mathrm{Ca}^{2+}$ could absolutely protect against the lethal effect of $\mathrm{Cu}^{2+}$ itself, but showed no protection against the fungicidal activity of $\mathrm{Cu}^{2+}$ newly generated in combination with allicin. $\mathrm{Cu}^{2+}$ accelerated an endogenous generation of reactive oxygen species (ROS) in $S$. cerevisiae cells at a lethal concentration, but such intracellular oxidative stress induction was not observed during cell death progression upon treatment with $\mathrm{Cu}^{2+}$ and allicin. A surfactant, sodium $N$-lauroyl sarcosinate (SLS), enhanced the solubilization of a few proteins including alkyl hydroperoxide reductase 1 (AHP1) in intact cells, accounting for the absence of this protein in the extract from allicin-treated cells. Allicin-treated cells were rendered extremely sensitive to the subsequent $\mathrm{Cu}^{2+}$ treatment as in the case of SLS-treated cells. Allicin-treated cells and SLS-treated cells similarly showed an increased sensitivity to exogenously added tert-butyl hydroperoxide $(t-\mathrm{BOOH})$, 
TABLE 21: Enhancement of antibiotic activity by niaziridin* in combination with antibiotics against different organisms [145, 146].

\begin{tabular}{|c|c|c|c|}
\hline Organisms & Antibiotics & Concentration $(\mu \mathrm{g} / \mathrm{mL})$ & Fold enhancement of activity \\
\hline \multirow{6}{*}{ E. coli (CA8000) } & Rifampicin & 20.0 & 38.8 \\
\hline & Rifampicin & 30.0 & 12.6 \\
\hline & Ampicillin & 6.0 & 5.3 \\
\hline & Tetracycline & 1.0 & 2.3 \\
\hline & Tetracycline & 2.0 & 5.2 \\
\hline & Nalidixic acid & 6.0 & 50.0 \\
\hline \multirow{4}{*}{ B. subtilis (MTCC121) } & Rifampicin & 0.05 & 19.4 \\
\hline & Ampicillin & 0.01 & 5.1 \\
\hline & Tetracycline & 1.0 & 3.5 \\
\hline & Nalidixic acid & 2.0 & 7.0 \\
\hline \multirow{4}{*}{ M. smegmatis (MC2 155) } & Rifampicin & 0.05 & 1.9 \\
\hline & Ampicillin & 0.01 & 4.7 \\
\hline & Tetracycline & 1.0 & 4.0 \\
\hline & Nalidixic acid & 2.0 & 1.2 \\
\hline
\end{tabular}

* Dose: E. coli $=0.1 \mu \mathrm{g} / \mathrm{kg} ;$ B. subtilis and M. smegmatis $=1.0 \mu \mathrm{g} / \mathrm{kg}$.

TABLE 22: Enhancement of antibiotic activity by glycyrrhizin $(1 \mu \mathrm{g} / \mathrm{mL})$ in combination with antibiotics against different organisms [154, 155].

\begin{tabular}{lccc}
\hline Organisms & Antibiotics & Concentration $(\mu \mathrm{g} / \mathrm{mL})$ & Fold enhancement of activity \\
\hline & Rifampicin & 10.0 & 3.8 \\
& Rifampicin & 20.0 & 14.0 \\
E. coli (ATCC 10536) & Nalidixic acid & 8.0 & 9.5 \\
& Ampicillin & 6.0 & 12.6 \\
& Ampicillin & 8.0 & 2.1 \\
& Tetracycline & 2.0 & 1.9 \\
& Tetracycline & 4.0 & 9.0 \\
B. subtilis (ATCC 6015) & Nalidixic acid & 6.0 & 4.5 \\
& Nalidixic acid & 8.0 & 6.75 \\
M. smegmatis (ATCC 14468) & Tetracycline & 1.0 & 5.0 \\
& Rifampicin & 0.5 & 6.5 \\
& Nalidixic acid & 4.0 & 7.7 \\
\end{tabular}

organic peroxide that is detoxified by the action of AHP1. Our study suggests that allicin influences the mode of cell surface localization or the related function of AHP1 as a defense against phospholipid peroxidation by the external action of $\mathrm{Cu}^{2+}[192]$.

4.7.2. Allicin and Amphotericin B. Enhancement of the fungicidal activity of amphotericin B (AmB) by allicin, an allyl-sulfur compound from garlic, against the yeast Saccharomyces cerevisiae as a model system was studied. AmB is a representative antibiotic for the control of serious fungal infections, and its fungicidal activity was greatly enhanced by allicin (Table 25). In addition to the plasma membrane permeability change, $\mathrm{AmB}$ induced vacuole membrane damage so that the organelles were visible as small discrete particles. Although allicin was ineffective in promoting AmB-induced plasma membrane disability, this compound enhanced AmB-induced structural damage to the vacuolar membrane even at a nonlethal dose of the antibiotic. Allicin could also enhance the antifungal activity of $\mathrm{AmB}$ against the pathogenic fungus $C$. albicans and against Aspergillus fumigatus. In contrast, allicin did not enhance the cytotoxic activity of AmB against cells of human promyelocytic leukemia (HL-60), a vacuole-less organism [187].

Allicin was found to inhibit ergosterol transport from the plasma membrane to the cytoplasm, which is considered to be a cellular protective response to AmB-induced vacuole disruption in $S$. cerevisiae. The study suggests that AmB lethality against $C$. albicans depends at least in part on its vacuole disruptive activity under the physiological condition permissive for invasive growth of the fungus [188].

Ogita et al. [193] reported that allicin enhances AmBinduced vacuole membrane damage by inhibiting ergosterol trafficking from the plasma membrane to the vacuole membrane. Ogita et al. [194] suggested that the fungicidal activity of AmB combined with allicin is involved in vacuole disruption but not in potassium ion efflux, and that the 
TABle 23: Percent enhancement in bioavailability of different compounds by supplementation of bioactive fractions from C. cyminum and its combination with piperine [166, 167].

\begin{tabular}{|c|c|c|c|}
\hline \multirow{2}{*}{ Category } & \multirow{2}{*}{ Compound } & \multicolumn{2}{|c|}{ Percent enhancement } \\
\hline & & BE from C. cyminum & BE from C. cyminum + piperine \\
\hline \multirow{3}{*}{ Macrolides } & Azithromycin & 83 & 97 \\
\hline & Erythromycin & 75 & 95 \\
\hline & Roxithromycin & 67 & 103 \\
\hline \multirow{2}{*}{ Cephalosporins } & Cefalexin & 60 & 75 \\
\hline & Cefadroxil & 90 & 79 \\
\hline \multirow{2}{*}{ Penicillins } & Amoxycillin & 75 & 98 \\
\hline & Cloxacillin & 94 & 95 \\
\hline Aminoglycosides & Kanamycin & 95 & 110 \\
\hline \multirow{3}{*}{ Fluoroquinolones } & Ciprofloxacin & 52 & 47 \\
\hline & Pefloxacin & 47 & 57 \\
\hline & Ofloxacin & 61 & 73 \\
\hline \multirow{2}{*}{ Antifungal } & Fluconazole & 170 & 126 \\
\hline & Ketoconazole & 136 & 156 \\
\hline \multirow{2}{*}{ Antiviral } & Acyclovir & 110 & 98 \\
\hline & Zidovudine & 330 & 415 \\
\hline CNS drugs & Alprazolam & 60 & 104 \\
\hline \multirow{4}{*}{ Anticancer } & Methotrexate & 125 & 30 \\
\hline & 5-Fluorouracil & 335 & 435 \\
\hline & Doxorubicin & 85 & 103 \\
\hline & Cisplatin & 70 & 79 \\
\hline \multirow{3}{*}{ Cardiovascular } & Amlodipine & 55 & 103 \\
\hline & Propranolol & 135 & 210 \\
\hline & Lisinopril & 83 & 98 \\
\hline \multirow{3}{*}{ Anti-inflammatory/Antiarthritic } & Diclofenac & 65 & 108 \\
\hline & Nimesulide & 168 & 150 \\
\hline & Piroxicam & 70 & 107 \\
\hline \multirow{4}{*}{ Antituberculosis/Antileprosy } & Rifampicin & 250 & 365 \\
\hline & Dapsone & 60 & 75 \\
\hline & Ethionamide & 78 & 65 \\
\hline & Cycloserine & 89 & 90 \\
\hline \multirow{3}{*}{ Antihistamines } & Salbutamol & 110 & 85 \\
\hline & Theophylline & 87 & 75 \\
\hline & Bromhexine & 50 & 90 \\
\hline \multirow[t]{2}{*}{ Corticosteroids } & Dexamethasone & 85 & 105 \\
\hline & Betamethasone & 95 & 82 \\
\hline \multirow{2}{*}{ Immuno-suppressants } & Cyclosporin A & 156 & 275 \\
\hline & Tacrolimus & 75 & 117 \\
\hline \multirow[t]{2}{*}{ Antiulcer } & Ranitidine & 117 & 89 \\
\hline & Cimetidine & 123 & 105 \\
\hline \multirow[t]{2}{*}{ Vitamins } & Vitamin A (1 mg/kg) & 26 & 18 \\
\hline & Vitamin $B_{1}(10 \mathrm{mg} / \mathrm{kg})$ & 37 & 33 \\
\hline \multirow{2}{*}{ Antioxidants } & $\beta$-Carotene $(15 \mathrm{mg} / \mathrm{kg})$ & 45 & 53 \\
\hline & Silymarin $(5 \mathrm{mg} / \mathrm{kg})$ & 32 & 41 \\
\hline Herbal products & Curcumin (50 mg/kg) & 39 & 29 \\
\hline
\end{tabular}


TABle 23: Continued.

\begin{tabular}{|c|c|c|c|}
\hline \multirow{2}{*}{ Category } & \multirow{2}{*}{ Compound } & \multicolumn{2}{|c|}{ Percent enhancement } \\
\hline & & BE from C. cyminum & BE from C. cyminum + piperine \\
\hline \multirow{7}{*}{ Herbal plants } & Echinacea & 72 & 90 \\
\hline & Tinospora cordifolia & 98 & 152 \\
\hline & Picrorhiza kurroa & 78 & 115 \\
\hline & Andrographis paniculata & 72 & 68 \\
\hline & Emblica ribes & 72 & 60 \\
\hline & Asparagus racemosus & 35 & 72 \\
\hline & Withania somnifera & 55 & 65 \\
\hline \multirow{5}{*}{ Amino acids } & Methionine (20 mg/kg) & 27 & 30 \\
\hline & Lysine (40 mg/kg) & 35 & 29 \\
\hline & Leucine $(50 \mathrm{mg} / \mathrm{kg})$ & 31 & 32 \\
\hline & Valine (25 mg/kg) & 25 & 24 \\
\hline & Isoleucine ( $25 \mathrm{mg} / \mathrm{kg})$ & 40 & 22 \\
\hline Essential elements & Iron $(0.5 \mathrm{mg} / \mathrm{kg})$ & 23 & 29 \\
\hline
\end{tabular}

expression of allicin-mediated activity of $\mathrm{AmB}$ requires the presence of ergosterol in the plasma membrane.

4.8. Lysergol. Lysergol, a phytomolecule, is obtained from Morning Glory Plant (Ipomoea spp.) which enhances the killing activities of different antibiotics on bacteria and is a promising herbal bioenhancer. It has been isolated from higher plants like Rivea corymbosa, Ipomoea violacea, and Ipomoea muricata. Bioenhancing activities of lysergol are under investigation. The effective amount of lysergol as a bioenhancer and bioavailability enhancer is in the range of $1-10 \mu \mathrm{g} / \mathrm{mL}$ but preferable dosage level is $10 \mu \mathrm{g} / \mathrm{mL}$. It enhances bioavailability of different drugs like rifampicin, tetracycline, and ampicillin. Lysergol enhances the antimicrobial effect of the antibiotic compound in the range of 2-12-fold (Table 26). It is effective against broad spectrum microbes, Gram-positive and Gram-negative, consisting E. coli (ATCC 10536), B. subtilis (ATCC 6051), M. smegmatis (ATCC 14468), and other similar microbes [2]. Patil et al. [195] reported that lysergol improved the bioavailability of berberine after oral administration in Sprague-Dawley rats.

4.9. Aloe Vera Gel and Whole Leaf Extract. Aloe vera had a salutary effect on both vitamin $\mathrm{C}$ and vitamin $\mathrm{E}$. Aloe vera gel and whole leaf extracts shown increased plasma concentration and improved absorption of both, vitamin $\mathrm{C}$ and vitamin E. The Aloe vera gel extract was especially effective in slowing down and increasing the absorption of ascorbate. It prolonged its plasma concentration significantly, even for $24 \mathrm{~h}$, and following an overnight fast. Both the gel and whole leaf extracts improved the absorption of vitamin $\mathrm{E}$ and prolonged its plasma concentration, especially after $8 \mathrm{~h}$. AUC for vitamin C and vitamin E with Aloe gel and whole leaf extract is shown in Table 27. Aloe vera is unique in its ability to increase bioavailability of both of these vitamins and should be considered as a future nutritional herbal bioenhancer [196].
4.10. Stevia rebaudiana. Stevia rebaudiana (Stevia) is known as honey leaf which has been used as sweetener in South America. The chief constituent of stevia is stevioside, the glycoside which is 200 times sweeter than sucrose. Other constituents include steviol, austroinulin, rebaudioside, and dulcoside A. Extracts/fractions/pure isolates of stevia either alone or in combination with piperine are selective in enhancing the bioavailability/bioefficacy of drugs, nutraceuticals, and herbal drugs/formulations. The percentage of stevia in the bioenhancing composition varies from 0.01 to $80 \%$. The dosage of bioenhancer derived from stevia extract is in the range of $0.01-50 \mathrm{mg} / \mathrm{kg}$ body weight and piperine is in the range of $0.01-12 \mathrm{mg} / \mathrm{kg}$ body weight. The dosage of bioenhancer derived from stevia bioactive fraction or pure compound is in the range of $0.01-40 \mathrm{mg} / \mathrm{kg}$ body weight, preferably $30 \mathrm{mg} / \mathrm{kg}$ body weight and piperine is in the range of $0.01-10 \mathrm{mg} / \mathrm{kg}$ body weight, preferably $8 \mathrm{mg} / \mathrm{kg}$ body weight. The dosage of bioenhancer derived from stevia leaf is in the range of $0.01-250 \mathrm{mg} /$ dose of the drug, nutraceutical, or herbal extract. The dosage of bioenhancer derived from stevia fraction or pure compound is in the range of $0.01-$ $75 \mathrm{mg}$ irrespective of the amount of drug in the composition, preferably $1-30 \mathrm{mg} /$ dose of the drug, nutraceutical, or herbal extract. Stevia enhanced bioavailability of different groups like antibiotics, antiobese drugs, antidiabetic drugs, antifungal drugs, antiviral drugs, anticancer drugs, cardiovascular drugs, anti-inflammatory, antiarthritic agents, antituberculosis/antileprosy drugs, anthelmintic/respiratory drugs, immune-modulators, antiulcer drugs, and herbal products or drugs [197].

4.11. Curcumin. Curcumin is the principal curcuminoid of the popular Indian spice turmeric (Curcuma longa). Curcumin suppresses drug metabolizing enzymes (CYP3A4) in the liver [198] as well as inducing changes in the drug transporter P-glycoprotein, hence increasing the $C_{\max }$ and AUC of celiprolol and midazolam in rats [199]. The 
TABLE 24: Percent enhancement in bioavailability of different drugs/compounds by supplementation of bioactive fractions from C. carvi and its combination with piperine and $Z$. officinale $[5,175]$.

\begin{tabular}{|c|c|c|c|c|c|}
\hline \multirow{2}{*}{ Category } & \multirow{2}{*}{ Compound } & \multirow{2}{*}{ Dose $(\mathrm{mg} / \mathrm{kg})$} & \multicolumn{3}{|c|}{ Percent enhancement } \\
\hline & & & BE from C. carvi & C. carvi + piperine & C. carvi + Z. officinale \\
\hline \multirow{3}{*}{ Macrolides } & Azithromycin & 25 & 55 & 90 & 86 \\
\hline & Erythromycin & 45 & 70 & 100 & 105 \\
\hline & Roxithromycin & 15 & 65 & 95 & 98 \\
\hline \multirow{5}{*}{ Cephalosporins } & Cefalexin & 45 & Nil & 90 & 79 \\
\hline & Cefadroxil & 45 & 67 & 95 & 85 \\
\hline & Ceftrioxone & 25 & 72 & 78 & 75 \\
\hline & Cefixime & 40 & 80 & 79 & 82 \\
\hline & Cefidinir & 40 & 89 & 95 & 130 \\
\hline \multirow{2}{*}{ Penicillins } & Amoxicillin & 45 & 75 & 115 & 100 \\
\hline & Cloxacillin & 25 & 110 & 95 & 110 \\
\hline \multirow{2}{*}{ Aminoglycosides } & Amikacin & 50 & 85 & 100 & 92 \\
\hline & Kanamycin & 50 & Nil & 87 & 68 \\
\hline \multirow{3}{*}{ Fluoroquinolones } & Ciprofloxacin & 45 & 78 & 110 & 133 \\
\hline & Ofloxacin & 20 & 65 & 167 & 170 \\
\hline & Norfloxacin & 40 & 55 & 65 & 60 \\
\hline \multirow{3}{*}{ Antifungal } & Fluconazole & 65 & 65 & 98 & 110 \\
\hline & Amphotericin B & 78 & 78 & 90 & 80 \\
\hline & Ketoconazole & 55 & 55 & 100 & 96 \\
\hline \multirow{2}{*}{ Antiviral } & Acyclovir & 40 & 78 & 100 & 90 \\
\hline & Zidovudine & 10 & 92 & 95 & 87 \\
\hline \multirow{2}{*}{ CNS drugs } & Alprazolam & 0.1 & Nil & 70 & 80 \\
\hline & Haloperidol & 0.5 & 95 & 90 & 85 \\
\hline \multirow{4}{*}{ Anticancer } & Methotrexate & 5 & 76 & 89 & 102 \\
\hline & 5-Fluorouracil & 25 & 90 & 110 & 100 \\
\hline & Doxorubicin & 5 & Nil & 70 & 69 \\
\hline & Cisplatin & 5 & Nil & Nil & 55 \\
\hline \multirow{4}{*}{ Cardiovascular } & Amlodipine & 1 & Nil & 50 & 65 \\
\hline & Lisinopril & 1 & 79 & 95 & 90 \\
\hline & Atenolol & 5 & 100 & 93 & 97 \\
\hline & Propranolol & 8 & 68 & 90 & 75 \\
\hline \multirow{4}{*}{ Anti-inflammatory/antiarthritic } & Diclofenac & 5 & Nil & 100 & 95 \\
\hline & Piroxicam & 2 & Nil & 98 & 76 \\
\hline & Nimesulide & 10 & 100 & 140 & 145 \\
\hline & Rofecoxib & 2.5 & 75 & 70 & 80 \\
\hline \multirow{5}{*}{ Antituberculosis/antileprosy } & Rifampicin & 40 & 110 & 170 & 140 \\
\hline & Pyrazinamide & 12.5 & 45 & 50 & 55 \\
\hline & Dapsone & 10 & 56 & 67 & 68 \\
\hline & Ethionamide & 25 & 68 & 65 & 70 \\
\hline & Cycloserine & 40 & 70 & 80 & 75 \\
\hline \multirow{4}{*}{ Antihistamines } & Salbutamol & 0.8 & 75 & 89 & 80 \\
\hline & Theophylline & 30 & 70 & 79 & 89 \\
\hline & Bromhexine & 25 & Nil & 70 & 71 \\
\hline & Loratidine & 1 & 76 & 70 & 80 \\
\hline \multirow{3}{*}{ Corticosteroids } & Prednisolone & 4 & 65 & 67 & 60 \\
\hline & Dexamethasone & 0.05 & 72 & 77 & 73 \\
\hline & Betamethasone & 0.1 & 80 & 89 & 77 \\
\hline
\end{tabular}


TABle 24: Continued.

\begin{tabular}{|c|c|c|c|c|c|}
\hline \multirow{2}{*}{ Category } & \multirow{2}{*}{ Compound } & \multirow{2}{*}{ Dose $(\mathrm{mg} / \mathrm{kg})$} & \multicolumn{3}{|c|}{ Percent enhancement } \\
\hline & & & BE from C. carvi & C. carvi + piperine & C. carvi $+Z$. officinale \\
\hline \multirow{2}{*}{ Immuno-suppressants } & Cyclosporin A & 10 & 100 & 105 & 120 \\
\hline & Tacrolimus & 5 & 90 & 95 & 114 \\
\hline \multirow{3}{*}{ Antiulcer } & Ranitidine & 30 & 67 & 70 & 150 \\
\hline & Cimetidine & 40 & 72 & 84 & 100 \\
\hline & Omeprazole & 2 & 76 & 70 & 75 \\
\hline \multirow{2}{*}{ Vitamins } & Vitamin A & 1 & 19 & 16 & 27 \\
\hline & Vitamin $B_{1}$ & 10 & 42 & 26 & 55 \\
\hline \multirow{2}{*}{ Antioxidants } & $\beta$-Carotene & 15 & 55 & 59 & 72 \\
\hline & Silymarin & 5 & 38 & 45 & 41 \\
\hline \multirow{2}{*}{ Herbal products } & Curcumin & 50 & 48 & 51 & 52 \\
\hline & Rutin & 40 & 45 & 40 & 42 \\
\hline \multirow{9}{*}{ Herbal plants } & Echinacea agustifolia & 10 & Nil & 76 & 65 \\
\hline & Tinospora cordifolia & 50 & 76 & 90 & 71 \\
\hline & Picrorhiza kurroa & 50 & 80 & 110 & 76 \\
\hline & Aegles marmelos & 1000 & 65 & 65 & 60 \\
\hline & Andrographis paniculata & 50 & 68 & 72 & 54 \\
\hline & Asparagus racemosus & 50 & Nil & 55 & 45 \\
\hline & Terminalia chebula & 50 & 92 & 87 & 91 \\
\hline & Withania somnifera & 60 & 76 & 70 & 76 \\
\hline & Centella asiatica & 30 & 68 & 65 & 62 \\
\hline \multirow{5}{*}{ Amino acids } & Methionine & 20 & 28 & 30 & 37 \\
\hline & Lysine & 40 & 29 & 38 & 43 \\
\hline & Leucine & 50 & 21 & 32 & 40 \\
\hline & Valine & 25 & 19 & 29 & 38 \\
\hline & Isoleucine & 25 & 34 & 44 & 50 \\
\hline
\end{tabular}

TABle 25: Enhancement of fungicidal activity of AmB by Allicin against S. cerevisiae [187].

\begin{tabular}{lcc}
\hline Drug/compound & Conc. $(\mu \mathrm{g})$ & Action against S. cerevisiae \\
\hline AmB alone & 1 & Mostly resistance to action \\
AmB alone & 5 & Subjected to lethal damage \\
Allicin alone & 120 & $\begin{array}{c}\text { Not lethal } \\
\text { AmB + allicin }\end{array}$ \\
\hline
\end{tabular}

influence of curcumin before treatment on pharmacokinetic disposition of norfloxacin was studied in rabbits after single oral administration. The pharmacokinetic data revealed that curcumin-treated animals had significantly $(P \leq 0.05)$ higher AUC and AUMC. Prior treatment of curcumin significantly $(P \leq 0.05)$ increased $t_{1 / 2 \beta}$ and $V_{d}$ of norfloxacin. Further treatment with curcumin reduced loading and maintenance doses by $26 \%$ and $24 \%$, respectively [200].

4.12. Sinomenine. Sinomenine is an alkaloid obtained from Sinomenium acutum, widely used for treatment of rheumatic and arthritic diseases in China and Japan.

A single dose of paeoniflorin $(150 \mathrm{mg} / \mathrm{kg})$ alone and with sinomenine hydrochloride $(90 \mathrm{mg} / \mathrm{kg})$ was administered by gastric gavage to unrestrained conscious male SpragueDawley rats (250-300 g). A Blood sample was collected periodically via a jugular vein before and after dosing from $10 \mathrm{~min}$ to $12 \mathrm{~h}$. HPLC assay was developed to determine the plasma concentrations of paeoniflorin. After coadministration of sinomenine, the $C_{\max }$ of paeoniflorin was elevated, $t_{\max }$ was delayed, $\mathrm{AUC}_{0-\infty}$ was increased, MRT was prolonged, $\mathrm{CL}_{B}$ was decreased, and $V_{d}$ was reduced. These results from Table 28 indicate that sinomenine hydrochloride significantly improved the bioavailability of paeoniflorin in rats [201].

Sinomenine at 16 and $136 \mu \mathrm{M}$ concentrations could significantly enhance the absorption of paeoniflorin $(20 \mu \mathrm{M})$ by 1.5 - and 2.5 -fold, respectively, and subsequently improve the bioavailability of paeoniflorin in rats. The mechanism underlying the improvement of paeoniflorin's bioavailability was proposed that sinomenine could decrease the efflux transport of paeoniflorin by P-glycoprotein [202].

4.13. Genistein. Genistein is an isoflavone found in a number of dietary plants like soybean (Glycine max) and kudzu (Pueraria lobata) and has been studied for a number of potential health effects including anticancer and antiinflammatory activity [203]. It is a well-known phytoestrogen [204]. 
TABLE 26: Enhancement of antibiotic activity by lysergol $(10 \mu \mathrm{g} / \mathrm{mL})$ in combination with rifampicin against different organisms [2].

\begin{tabular}{|c|c|c|c|}
\hline Organisms & Antibiotics & Concentration $(\mu \mathrm{g} / \mathrm{mL})$ & Fold enhancement of activity \\
\hline \multirow{2}{*}{ E. coli (ATCC 10536) } & Rifampicin & 10 & $6-12$ \\
\hline & Rifampicin & 20 & $3-5$ \\
\hline B. subtilis (ATCC 6051) & Rifampicin & 0.4 & $3-4.6$ \\
\hline M. smegmatis (ATCC 14468) & Rifampicin & 0.2 & $4.5-6$ \\
\hline
\end{tabular}

TABLE 27: AUC of vitamins $\mathrm{C}$ and $\mathrm{E}$ alone or with Aloe gel or Aloe whole leaf extract [196].

\begin{tabular}{lc}
\hline Supplement & AUC $(\mu \mathrm{Mh})$ \\
\hline Vitamin C (500 mg) & $339 \pm 124$ \\
Vitamin C + Aloe whole leaf extract & $272 \pm 144$ \\
Vitamin C + Aloe gel & $1031 \pm 513$ \\
Vitamin E (420 mg) & $19.3 \pm 23.2$ \\
Vitamin E + Aloe whole leaf extract & $38.3 \pm 17.0$ \\
Vitamin E + Aloe gel & $71.3 \pm 22.5$ \\
\hline
\end{tabular}

mean \pm SE.

TABLE 28: Pharmacokinetic parameters of paeoniflorin $(150 \mathrm{mg} / \mathrm{kg})$ and in combination with sinomenine $(90 \mathrm{mg} / \mathrm{kg})$ after oral administration in rats [201].

\begin{tabular}{lcc}
\hline Parameters & Paeoniflorin & Sinomenine + paeoniflorin \\
\hline $\begin{array}{l}\mathrm{AUC} \mathrm{C}_{0-\infty} \\
(\mu \mathrm{g} \cdot \mathrm{h} / \mathrm{mL})\end{array}$ & $124.62 \pm 36.91$ & $1540.43 \pm 548.96^{* *}$ \\
$C_{\max }$ & $1.26 \pm 0.23$ & $6.03 \pm 2.45^{*}$ \\
$(\mu \mathrm{g} / \mathrm{mL})$ & $45.00 \pm 5.00$ & $77.30 \pm 17.50^{*}$ \\
$t_{\max }(\mathrm{min})$ & $19.58 \pm 9.01$ & $53.78 \pm 22.17^{* * *}$ \\
$t_{1 / 2}(\mathrm{~min})$ & $1301.83 \pm 429.03$ & $110.44 \pm 45.61^{*}$ \\
$\mathrm{Cl}_{B}$ & $(\mathrm{~mL} / \mathrm{kg} / \mathrm{min})$ & $16064.25 \pm 17189.33^{* * *}$ \\
$V_{d}(\mathrm{~mL} / \mathrm{kg})$ & $102044.14 \pm 46608.43$ & $224.07 \pm 26.62^{*}$ \\
\hline $\mathrm{MRT}(\mathrm{min})$ & $133.12 \pm 38.63$ & \\
\hline$n=6, \mathrm{mean} \pm \mathrm{SD} ;{ }^{*} P<0.01, * * P<0.001,{ }^{* * *} P<0.05$.
\end{tabular}

4.13.1. Genistein and Paclitaxel. The effect of orally administered genistein on the pharmacokinetics of paclitaxel administered through oral and intravenous route in rats was studied. A single dose of paclitaxel was administered orally $(30 \mathrm{mg} / \mathrm{kg})$ or intravenous route $(3 \mathrm{mg} / \mathrm{kg})$ alone or $30 \mathrm{~min}$ after oral administration of genistein $(3.3 \mathrm{mg} / \mathrm{kg}$ or $10 \mathrm{mg} / \mathrm{kg}$ ). The presence of $10 \mathrm{mg} / \mathrm{kg}$ genistein significantly $(P<0.05)$ increased the AUC $(54.7 \%)$ of orally administered paclitaxel, which was due to the significantly $(P<0.05)$ decreased $\mathrm{CL}_{F}$ of paclitaxel (35.2\%). Genistein also increased $C_{\max }$ of paclitaxel significantly $(P<0.05$ by $3.3 \mathrm{mg} / \mathrm{kg}$, $66.8 \% ; P<0.01$ by $10 \mathrm{mg} / \mathrm{kg}, 91.8 \%)$. Consequently, the $A B$ of paclitaxel in the presence of genistein was $0.020-0.025$, which was elevated more than the control group $(0.016)$; the $R B$ of orally administered paclitaxel was increased from 1.26 to 1.55 -fold. $10 \mathrm{mg} / \mathrm{kg}$ genistein also significantly $(P<0.05)$ increased the AUC (40.5\%) and reduced the $\mathrm{CL}_{B}(30 \%)$ of intravenously administered paclitaxel. The presence of genistein improved the systemic exposure of paclitaxel in this study [205].
4.13.2. Genistein and Epigallocatechin Gallate. Cotreatment of HT-29 human colon cancer cells with genistein increased cytosolic EGCG by 2-5-fold compared with treatment with EGCG only. Intragastric coadministration of EGCG $(75 \mathrm{mg} / \mathrm{kg})$ and genistein $(200 \mathrm{mg} / \mathrm{kg})$ to CF-1 mice resulted in an increase in $t_{1 / 2}(148.7 \pm 16.4$ versus $111.5 \pm 23.4 \mathrm{~min})$ and AUC $(183.9 \pm 20.2$ versus $125.8 \pm 26.4 \mathrm{mg} / \mathrm{mL}$ at $3 \mathrm{~min})$ of EGCG. Cotreatment with genistein also increased the $C_{\max }, 6 \mathrm{~h}$ exposure AUC, and $t_{1 / 2}$ of EGCG in the small intestine by 2.0-, 4.7-, and 1.4-fold, respectively, compared with mice treated with EGCG only. This study demonstrates that genistein can enhance EGCG bioavailability [206].

4.14. Ammannia multiflora. The methanolic extract of Ammannia multiflora (Lythraceae) showed significant bioenhancing activity with the antibiotic nalidixic acid. A. multiflora contains a novel compound ammaniol along with other compounds. The methanolic extract of Ammannia multiflora bioenhancing activity in combination with nalidixic acid against the two strains, CA8000 and DH5 $\alpha$ of Escherichia coli. The results showed that the methanolic extract of $A$. multiflora possessed significant bioenhancing activity and reduced the dose of nalidixic acid fourfold. The methanolic extract of Ammannia multiflora was also tested for antimycobacterial activity against Mycobacterium $\mathrm{H} 37 \mathrm{Rv}$ and was found to show moderate activity (MIC $25 \mu \mathrm{g} / \mathrm{mL}$ ) against this pathogen [207].

4.15. Capsaicin. Capsaicin is the active component of chili peppers (Capsicum annum). It is an irritant for mammals, including humans, and produces a sensation of burning in any tissue with which it comes into contact. Cruz et al. [208] reported that Capsicum annum reduces bioavailability of aspirin after oral administration in rats. Lopez et al. [209] have shown that capsaicin has little or no impact on bioavailability of ciprofloxacin.

Absorption and bioavailability of theophylline from a sustained release gelatin capsule were investigated in 10 male rabbits after oral administration $(20 \mathrm{mg} / \mathrm{kg})$, with and without a ground capsicum fruit suspension. Comparison of pharmacokinetic parameters showed that the concomitant absorption of capsicum increases AUC from $86.06 \pm$ $9.78 \mathrm{mg} \cdot \mathrm{h} / \mathrm{L}$ to $138.32 \pm 17.27 \mathrm{mg} \cdot \mathrm{h} / \mathrm{L}, P<0.001, C_{\max }$ from $6.65 \pm 0.76$ to $8.78 \pm 0.98 \mathrm{mg} / \mathrm{L}, P<0.01$, and MRT from $14.94 \pm 2.97 \mathrm{~h}$ to $20.98 \pm 5.75 \mathrm{~h}, P<0.001$. A second administration of the capsicum suspension, 11 hours after dosing, produced a new rise of theophylline plasma levels in every rabbit. This indicated that due to action of capsaicin bioavailability of theophylline was enhanced [210]. 


\section{Other Bioenhancers}

5.1. Quercetin. Quercetin is a plant-derived flavonoid found in fruits, vegetables, leaves, and grains. Quercetin has exhibited activities including antioxidant, radical scavenging, antiinflammatory, antiatherosclerotic, anticancer, and antiviral effects [211]. Quercetin is an inhibitor of CYP3A4 and a modulator of P-glycoprotein [212-215]. It has been shown to decrease bioavailability of cyclosporin in pigs and rats [212]. Wang et al. [216] reported that coadministration of quercetin with digoxin leads to lethal effects in pigs.

5.1.1. Quercetin and Paclitaxel. The effect of quercetin on the bioavailability of paclitaxel was studied after oral administration in rats. Paclitaxel $(40 \mathrm{mg} / \mathrm{kg})$ and prodrug ( $280 \mathrm{mg} / \mathrm{kg}, 40 \mathrm{mg} / \mathrm{kg}$ as the paclitaxel) were administered orally to rats pretreated with quercetin $(2,10,20 \mathrm{mg} / \mathrm{kg})$. The pharmacokinetic parameters shown in Table 29 indicated that quercetin increases bioavailability of paclitaxel in rats [217].

5.1.2. Quercetin and Verapamil. Pharmacokinetic parameters of verapamil and norverapamil were determined after the oral administration of verapamil $(10 \mathrm{mg} / \mathrm{kg})$ to rabbits in the presence and absence of quercetin $(5.0$ and $15 \mathrm{mg} / \mathrm{kg}$ ). While coadministration of quercetin concurrently was not effective to enhance the oral exposure of verapamil, pretreatment of quercetin 30 min before verapamil administration significantly altered the pharmacokinetics of verapamil. Compared with the control group, the $C_{\max }$ and AUC of verapamil increased approximately 2 -fold in the rabbits pretreated with $15 \mathrm{mg} / \mathrm{kg}$ quercetin. There was no significant change in $t_{\max }$ and $t_{1 / 2}$ of verapamil in the presence of quercetin. Consequently, absolute and relative bioavailability values of verapamil in the rabbits pretreated with quercetin were significantly higher $(P<0.05)$ than those from the control group. In conclusion, pretreatment of quercetin significantly enhanced the oral exposure of verapamil [218].

5.1.3. Quercetin and Diltiazem. The effect of quercetin $(2,10$, $20 \mathrm{mg} / \mathrm{kg}$ ) pretreatment on the bioavailability of diltiazem $(15 \mathrm{mg} / \mathrm{kg}$ ) was studied in rabbits after oral administration. The plasma concentrations of diltiazem in the rabbits pretreated with quercetin were increased significantly $(P<$ 0.05 , at $2 \mathrm{mg} / \mathrm{kg} ; P<0.01$, at 10 and $20 \mathrm{mg} / \mathrm{kg}$ ) compared with the control, but the plasma concentrations of diltiazem coadministered with quercetin were not significant. The AUC and $C_{\max }$ of the diltiazem in the rabbits pretreated with quercetin were significantly higher $(P<0.05$, at $2 \mathrm{mg} / \mathrm{kg}$; $P<0.01$, at 10 and $20 \mathrm{mg} / \mathrm{kg}$ ) than the control. The $A B$ of diltiazem in the rabbits pretreated with quercetin was significantly $(P<0.05$ at $2 \mathrm{mg} / \mathrm{kg}, P<0.01$ at 10 and $20 \mathrm{mg} / \mathrm{kg}$ ) higher $(9.10-12.81 \%)$ than the control $(4.64 \%)$. The bioavailability of diltiazem in the rabbits pretreated with quercetin is increased significantly compared with the control, but not in the rabbits coadministered with quercetin [213].
5.1.4. Quercetin and Tamoxifen. The pharmacokinetic parameters of tamoxifen in plasma were determined after oral administration of tamoxifen $(10 \mathrm{mg} / \mathrm{kg})$ with or without quercetin $(2.5,7.5$ and $15 \mathrm{mg} / \mathrm{kg})$. The coadministration of quercetin $(2.5$ and $7.5 \mathrm{mg} / \mathrm{kg})$ significantly $(P<0.05)$ increased the $K_{a}, C_{\max }$, and AUC of tamoxifen. The $A B$ of tamoxifen with 2.5 and $7.5 \mathrm{mg} / \mathrm{kg}$ quercetin ranged from 18.0 to $24.1 \%$, which was significantly higher than the control group, $15.0 \%(P<0.05)$. The $R B$ of tamoxifen coadministered with quercetin was 1.20-1.61 times higher than the control group. The coadministration of quercetin caused no significant changes in the terminal $t_{1 / 2}$ and $t_{\max }$ of tamoxifen. The enhanced bioavailability of tamoxifen as a result of its coadministration with quercetin might be due to the effect of quercetin promoting the intestinal absorption and reducing the first-pass metabolism of tamoxifen [214].

5.1.5. Quercetin and Fexofenadine. Short-term effect of quercetin on the pharmacokinetics of fexofenadine was studied in 12 healthy volunteers. Subjects were treated daily for 7 days with $500 \mathrm{mg}$ quercetin or placebo 3 times a day. On day 7, a single dose of $60 \mathrm{mg}$ fexofenadine was administered orally. Effects on AUC, $C_{\max }, t_{1 / 2}, K_{\mathrm{el}}$, and $\mathrm{Cl}_{R}$ are shown in Table 30 after administration of fexofenadine and in combination with quercetin. The results showed that shortterm use of quercetin elevated the plasma concentrations of fexofenadine in humans [219].

5.1.6. Quercetin and Etoposide. The effect of quercetin on the pharmacokinetics of etoposide was studied in rats. Etoposide was administered to rats orally $(9 \mathrm{mg} / \mathrm{kg})$ or intravenous $(3 \mathrm{mg} / \mathrm{kg}$ ) without or with quercetin $(1,5$, or $15 \mathrm{mg} / \mathrm{kg})$. The plasma concentration of etoposide was determined by HPLC with fluorescence detector. In the presence of quercetin, the pharmacokinetic parameters of etoposide were significantly altered in the oral group, but not in the intravenous group. The presence of quercetin significantly $(5 \mathrm{mg} / \mathrm{kg}, P<0.05 ; 15 \mathrm{mg} / \mathrm{kg}, P<0.01)$ increased the AUC of orally administered etoposide from $43.0-53.2 \%$. The presence of 5 or $15 \mathrm{mg} / \mathrm{kg}$ of quercetin significantly $(P<$ $0.05)$ decreased the $\mathrm{CL}_{B}$ of oral etoposide. Consequently, compared to the control group $(8.87 \%)$, the presence of quercetin significantly $(5 \mathrm{mg} / \mathrm{kg}, P<0.05 ; 15 \mathrm{mg} / \mathrm{kg}, P<$ 0.01 ) increased the $A B$ of etoposide to 12.7 or $13.6 \%$. The results from Table 31 indicated that oral bioavailability of etoposide was enhanced by quercetin [220].

5.1.7. Quercetin and Epigallocatechin Gallate. Epigallocatechin gallate (EGCG) is a main anticancer component in green tea. The pharmacokinetic parameters after oral administration of green tea extract (GTE) and GTE + quercetin (Q). In rat, supplementations of GTE and GTE $+\mathrm{Q}$ raised the plasma $C_{\max }$ were $55.29 \pm 1.70$ and $94.44 \pm 1.59 \mathrm{ng} / \mathrm{mL}$, respectively. The corresponding $t_{1 / 2}$ elimination was $2.04 \pm$ $0.2 \mathrm{~h}$ and $2.28 \pm 0.049 \mathrm{~h}$. The $\mathrm{AUC}_{0-24 \mathrm{~h}}$ was $510.16 \pm$ $9.88 \mathrm{ng} \cdot \mathrm{h} / \mathrm{mL}$ and $794.08 \pm 15.27 \mathrm{ng} \cdot \mathrm{h} / \mathrm{mL}(P \leq 0.05)$, respectively. The results showed that quercetin increased bioavailability of EGCG in rats [221]. 
TABLE 29: Pharmacokinetic parameters of paclitaxel $(40 \mathrm{mg} / \mathrm{kg})$ and in combination with pretreated quercetin rats after oral administration [218].

\begin{tabular}{lcccccc}
\hline \multirow{2}{*}{ Parameters } & \multirow{2}{*}{ Paclitaxel control } & $2 \mathrm{mg} / \mathrm{kg}$ & $10 \mathrm{mg} / \mathrm{kg}$ & $20 \mathrm{mg} / \mathrm{kg}$ & 3 days, $10 \mathrm{mg} / \mathrm{kg}$ & $3 \mathrm{days}, 20 \mathrm{mg} / \mathrm{kg}$ \\
\hline AUC $(\mathrm{ng} \cdot \mathrm{h} / \mathrm{mL})$ & $1605 \pm 409$ & $2835 \pm 721^{*}$ & $4205 \pm 1103^{* *}$ & $4978 \pm 1211^{* *}$ & $5123 \pm 1263^{* *}$ & $5301 \pm 1328^{* *}$ \\
$C_{\max }(\mathrm{ng} / \mathrm{mL})$ & $104 \pm 27$ & $161 \pm 31^{*}$ & $248 \pm 63^{* *}$ & $279 \pm 71^{* *}$ & $288 \pm 74^{* *}$ & $299 \pm 76^{* *}$ \\
$t_{\max }(\mathrm{h})$ & $2.0 \pm 0.6$ & $1.6 \pm 0.5$ & $1.5 \pm 0.4$ & $1.5 \pm 0.5$ & $1.5 \pm 0.4$ & $1.5 \pm 0.4$ \\
$t_{1 / 2}(\mathrm{~h})$ & $9.9 \pm 2.5$ & $13.9 \pm 3.5$ & $16.6 \pm 4.4^{*}$ & $17.5 \pm 4.5^{*}$ & $17.6 \pm 4.6^{*}$ & $17.9 \pm 4.7^{*}$ \\
MRT (h) & $15 \pm 3.8$ & $22 \pm 5.6$ & $25 \pm 6.4^{*}$ & $26 \pm 6.5^{*}$ & $26 \pm 6.4^{*}$ & $26 \pm 6.5^{*}$ \\
$A B(\%)$ & 2.0 & $3.5^{*}$ & $5.3^{* *}$ & $6.2^{* *}$ & $6.4^{* *}$ & 318 \\
$R B(\%)$ & 100 & 176 & 261 & 309 & 329 \\
\hline
\end{tabular}

$n=8$, mean $\pm \mathrm{SD} ; * P<0.05 ; * * P<0.01$, significant difference compared to control.

TABLE 30: Pharmacokinetic parameters of fexofenadine $(60 \mathrm{mg})$ and in combination quercetin (500) $\mathrm{mg}$ after a single-dose administration $[50]$.

\begin{tabular}{lcc}
\hline Parameters & Fexofenadine & Fexofenadine + quercetin \\
\hline $\mathrm{AUC}_{0-\infty}(\mathrm{ng} \cdot \mathrm{h} / \mathrm{mL})$ & $2,075.5 \pm 461.7$ & $3,227.1 \pm 665.9$ \\
$C_{\max }(\mathrm{ng} / \mathrm{mL})$ & $295.3 \pm 135.4$ & $480.3 \pm 163.7$ \\
$t_{\max }(\mathrm{h})$ & $2.0(0.5-5)$ & $2(1.5-3)$ \\
$K_{\mathrm{el}}(/ \mathrm{h})$ & $0.16 \pm 0.02$ & $0.16 \pm 0.05$ \\
$t_{1 / 2}(\mathrm{~h})$ & $4.5 \pm 0.8$ & $4.7 \pm 1.5$ \\
$\mathrm{Cl}_{R}(\mathrm{~L} / \mathrm{h})$ & $4.72 \pm 1.13$ & $4.29 \pm 1.40$ \\
\hline
\end{tabular}

Data are expressed as mean \pm SD except for $t_{\max }$, which is expressed as median (range).

5.1.8. Quercetin and Doxorubicin. The pharmacokinetic parameters of doxorubicin were determined in rats after oral $(50 \mathrm{mg} / \mathrm{kg})$ or intravenous $(10 \mathrm{mg} / \mathrm{kg})$ administration in the presence and absence of quercetin $(0.6,3$ or $15 \mathrm{mg} / \mathrm{kg})$. Compared to control, quercetin significantly increased the AUC and $C_{\max }$ of oral doxorubicin, while there was no significant change in $t_{\max }$ and $t_{1 / 2}$ of doxorubicin. Consequently, the $A B$ of doxorubicin was increased by quercetin compared to control, and the $R B$ of oral doxorubicin was increased by 1.32-2.36-fold (Table 32). In contrast, the pharmacokinetics of intravenous doxorubicin was not affected by quercetin [215].

Park et al. [223] reported that quercetin did not affect the in vivo pharmacokinetics of intravenously administered doxorubicin.

5.2. Naringin. Naringin is the major flavonoid glycoside found in grapefruit, apples, onions, and tea [224]. Naringin exerts a variety of pharmacological effects such as antioxidant activity, antiulcer activity, antiallergic activity and anticancer activity [211], and blood lipid lowering. Naringin has been reported as a CYP3A4 inhibitor $[225,226]$ as well as a Pglycoprotein modulator [226, 227]. Park et al. [223] reported that naringin did not affect the in vivo pharmacokinetics of intravenously administered doxorubicin.

5.2.1. Naringin and Diltiazem. Pharmacokinetic parameters of diltiazem were determined in rats following an oral administration of diltiazem $(15 \mathrm{mg} / \mathrm{kg})$ to rats in the presence and absence of naringin ( 5 and $15 \mathrm{mg} / \mathrm{kg}$ ). Compared to the control given diltiazem alone, the $C_{\max }$ and AUC of diltiazem increased by 2 -fold in rats pretreated with naringin, while there was no significant change in $t_{\max }$ and terminal $t_{1 / 2}$ of diltiazem. Consequently, $A B$ and $R B$ values of diltiazem in the presence of naringin were significantly higher $(P<$ $0.05)$ than those from the control group. Metabolite-parent AUC ratio in the presence of naringin decreased by $30 \%$ compared to the control group, implying that naringin could be effective to inhibit the metabolism of diltiazem. In conclusion, the concomitant use of naringin significantly enhanced the oral exposure of diltiazem in rats [228].

5.2.2. Naringin and Paclitaxel. The effect of oral naringin on the pharmacokinetics of intravenous paclitaxel was studied in rats. Oral naringin $(3.3$ and $10 \mathrm{mg} / \mathrm{kg})$ was pretreated $30 \mathrm{~min}$ before intravenous $(3 \mathrm{mg} / \mathrm{kg})$ administration of paclitaxel. After intravenous administration of paclitaxel, the AUC was significantly greater $(40.8 \%$ and $49.1 \%$ for naringin doses of 3.3 and $10 \mathrm{mg} / \mathrm{kg}$, resp.), and $\mathrm{Cl}_{B}$ was significantly slower $(29.0 \%$ and $33.0 \%$ decrease, resp.) than controls. The significantly greater AUC could be due mainly to an inhibition of metabolism of paclitaxel via CYP3A1/2 by oral naringin. The inhibition of hepatic P-glycoprotein by oral naringin could also contribute to the significantly greater AUC of intravenous paclitaxel by oral naringin [229].

5.2.3. Naringin and Verapamil. The effect of naringin on the pharmacokinetics of verapamil was studied in rabbits. The pharmacokinetic parameters of verapamil were determined after administering verapamil $(9 \mathrm{mg} / \mathrm{kg})$ orally to rabbits in the pretreated with naringin $(1.5,7.5$, and $15 \mathrm{mg} / \mathrm{kg})$. Naringin pretreatment significantly altered the pharmacokinetic parameters of verapamil. Compared with the control group (given verapamil alone), the $K_{a}, C_{\max }$, and AUC of verapamil were significantly increased in the pretreatment of naringin. However, there were no significant change in $t_{\max }$ and $t_{1 / 2}$ of verapamil. Consequently, pretreatment of naringin significantly increased the $A B$ of verapamil significantly in a dose-dependent manner and elevated the $R B$ of verapamil by 1.26-1.69-fold (Table 33). In conclusion, pretreatment of naringin enhanced the oral bioavailability of verapamil [222]. 
TABLE 31: Pharmacokinetic parameters of etoposide $(9 \mathrm{mg} / \mathrm{kg})$ and in combination with quercetin after oral administration in rats [220].

\begin{tabular}{|c|c|c|c|c|}
\hline \multirow{2}{*}{ Parameters } & \multirow{2}{*}{ Etoposide control } & \multicolumn{3}{|c|}{ Quercetin + etoposide } \\
\hline & & $1 \mathrm{mg} / \mathrm{kg}$ & $5 \mathrm{mg} / \mathrm{kg}$ & $15 \mathrm{mg} / \mathrm{kg}$ \\
\hline $\operatorname{AUC}(\mathrm{ng} \cdot \mathrm{h} / \mathrm{mL})$ & $1226 \pm 154$ & $1419 \pm 222$ & $1753 \pm 315^{*}$ & $1878 \pm 364^{* *}$ \\
\hline$C_{\max }(\mathrm{ng} / \mathrm{mL})$ & $484 \pm 74.7$ & $455 \pm 80.5$ & $586 \pm 89.5^{*}$ & $673 \pm 93.3^{*}$ \\
\hline $\mathrm{Cl}_{B}(\mathrm{~mL} / \mathrm{kg} / \mathrm{h})$ & $8265 \pm 1566$ & $7178 \pm 1391$ & $5980 \pm 1292 *$ & $5481 \pm 1167^{*}$ \\
\hline$t_{\max }(\mathrm{h})$ & $0.500 \pm 0.158$ & $0.667 \pm 0.129$ & $0.693 \pm 0.154$ & $0.708 \pm 0.188$ \\
\hline$K_{\mathrm{el}}(/ \mathrm{h})$ & $0.255 \pm 0.031$ & $0.230 \pm 0.027$ & $0.225 \pm 0.025$ & $0.221 \pm 0.018$ \\
\hline$t_{1 / 2}(\mathrm{~h})$ & $2.75 \pm 0.32$ & $3.05 \pm 0.37$ & $3.11 \pm 0.39$ & $3.16 \pm 0.41$ \\
\hline$A B(\%)$ & $8.87 \pm 1.33$ & $10.3 \pm 1.55$ & $12.7 \pm 1.96^{*}$ & $13.6 \pm 2.24^{* *}$ \\
\hline$R B(\%)$ & 100 & 116 & 143 & 153 \\
\hline
\end{tabular}

$n=6$, mean $\pm \mathrm{SD} ;{ }^{*} P<0.05,{ }^{*} P<0.01$ compared to control.

TABle 32: Pharmacokinetic parameters of doxorubicin $(50 \mathrm{mg} / \mathrm{kg})$ and in the presence or absence (control) of quercetin $(0.6,3$, and $15 \mathrm{mg} / \mathrm{kg}$ ) after oral administration [215].

\begin{tabular}{|c|c|c|c|c|}
\hline \multirow{2}{*}{ Parameters } & \multirow{2}{*}{ Doxorubicin (control) } & \multicolumn{3}{|c|}{ Doxorubicin + quercetin } \\
\hline & & $0.6 \mathrm{mg} / \mathrm{kg}$ & $3 \mathrm{mg} / \mathrm{kg}$ & $15 \mathrm{mg} / \mathrm{kg}$ \\
\hline $\mathrm{AUC}_{0-\infty}(\mathrm{ng} \cdot \mathrm{h} / \mathrm{mL})$ & $186 \pm 44.6$ & $244 \pm 63.2^{*}$ & $344 \pm 98.6^{* *}$ & $439 \pm 107.3^{* *}$ \\
\hline$C_{\max }(\mathrm{ng} / \mathrm{mL})$ & $20.2 \pm 5.13$ & $27.3 \pm 6.42^{*}$ & $38.0 \pm 9.28^{*}$ & $45.6 \pm 11.16^{* *}$ \\
\hline$t_{\max }(\mathrm{h})$ & 0.25 & 0.25 & 0.25 & 0.25 \\
\hline$V_{\mathrm{ss}}(\mathrm{L} / \mathrm{min})$ & $6.54 \pm 1.45$ & $5.06 \pm 1.13$ & $2.88 \pm 0.64^{*}$ & $2.23 \pm 0.52^{*}$ \\
\hline$t_{1 / 2}(\mathrm{~h})$ & $13.5 \pm 3.32$ & $13.7 \pm 3.41$ & $13.8 \pm 3.51$ & $13.9 \pm 3.82$ \\
\hline$A B(\%)$ & $3.04 \pm 0.74$ & $4.01 \pm 0.94^{*}$ & $5.58 \pm 1.32^{* *}$ & $7.12 \pm 1.71^{* *}$ \\
\hline$R B(\%)$ & 100 & 132 & 185 & 236 \\
\hline
\end{tabular}

$n=7$, mean $\pm \mathrm{SD} ; * P<0.05,{ }^{*} P<0.01$ significant difference compared to control.

5.3. Capmul. Capmul is a glyceryl caprate produced from edible fats and oils. It is commonly used in lip products. Cho et al. [230] reported that capmul MCM C10 enhanced the bioavailability of ceftriaxone by $55-79 \%$ in rats.

5.4. Cow Urine Distillate. Cow urine distillate is more effective as bioenhancer than cow urine, to increase the effectiveness of antimicrobial, antifungal, and anticancer drugs [231].

Cow urine has antitoxic activity against the cadmium chloride toxicity and it can be used as a bioenhancer of zinc. Mature male mice exposed to cadmium chloride only showed $0 \%$ fertility rate. However, the animals exposed to cadmium chloride + cow urine distillate + zinc sulfate showed $90 \%$ fertility rate with $100 \%$ viability and lactation indices. Fertility index was also found to be $88 \%$ in group treated with cadmium chloride + cow urine distillate. Thus, these results indicate that cow urine distillate works as an antitoxic against the cadmium chloride toxicity and it can be used as a bioenhancer of zinc [232].

Cow urine distillate increased the activity of rifampicin by about 5-7 times against Escherichia coli and 3-11 times against Gram-positive bacteria. It probably acts by enhancing the transport of antibiotics across the membrane of gastrointestinal tract. The enhancement in transport is approximately 2-7 times [109].

Cow urine distillate enhanced the gonadotropin releasing hormone conjugate on the reproductive hormones and estrous cycle of female mice [233]. Cow urine distillate significantly enhanced the effect of gonadotropin releasing hormone on the gonadosomatic indices, sperm motility, sperm count, and sperm morphology, especially in 90- and 120 -day-treated groups $(P<0.05)$ in male mice.Cow urine distillate enhanced these effects because of its immunomodulatory properties [234].

\section{Conclusions}

The effective formulation strategy for the optimization of the pharmacokinetic characteristics of dietary components is crucial to improve their in vivo performance and ultimately maximize their effectiveness as a bioavailability enhancer [235]. The available scientific research on bioenhancers has shown to produce significant enhancing effect on bioavailability when coadministered or pretreated with many drugs and nutraceuticals. These natural compounds include piperine, Zingiber officinale, niaziridin, glycyrrhizin, Cuminum cyminum, Carum carvi, allicin, lysergol, Aloe vera, Stevia rebaudiana, curcumin, sinomenine, genistein, Ammannia multiflora, capsaicin, quercetin, naringin, capmul and cow urine distillate. They reduce the dose, shorten treatment, and thus reduce drug-resistance and drug toxicity or adverse reactions. Due to dose economy, treatment is cost-effective. Bioenhancers are also found to decrease or having no effect or little effect on the bioavailability of some drugs [73, 128, 129].

The current paper discussed the enhancing effects of bioenhancers of drugs in animals and humans but these compounds have not been completely explored in experimental animals till date. However, these studies lack information on their exact mechanism of action, toxicity evaluation 
TABLE 33: Pharmacokinetic parameters of verapamil $(9 \mathrm{mg} / \mathrm{kg})$ and in combination with naringin pretreated rabbits after oral administration [222].

\begin{tabular}{|c|c|c|c|c|}
\hline \multirow{2}{*}{ Parameters } & \multirow{2}{*}{ Verapamil control } & \multicolumn{3}{|c|}{ Naringin pretreatment } \\
\hline & & $1.5 \mathrm{mg} / \mathrm{kg}$ & $7.5 \mathrm{mg} / \mathrm{kg}$ & $15 \mathrm{mg} / \mathrm{kg}$ \\
\hline$\overline{\mathrm{AUC}}(\mathrm{ng} \cdot \mathrm{h} / \mathrm{mL})$ & $291 \pm 75.7$ & $370 \pm 96.1^{*}$ & $445 \pm 1025^{* *}$ & $494 \pm 142^{* *}$ \\
\hline$C_{\max }(\mathrm{ng} / \mathrm{mL})$ & $55.3 \pm 14.4$ & $66.5 \pm 17.3$ & $86.9 \pm 53.3^{* *}$ & $92.6 \pm 54.5^{* *}$ \\
\hline$t_{\max }(\mathrm{h})$ & $0.25 \pm 0.07$ & $0.25 \pm 0.08$ & $0.25 \pm 0.06$ & $0.25 \pm 0.08$ \\
\hline$K_{a}(/ \mathrm{h})$ & $3.8 \pm 0.99$ & $5.1 \pm 1.30$ & $6.1 \pm 1.59^{*}$ & $6.8 \pm 1.72^{*}$ \\
\hline$t_{1 / 2}(\mathrm{~h})$ & $12.0 \pm 3.12$ & $13.4 \pm 3.46$ & $13.6 \pm 3.51$ & $13.9 \pm 3.61$ \\
\hline$A B(\%)$ & $8.8 \pm 2.3$ & $11.2 \pm 2.8^{*}$ & $13.5 \pm 3.2^{* *}$ & $15.0 \pm 3.4^{* *}$ \\
\hline$R B(\%)$ & 100 & 126 & 153 & 169 \\
\hline
\end{tabular}

$n=6$, mean $\pm \mathrm{SD} ;{ }^{*} P<0.05,{ }^{* *} P<0.01$, significant difference compared to control.

of extracts, and suitable combinations. Therefore, we have to focus on this area for further research on their active principles, mechanisms of actions, toxicity evaluation, and suitable combinations with other drugs. So we can explore novel principles with high bioenhancing ability and less toxic effects.

\section{Abbreviations}

AB: Absolute bioavailability

AUC: Area under the plasma concentration-time curve

AUC: Area under the plasma concentration-time curve from $0 \mathrm{~h}$ to infinity

AUC: Area under the plasma concentration-time curve from $0 \mathrm{~h}$ to $24 \mathrm{~h}$

$\mathrm{AUC}_{t}$ : Area under the plasma concentration-time curve from 0 hours to the last measurable concentration

AUMC: Area under the first moment of plasma drug concentration-time curve

$\beta$ : $\quad$ Overall elimination rate constant

BE: Bioavailability enhancer

$C_{\max }$ : Peak concentration

$C_{\text {last }}$ : Last measurable concentration

$C_{\mathrm{ss}}$ : $\quad$ Steady state plasma concentration

$\mathrm{Cl}_{B}$ : Total body clearance

$\mathrm{Cl}_{F}$ : Total plasma clearance

$\mathrm{Cl}_{R}$ : Renal clearance

HPLC: High-performance liquid chromatography

$K_{a}$ : $\quad$ Absorption rate constant

$K_{\mathrm{el}}: \quad$ Elimination rate constant

$K_{i}$ : $\quad$ Ionization constant

$K_{m}$ : Michaelis constant

$\mathrm{LD}_{50}$ : Half-maximal lethal dose

MIC: Minimum inhibitory concentration

MRT: Mean residence time

RB: $\quad$ Relative bioavailability

$t_{1 / 2}$ : Terminal halflife

$t_{1 / 2 \alpha}$ : Absorption half life

$t_{1 / 2 \beta}$ : Elimination half life

$t_{\max }$ : Time to reach peak concentration

$t_{d}$ : Total duration of pharmacological effect
$V_{d}: \quad$ Volume of distribution

$V_{d \text { (area) }}$ : Total area under the plasma drug concentration curve

$V_{d(B)}$ : Apparent volume of distribution based on the zero time plasma concentration intercept of the elimination phase

$V_{\max }$ : Maximum enzyme velocity.

\section{Acknowledgments}

The authors are thankful to Dr. S. K. Mody and Dr. H. B. Patel for their help and guidance in preparation and editing. No conflict of interests declared.

\section{References}

[1] N. Atal and K. L. Bedi, "Bioenhancers: revolutionary concept to market," Journal of Ayurveda and Integrative Medicine, vol. 1, no. 2, pp. 96-99, 2010.

[2] S. P. S. Khanuja, J. S. Arya, S. K. Srivastava et al., "Antibiotic pharmaceutical composition with lysergol as bioenhancer and method of treatment," United States Patent Number, 20070060604A1, 2007.

[3] K. G. Bose, Pharmacopoeia India, Bose Laboratories, Calcutta, India, 1929.

[4] C. K. Atal, "A breakthrough in drug bioavailability-a clue from age old wisdom of Ayurveda," IMDA Bulletin, vol. 10, pp. 483-484, 1979.

[5] G. N. Qazi, K. L. Bedi, R. K. Johri et al., "Bioavailability enhancing activity of Carum carvi extracts and fractions thereof," United States Patent Number, US20070020347A1, 2007.

[6] P. Breedveld, J. H. Beijnen, and J. H. M. Schellens, "Use of Pglycoprotein and BCRP inhibitors to improve oral bioavailability and CNS penetration of anticancer drugs," Trends in Pharmacological Sciences, vol. 27, no. 1, pp. 17-24, 2006.

[7] M. J. Kang, J. Y. Cho, B. H. Shim, D. K. Kim, and J. Lee, "Bioavailability enhancing activities of natural compounds from medicinal plants," Journal of Medicinal Plant Research, vol. 3, no. 13, pp. 1204-1211, 2009.

[8] I. A. Khan, Z. M. Mirza, A. Kumar, V. Verma, and G. N. Qazi, "Piperine, a phytochemical potentiator of ciprofloxacin against Staphylococcus aureus," Antimicrobial Agents and Chemotherapy, vol. 50, no. 2, pp. 810-812, 2006. 
[9] W. Reanmongkol, W. Janthasoot, W. Wattanatorn, P. Dhumma-Upakorn, and P. Chudapongse, "Effects of piperine on bioenergetic functions of isolated rat liver mitochondria," Biochemical Pharmacology, vol. 37, no. 4, pp. 753-757, 1988.

[10] D. S. Jamwal and J. Singh, "Effects of piperine on enzyme activities and bioenergetic functions in isolated rat liver mitochondria and hepatocytes," Journal of Biochemical Toxicology, vol. 8, no. 4, pp. 167-174, 1993.

[11] A. R. Annamalai and R. Manavalan, "Effects of "Trikatu" and its individual components and piperine on gastro intestinal tracts: trikatu: a bioavailable enhancer," Indian Drugs, vol. 27, no. 12, pp. 595-604, 1990.

[12] R. K. Johri, N. Thusu, A. Khajuria, and U. Zutshi, "Piperinemediated changes in the permeability of rat intestinal epithelial cells. The status of $\gamma$-glutamyl transpeptidase activity, uptake of amino acids and lipid peroxidation," Biochemical Pharmacology, vol. 43, no. 7, pp. 1401-1407, 1992.

[13] M. Majeed, V. Badmaev, and R. Rajendran, "Use of piperine to increase bioavailability of nutritional compounds," United States Patent Number, US005536506A, 1996.

[14] S. Bajad, K. L. Bedi, A. K. Singla, and R. K. Johri, "Piperine inhibits gastric emptying and gastrointestinal transit in rats and mice," Planta Medica, vol. 67, no. 2, pp. 176-179, 2001.

[15] C. K. Atal, R. K. Dubey, and J. Singh, "Biochemical basis of enhanced drug bioavailability by piperine: evidence that piperine is a potent inhibitor of drug metabolism," Journal of Pharmacology and Experimental Therapeutics, vol. 232, no. 1, pp. 258-262, 1985.

[16] R. K. Reen, D. S. Jamwal, S. C. Taneja et al., "Impairment of UDP-glucose dehydrogenase and glucuronidation activities in liver and small intestine of rat and guinea pig in vitro by piperine," Biochemical Pharmacology, vol. 46, no. 2, pp. 229238, 1993.

[17] R. K. Bhardwaj, H. Glaeser, L. Becquemont, U. Klotz, S. K. Gupta, and M. F. Fromm, "Piperine, a major constituent of black pepper, inhibits human P-glycoprotein and CYP3A4," Journal of Pharmacology and Experimental Therapeutics, vol. 302, no. 2, pp. 645-650, 2002.

[18] A. Khajuria, N. Thusu, and U. Zutshi, "Piperine modulates permeability characteristics of intestine by inducing alterations in membrane dynamics: influence on brush border membrane fluidity, ultrastructure and enzyme kinetics," Phytomedicine, vol. 9, no. 3, pp. 224-231, 2002.

[19] M. Majeed, V. Badmaev, and R. Rajendran, "Use of piperine as a bioavailability enhancer," United States Patent Number, 5744161, 1998.

[20] V. Badmaev, M. Majeed, and E. P. Norkus, "Piperine, an alkaloid derived from black pepper increases serum response of beta-carotene during 14-days of oral beta-carotene supplementation," Nutrition Research, vol. 19, no. 3, pp. 381-388, 1999.

[21] R. D’Hooge, Y. Q. Pei, A. Raes, P. Lebrun, P. P. Van Bogaert, and P. P. De Deyn, "Anticonvulsant activity of piperine on seizures induced by excitatory amino acid receptor agonists," Arzneimittel-Forschung/Drug Research, vol. 46, no. 6, pp. 557560, 1996.

[22] A. M. Mujumdar, J. N. Dhuley, V. K. Deshmukh, P. H. Raman, and S. R. Naik, "Anti-inflammatory activity of piperine," Japanese Journal of Medical Science and Biology, vol. 43, no. 3, pp. 95-100, 1990.

[23] S. Kumar, V. Singhal, R. Roshan, A. Sharma, G. W. Rembhotkar, and B. Ghosh, "Piperine inhibits TNF- $\alpha$ induced adhesion of neutrophils to endothelial monolayer through suppression of NF- $\kappa \mathrm{B}$ and $\mathrm{I} \kappa \mathrm{B}$ kinase activation," European Journal of Pharmacology, vol. 575, no. 1-3, pp. 177-186, 2007.

[24] V. S. Parmar, S. C. Jain, K. S. Bisht et al., "Phytochemistry of the genus Piper," Phytochemistry, vol. 46, no. 4, pp. 597-673, 1997.

[25] P. Piyachaturawa and C. Pholpramool, "Enhancement of fertilization by piperine in hamsters," Cell Biology International, vol. 21, no. 7, pp. 405-409, 1997.

[26] H. M. D. Navickiene, A. C. Alécio, M. J. Kato et al., "Antifungal amides from Piper hispidum and Piper tuberculatum," Phytochemistry, vol. 55, no. 6, pp. 621-626, 2000.

[27] S. Bajad, K. L. Bedi, A. K. Singla, and R. K. Johri, "Antidiarrhoeal activity of piperine in mice," Planta Medica, vol. 67, no. 3, pp. 284-287, 2001.

[28] R. Mittal and R. L. Gupta, "in vitro antioxidant activity of piperine," Methods and Findings in Experimental and Clinical Pharmacology, vol. 22, no. 5, pp. 271-274, 2000.

[29] K. A. Naidu and N. B. Thippeswamy, "Inhibition of human low density lipoprotein oxidation by active principles from spices," Molecular and Cellular Biochemistry, vol. 229, no. 12, pp. 19-23, 2002.

[30] R. S. Vijayakumar, D. Surya, and N. Nalini, "Antioxidant efficacy of black pepper (Piper nigrum L.) and piperine in rats with high fat diet induced oxidative stress," Redox Report, vol. 9, no. 2, pp. 105-110, 2004.

[31] I. Gülçin, "The antioxidant and radical scavenging activities of black pepper (Piper nigrum) seeds," International Journal of Food Sciences and Nutrition, vol. 56, no. 7, pp. 491-499, 2005.

[32] K. Selvendiran, R. Padmavathi, V. Magesh, and D. Sakthisekaran, "Preliminary study on inhibition of genotoxicity by piperine in mice," Fitoterapia, vol. 76, no. 3-4, pp. 296300, 2005.

[33] N. Jain and R. N. Mishra, "Antioxidant activity of Trikatu megaExt," International Journal of Research in Pharmaceutical and Biomedical Sciences, vol. 2, pp. 624-624, 2011.

[34] C. R. Pradeep and G. Kuttan, "Effect of piperine on the inhibition of lung metastasis induced B16F-10 melanoma cells in mice," Clinical and Experimental Metastasis, vol. 19, no. 8, pp. 703-708, 2002.

[35] S. Panda and A. Kar, "Piperine lowers the serum concentrations of thyroid hormones, glucose and hepatic 5'D activity in adult male mice," Hormone and Metabolic Research, vol. 35 , no. 9, pp. 523-526, 2003.

[36] R. S. Vijayakumar and N. Nalini, "Piperine, an active principle from Piper nigrum, modulates hormonal and apolipoprotein profiles in hyperlipidemic rats," Journal of Basic and Clinical Physiology and Pharmacology, vol. 17, no. 2, pp. 7186, 2006.

[37] R. El Hamss, M. Idaomar, A. Alonso-Moraga, and A. Muñoz Serrano, "Antimutagenic properties of bell and black peppers," Food and Chemical Toxicology, vol. 41, no. 1, pp. 41-47, 2003.

[38] K. Selvendiran, S. M. Banu, and D. Sakthisekaran, "Oral supplementation of piperine leads to altered phase II enzymes and reduced DNA damage and DNA-protein cross links in Benzo(a)pyrene induced experimental lung carcinogenesis," Molecular and Cellular Biochemistry, vol. 268, no. 1-2, pp. 141-147, 2005.

[39] K. Srinivasan, "Black pepper and its pungent principlepiperine: a review of diverse physiological effects," Critical Reviews in Food Science and Nutrition, vol. 47, no. 8, pp. 735748, 2007. 
[40] S. Wongpa, L. Himakoun, S. Soontornchai, and P. Temcharoen, "Antimutagenic effects of piperine on cyclophosphamide-induced chromosome aberrations in rat bone marrow cells," Asian Pacific Journal of Cancer Prevention, vol. 8, no. 4, pp. 623-627, 2007.

[41] E. S. Sunila and G. Kuttan, "Immunomodulatory and antitumor activity of Piper longum Linn. and piperine," Journal of Ethnopharmacology, vol. 90, no. 2-3, pp. 339-346, 2004.

[42] S. Manoharan, S. Balakrishnan, V. P. Menon, L. M. Alias, and A. R. Reena, "Chemopreventive \& efficacy of curcumin and piperine during 7,12-dimethylbenz (a)anthracene-induced hamster buccal pouch carcinogenesis," Singapore Medical Journal, vol. 50, no. 2, pp. 139-146, 2009.

[43] S. A. Lee, S. S. Hong, X. H. Han et al., "Piperine from the fruits of Piper longum with inhibitory effect on monoamine oxidase and antidepressant-like activity," Chemical and Pharmaceutical Bulletin, vol. 53, no. 7, pp. 832-835, 2005.

[44] S. Li, C. Wang, M. Wang, W. Li, K. Matsumoto, and Y. Tang, "Antidepressant like effects of piperine in chronic mild stress treated mice and its possible mechanisms," Life Sciences, vol. 80, no. 15, pp. 1373-1381, 2007.

[45] J. Wattanathorn, P. Chonpathompikunlert, S. Muchimapura, A. Priprem, and O. Tankamnerdthai, "Piperine, the potential functional food for mood and cognitive disorders," Food and Chemical Toxicology, vol. 46, no. 9, pp. 3106-3110, 2008.

[46] B. S. Park, D. J. Son, Y. H. Park, T. W. Kim, and S. E. Lee, "Antiplatelet effects of acidamides isolated from the fruits of Piper longum L," Phytomedicine, vol. 14, no. 12, pp. 853-855, 2007.

[47] S. Pooja, R. P. Agrawal, P. Nyati, V. Savita, and P. Phadnis, "Analgesic activity ofPiper nigrumextract per se and its interaction with diclofenac sodium and pentazocine in albino mice," The Internet Journal of Pharmacology, vol. 5, no. 1, p. 3, 2007.

[48] H. Matsuda, K. Ninomiya, T. Morikawa, D. Yasuda, I. Yamaguchi, and M. Yoshikawa, "Protective effects of amide constituents from the fruit of Piper chaba on d-galactosamine/ TNF- $\alpha$-induced cell death in mouse hepatocytes," Bioorganic and Medicinal Chemistry Letters, vol. 18, no. 6, pp. 20382042, 2008.

[49] S. I. H. Taqvi, A. J. Shah, and A. H. Gilani, "Blood pressure lowering and vasomodulator effects of piperine," Journal of Cardiovascular Pharmacology, vol. 52, no. 5, pp. 452-458, 2008.

[50] S. H. Kim and Y. C. Lee, "Piperine inhibits eosinophil infiltration and airway hyperresponsiveness by suppressing $\mathrm{T}$ cell activity and Th2 cytokine production in the ovalbumininduced asthma model," Journal of Pharmacy and Pharmacology, vol. 61, no. 3, pp. 353-359, 2009.

[51] I. B. Koul and A. Kapil, "Evaluation of the liver protective potential of piperine, an active principle of black and long peppers," Planta Medica, vol. 59, no. 5, pp. 413-417, 1993.

[52] S. Unchern, H. Saito, and N. Nishiyama, "Selective cytotoxicity of piperine on cultured rat hippocampal neurons in comparison with cultured astrocytes: the possible involvement of lipid peroxidation," Biological and Pharmaceutical Bulletin, vol. 20, no. 9, pp. 958-961, 1997.

[53] M. B. Daware, A. M. Mujumdar, and S. Ghaskadbi, "Reproductive toxicity of piperine in Swiss albino mice," Planta Medica, vol. 66, no. 3, pp. 231-236, 2000.

[54] R. K. S. Dogra, S. Khanna, and R. Shanker, "Immunotoxicological effects of piperine in mice," Toxicology, vol. 196, no. 3, pp. 229-236, 2004.
[55] J. Singh, R. K. Reen, and F. J. Wiebel, "Piperine, a major ingredient of black and long peppers, protects against AFB1induced cytotoxicity and micronuclei formation in H4IIEC3 rat hepatoma cells," Cancer Letters, vol. 86, no. 2, pp. 195200, 1994.

[56] R. K. Reen, F. J. Wiebel, and J. Singh, "Piperine inhibits aflatoxin $\mathrm{B}_{1}$-induced cytotoxicity and genotoxicity in V79 Chinese hamster cells genetically engineered to express rat cytochrome P4502B1," Journal of Ethnopharmacology, vol. 58, no. 3, pp. 165-173, 1997.

[57] A. Khajuria, N. Thusu, U. Zutshi, and K. L. Bedi, "Piperine modulation of carcinogen induced oxidative stress in intestinal mucosa," Molecular and Cellular Biochemistry, vol. 189, no. 1-2, pp. 113-118, 1998.

[58] K. Selvendiran, S. M. Banu, and D. Sakthisekaran, "Protective effect of piperine on benzo(a)pyrene-induced lung carcinogenesis in Swiss albino mice," Clinica Chimica Acta, vol. 350, no. 1-2, pp. 73-78, 2004.

[59] K. Selvendiran, J. P. V. Singh, K. B. Krishnan, and D. Sakthisekaran, "Cytoprotective effect of piperine against benzo[a]pyrene induced lung cancer with reference to lipid peroxidation and antioxidant system in Swiss albino mice," Fitoterapia, vol. 74, no. 1-2, pp. 109-115, 2003.

[60] K. Selvendiran, P. Senthilnathan, V. Magesh, and D. Sakthisekaran, "Modulatory effect of Piperine on mitochondrial antioxidant system in Benzo(a)pyrene-induced experimental lung carcinogenesis," Phytomedicine, vol. 11, no. 1, pp. 85-89, 2004.

[61] K. Selvendiran, C. Thirunavukkarasu, J. P. V. Singh, R. Padmavathi, and D. Sakthisekaran, "Chemopreventive effect of piperine on mitochondrial TCA cycle and phase-I and glutathione-metabolizing enzymes in benzo(a)pyrene induced lung carcinogenesis in Swiss albino mice," Molecular and Cellular Biochemistry, vol. 271, no. 1-2, pp. 101-106, 2005.

[62] B. M. Choi, S. M. Kim, T. K. Park et al., "Piperine protects cisplatin-induced apoptosis via heme oxygenase-1 induction in auditory cells," Journal of Nutritional Biochemistry, vol. 18, no. 9, pp. 615-622, 2007.

[63] J. Q. Zhao, G. Z. Du, Y. C. Xiong, Y. F. Wen, M. Bhadauria, and S. K. Nirala, "Attenuation of beryllium induced hepatorenal dysfunction and oxidative stress in rodents by combined effect of gallic acid and piperine," Archives of Pharmacal Research, vol. 30, no. 12, pp. 1575-1583, 2007.

[64] N. Pathak and S. Khandelwal, "Comparative efficacy of piperine, curcumin and picroliv against $\mathrm{Cd}$ immunotoxicity in mice," BioMetals, vol. 21, no. 6, pp. 649-661, 2008.

[65] P. Piyachaturawat, T. Glinsukon, and C. Toskulkao, "Acute and subacute toxicity of piperine in mice, rats and hamsters," Toxicology Letters, vol. 16, no. 3-4, pp. 351-359, 1983.

[66] J. Singh, R. K. Dubey, and C. K. Atal, "Piperine-mediated inhibition of glucuronidation activity in isolated epithelial cells of the guinea-pig small intestine: evidence that piperine lowers the endogeneous UDP-glucuronic acid content," Journal of Pharmacology and Experimental Therapeutics, vol. 236, no. 2, pp. 488-493, 1986.

[67] J. R. Stöhr, P. G. Xiao, and R. Bauer, "Constituents of Chinese Piper species and their inhibitory activity on prostaglandin and leukotriene biosynthesis in vitro," Journal of Ethnopharmacology, vol. 75, no. 2-3, pp. 133-139, 2001.

[68] A. Allameh, M. Saxena, G. Biswas, H. G. Raj, J. Singh, and N. Srivastava, "Piperine, a plant alkaloid of the piper species, enhances the bioavailability of aflatoxin $\mathrm{B}_{1}$ in rat tissues," Cancer Letters, vol. 61, no. 3, pp. 195-199, 1992. 
[69] T. Malini, R. R. Manimaran, J. Arunakaran, M. M. Aruldhas, and P. Govindarajulu, "Effects of piperine on testis of albino rats," Journal of Ethnopharmacology, vol. 64, no. 3, pp. 219225, 1999.

[70] S. A. Dhanukar, A. B. Kapadia, and S. M. Karandikar, "Influence of Trikatu powder on rifampicin bioavailability," Indian Drugs, vol. 20, pp. 402-404, 1983.

[71] R. S. Karan, V. K. Bhargava, and S. K. Garg, "Effect of trikatu, an Ayurvedic prescription, on the pharmacokinetic profile of rifampicin in rabbits," Journal of Ethnopharmacology, vol. 64, no. 3, pp. 259-264, 1999.

[72] R. S. Karan, V. K. Bhargava, and S. K. Garg, "Effect of Trikatu (PIPERINE) on the pharmacokinetic profile of isoniazld in rabbits," Indian Journal of Pharmacology, vol. 30, no. 4, pp. 254-256, 1998.

[73] L. G. Lala, P. M. D’Mello, and S. R. Naik, "Pharmacokinetic and pharmacodynamic studies on interaction of "trikatu" with diclofenac sodium," Journal of Ethnopharmacology, vol. 91, no. 2-3, pp. 277-280, 2004.

[74] U. Zutshi and J. L. Kaul, "The impact of Ayurvedic herbals on drug bioavailability," Indian Drugs, vol. 19, pp. 476-479, 1982.

[75] U. Zutshi, "A process for the preparation of pharmaceutical combination with enhanced activity for treatment of tuberculosis and leprosy," Indian Patent No. 1232/DEL/89, 1989.

[76] G. Bano, V. Amla, R. K. Raina, U. Zutshi, and C. L. Chopra, "The effect of piperine on pharmacokinetics of phenytoin in healthy volunteers," Planta Medica, vol. 53, no. 6, pp. 568$569,1987$.

[77] G. Bano, R. K. Raina, U. Zutshi, K. L. Bedi, R. K. Johri, and S. C. Sharma, "Effect of piperine on bioavailability and pharmacokinetics of propranolol and theophylline in healthy volunteers," European Journal of Clinical Pharmacology, vol. 41, no. 6, pp. 615-617, 1991.

[78] A. M. Mujumdar, J. N. Dhuley, V. K. Deshmukh, P. H. Raman, S. L. Thorat, and S. R. Naik, "Effect of piperine on pentobarbitone induced hypnosis in rats," Indian Journal of Experimental Biology, vol. 28, no. 5, pp. 486-487, 1990.

[79] G. Shoba, D. Joy, T. Joseph, M. Majeed, R. Rajendran, and P. S. S. R. Srinivas, "Influence of piperine on the pharmacokinetics of curcumin in animals and human volunteers," Planta Medica, vol. 64, no. 4, pp. 353-356, 1998.

[80] J. Shaikh, D. D. Ankola, V. Beniwal, D. Singh, and M. N. V. R. Kumar, "Nanoparticle encapsulation improves oral bioavailability of curcumin by at least 9 -fold when compared to curcumin administered with piperine as absorption enhancer," European Journal of Pharmaceutical Sciences, vol. 37, no. 3-4, pp. 223-230, 2009.

[81] D. Suresh and K. Srinivasan, "Tissue distribution \& elimination of capsaicin, piperine \& curcumin following oral intake in rats," Indian Journal of Medical Research, vol. 131, no. 5, pp. 682-691, 2010.

[82] S. K. Gupta, T. Velpandian, S. Sengupta, P. Mathur, and P. Sapra, "Influence of piperine on nimesulide induced antinociception," Phytotherapy Research, vol. 12, pp. 266-269, 1998.

[83] R. S. Karan, V. K. Bhargava, and S. K. Garg, "Effect of trikatu on the pharmacokinetic profile of indomethacin in rabbits," Indian Journal of Pharmacology, vol. 31, no. 2, pp. 160-161, 1999.

[84] A. M. Mujumdar, J. N. Dhuley, V. K. Deshmukh, and S. R. Naik, "Effect of piperine on bioavailability of oxyphenylbutazone in rats," Indian Drugs, vol. 36, no. 2, pp. 123-126, 1999.
[85] T. Velpandian, R. Jasuja, R. K. Bhardwaj, J. Jaiswal, and S. K. Gupta, "Piperine in food: interference in the pharmacokinetics of phenytoin," European Journal of Drug Metabolism and Pharmacokinetics, vol. 26, no. 4, pp. 241-247, 2001.

[86] S. Pattanaik, D. Hota, S. Prabhakar, P. Kharbanda, and P. Pandhi, "Effect of piperine on the steady-state pharmacokinetics of phenytoin in patients with epilepsy," Phytotherapy Research, vol. 20, no. 8, pp. 683-686, 2006.

[87] R. K. Zutshi, R. Singh, U. Zutshi, R. K. Johri, and C. K. Atal, "Influence of piperine on rifampicin blood levels in patients of pulmonary tuberculosis," The Journal of the Association of Physicians of India, vol. 33, no. 3, pp. 223-224, 1985.

[88] V. Balakrishnan, S. Varma, and D. Chatterji, "Piperine augments transcription inhibitory activity of rifampicin by severalfold in Mycobacterium smegmatis," Current Science, vol. 80, no. 10, pp. 1302-1305, 2001.

[89] A. R. Hiwale, J. N. Dhuley, and S. R. Naik, "Effect of coadministration of piperine on pharmacokinetics of $\beta$-lactam antibiotics in rats," Indian Journal of Experimental Biology, vol. 40, no. 3, pp. 277-281, 2002.

[90] J. D. Lambert, J. Hong, D. H. Kim, V. M. Mishin, and C. S. Yang, "Piperine enhances the bioavailability of the tea polyphenol (-)-epigallocatechin-3-gallate in mice," Journal of Nutrition, vol. 134, no. 8, pp. 1948-1952, 2004.

[91] M. Singh, C. Varshneya, R. S. Telang, and A. K. Srivastava, "Alteration of pharmacokinetics of oxytetracycline following oral administration of Piper longum in hens," Journal of Veterinary Science, vol. 6, no. 3, pp. 197-200, 2005.

[92] B. S. Balkrishna and P. V. Yogesh, "Influence of co-administration of piperine on pharmacokinetic profile of ciprofloxacin," Indian Drugs, vol. 39, no. 3, pp. 166-168, 2002.

[93] R. Kasibhatta and M. U. R. Naidu, "Influence of piperine on the pharmacokinetics of nevirapine under fasting conditions: a randomised, crossover, placebo-controlled study," Drugs in $R$ and D, vol. 8, no. 6, pp. 383-391, 2007.

[94] M. S. Dama, C. Varshneya, M. S. Dardi, and V. C. Katoch, "Effect of trikatu pretreatment on the pharmacokinetics of pefloxacin administered orally in mountain Gaddi goats," Journal of Veterinary Science, vol. 9, no. 1, pp. 25-29, 2008.

[95] K. Janakiraman and R. Manavalan, "Compatibility and stability studies of ampicillin trihydrate and piperine mixture," International Journal of Pharmaceutical Sciences and Research, vol. 2, pp. 1176-1181, 2008.

[96] S. Pattanaik, D. Hota, S. Prabhakar, P. Kharbanda, and P. Pandhi, "Pharmacokinetic interaction of single dose of piperine with steady-state carbamazepine in epilepsy patients," Phytotherapy Research, vol. 23, no. 9, pp. 1281-1286, 2009.

[97] M. J. Jin and H. K. Han, "Effect of piperine, a major component of black pepper, on the intestinal absorption of fexofenadine and its implication on food-drug interaction," Journal of Food Science, vol. 75, no. 3, pp. H93-H96, 2010.

[98] A. Singh, V. K. Pawar, V. Jakhmola, M. H. Parabia, R. Awasthi, and G. Sharma, "In vivo assessment of enhanced bioavailability of metronidazole with piperine in rabbits," Research Journal of Pharmaceutical, Biological and Chemical Sciences, vol. 1, no. 4, pp. 273-278, 2010.

[99] K. Janakiraman and R. Manavalan, "Studies on effect of piperine on oral bioavailability of ampicillin and norfloxacin," African Journal of Traditional, Complementary and Alternative Medicines, vol. 5, pp. 257-262, 2011.

[100] J. J. Johnson, M. Nihal, I. A. Siddiqui et al., "Enhancing the bioavailability of resveratrol by combining it with piperine," Molecular Nutrition and Food Research, vol. 55, no. 8, pp. 1169-1176, 2011. 
[101] S. Patel, S. Devada, H. Patel, N. Patel, S. Bhavsar, and A. Thaker, "Influence of co-administration of piperine on pharmacokinetic profile of gatifloxacin in layer birds," Global Veterinaria, vol. 7, pp. 427-432, 2011.

[102] S. S. Devada, S. D. Patel, H. B. Patel, N. N. Patel, S. K. Bhavsar, and A. M. Thaker, "Bioenhancing activity of piperine on pharmacokinetics of gatifloxacin in broiler birds," Inventi Impact: Planta Activa, vol. 2011, Article ID: Inventi:ppa/10/11, 2011, http://www.inventi.in/Article/ppa/ 10/11.aspx.

[103] A. Singh and S. Chand, "Improved bioavailability of atenolol with piperine in rats," International Journal of Pharmaceutical Research, vol. 3, pp. 88-91, 2011.

[104] S. Venkatesh, K. D. Durga, Y. Padmavathi, B. M. Reddy, and R. Mullangi, "Influence of piperine on ibuprofen induced antinociception and its pharmacokinetics," Drug Research, vol. 61, pp. 506-509, 2011.

[105] A. Singh, D. A. Jain, S. Kumar, N. Jaishwal, R. K. Singh, and P. S. Patel, "Enhanced bioavailability of losartan potassium with piperine in rats," International Journal of Pharmacy Research and Technology, vol. 2, pp. 34-36, 2012.

[106] V. Badmaev, M. Majeed, and L. Prakash, "Piperine derived from black pepper increases the plasma levels of coenzyme $\mathrm{Q}_{10}$ following oral supplementation," Journal of Nutritional Biochemistry, vol. 11, no. 2, pp. 109-113, 2000.

[107] R. S. Kapil, U. Zutshi, K. L. Bedi et al., "Process of preparation of pharmaceutical composition with enhanced activity for treatment of tuberculosis and leprosy," United States Patent Number, US005439891A, 1995.

[108] R. S. Kapil, U. Zutshi, K. L. Bedi et al., "Pharmaceutical compositions containing piperine and an antituberculosis or antileprosy drug," European Patent Number, EP0650728B1, 2002.

[109] P. C. Chawla, "Resorine:a novel CSIR drug curtails TB treatment,” CSIR News, vol. 60, pp. 52-54, 2010.

[110] V.S. Govindarajan, "Ginger-chemistry, technology, and quality evaluation: part 2," Critical Reviews in Food Science and Nutrition, vol. 17, no. 3, pp. 189-258, 1982.

[111] S. D. Jolad, R. C. Lantz, A. M. Solyom, G. J. Chen, R. B. Bates, and B. N. Timmermann, "Fresh organically grown ginger (Zingiber officinale): composition and effects on LPS-induced PGE2 production," Phytochemistry, vol. 65, no. 13, pp. 19371954, 2004.

[112] W. C. Evans, Ginger. Trease and Evans Pharmacognosy, WB Saunders, Edinburgh, UK, 15th edition, 2002.

[113] M. O’Hara, D. Kiefer, K. Farrell, and K. Kemper, "A review of 12 commonly used medicinal herbs," Archives of Family Medicine, vol. 7, no. 6, pp. 523-536, 1998.

[114] A. A. Oyagbemi, A. B. Saba, and O. I. Azeez, "Molecular targets of [6]-gingerol: its potential roles in cancer chemoprevention," BioFactors, vol. 36, no. 3, pp. 169-178, 2010.

[115] J. Yamahara, M. Mochizuki, H. Q. Rong, H. Matsuda, and H. Fujimura, "The anti-ulcer effect in rats of ginger constituents," Journal of Ethnopharmacology, vol. 23, no. 2-3, pp. 299-304, 1988.

[116] H. Wu, D. Ye, Y. Bai, and Y. Zhao, "Effect of dry ginger and roasted ginger on experimental gastric ulcers in rats," China Journal of Chinese Materia Medica, vol. 15, no. 5, pp. 278-317, 1990.

[117] M. Thomson, K. K. Al-Qattan, S. M. Al-Sawan, M. A. Alnaqeeb, I. Khan, and M. Ali, "The use of ginger (Zingiber officinale Rosc.) as a potential anti-inflammatory and antithrombotic agent," Prostaglandins Leukotrienes and Essential Fatty Acids, vol. 67, no. 6, pp. 475-478, 2002.
[118] G. C. Jagetia, M. S. Baliga, P. Venkatesh, and J. N. Ulloor, "Influence of ginger rhizome (Zingiber officinale Rosc) on survival, glutathione and lipid peroxidation in mice after whole-body exposure to Gamma radiation," Radiation Research, vol. 160, no. 5, pp. 584-592, 2003.

[119] C. Ficker, M. L. Smith, K. Akpagana et al., "Bioassay-guided isolation and identification of antifungal compounds from ginger," Phytotherapy Research, vol. 17, no. 8, pp. 897-902, 2003.

[120] R. Grzanna, L. Lindmark, and C. G. Frondoza, "Gingeran herbal medicinal product with broad anti-inflammatory actions," Journal of Medicinal Food, vol. 8, no. 2, pp. 125-132, 2005.

[121] J. A. O. Ojewole, "Analgesic, antiinflammatory and hypoglycaemic effects of ethanol extract of Zingiber officinale (Roscoe) rhizomes (Zingiberaceae) in mice and rats," Phytotherapy Research, vol. 20, no. 9, pp. 764-772, 2006.

[122] J. K. Kim, Y. Kim, K. M. Na, Y. J. Surh, and T. Y. Kim, “[6]gingerol prevents UVB-induced ROS production and COX-2 expression in vitro and in vivo," Free Radical Research, vol. 41, no. 5, pp. 603-614, 2007.

[123] Z. M. Al-Amin, M. Thomson, K. K. Al-Qattan, and M. Ali, "Anti-diabetic and hypolipidaemic properties of ginger (Zingiber officinale) in streptozotocin-induced diabetic rats," British Journal of Nutrition, vol. 96, no. 4, pp. 660-666, 2006.

[124] S. A. Boone and K. M. Shields, "Treating pregnancy-related nausea and vomiting with ginger," Annals of Pharmacotherapy, vol. 39, no. 10, pp. 1710-1713, 2005.

[125] N. Chaiyakunapruk, N. Kitikannakorn, S. Nathisuwan, K. Leeprakobboon, and C. Leelasettagool, "The efficacy of ginger for the prevention of postoperative nausea and vomiting: a meta-analysis," American Journal of Obstetrics and Gynecology, vol. 194, no. 1, pp. 95-99, 2006.

[126] Z. Iqbal, M. Lateef, M. S. Akhtar, M. N. Ghayur, and A. H. Gilani, "In vivo anthelmintic activity of ginger against gastrointestinal nematodes of sheep," Journal of Ethnopharmacology, vol. 106, no. 2, pp. 285-287, 2006.

[127] Y. Shukla and M. Singh, "Cancer preventive properties of ginger: a brief review," Food and Chemical Toxicology, vol. 45, no. 5, pp. 683-690, 2007.

[128] G. N. Qazi, K. L. Bedi, R. K. Johri et al., "Bioavailability enhancing activity of Zingiber officinale and its extracts/ fractions thereof," United States Patent Number, US2003/ 0170326A1, 2003.

[129] G. N. Qazi, C. L. Tikoo, A. K. Gupta et al., "Bioavailability enhancing activity of Zingiber officinale Linn and its extracts/ fractions thereof," World Intellectual Property Organization, International Publication Number, WO03049753A1, 2003.

[130] K. Shanker, M. M. Gupta, S. K. Srivastava, D. U. Bawankule, A. Pal, and S. P. S. Khanuja, "Determination of bioactive nitrile glycoside(s) in drumstick (Moringa oleifera) by reverse phase HPLC," Food Chemistry, vol. 105, no. 1, pp. 376-382, 2007.

[131] S. Shukla, R. Mathur, and A. O. Prakash, "Antifertility profile of the aqueous extract of Moringa oleifera roots," Journal of Ethnopharmacology, vol. 22, no. 1, pp. 51-62, 1988.

[132] A. Caceres, O. Cabrera, O. Morales, P. Mollinedo, and P. Mendia, "Pharmacological properties of Moringa oleifera. 1: preliminary screening for antimicrobial activity," Journal of Ethnopharmacology, vol. 33, no. 3, pp. 213-216, 1991.

[133] A. Caceres, A. Saravia, S. Rizzo, L. Zabala, E. De Leon, and F. Nave, "Pharmacologic properties of Moringa oleifera. 2: screening for antispasmodic, antiinflammatory and diuretic 
activity," Journal of Ethnopharmacology, vol. 36, no. 3, pp. 233-237, 1992.

[134] K. Aruna and V. M. Sivaramakrishnan, "Anticarcinogenic effects of some Indian plant products," Food and Chemical Toxicology, vol. 30, no. 11, pp. 953-956, 1992.

[135] A. P. Guevara and C. Vargas, "Anti-inflammatory and antitumor activities of seed extracts of malunggay, Moringa oleiferaL. (Moringaceae)," Philippine Journal of Science, vol. 125, pp. 175-184, 1996.

[136] A. H. Gilani, K. Aftab, A. Suria et al., "Pharmacological studies on hypotensive and spasmolytic activities of pure compounds from Moringa oleifera," Phytotherapy Research, vol. 8, no. 2, pp. 87-91, 1994.

[137] M. O. Nwosu and J. I. Okafor, "Preliminary studies of the antifungal activities of some medicinal plants against Basidiobolus and some other pathogenic fungi," Mycoses, vol. 38, no. 5-6, pp. 191-195, 1995.

[138] S. K. Pal, P. K. Mukherjee, and B. P. Saha, "Studies on the antiulcer activity of Moringa oleifera leaf extract on gastric ulcer models in rats," Phytotherapy Research, vol. 9, no. 6, pp. 463-465, 1995.

[139] P. Siddhuraju and K. Becker, "Antioxidant properties of various solvent extracts of total phenolic constituents from three different agroclimatic origins of drumstick tree (Moringa oleifera Lam.) leaves," Journal of Agricultural and Food Chemistry, vol. 51, no. 8, pp. 2144-2155, 2003.

[140] N. Oinam, A. Urooj, P. P. Phillips, and N. P. Niranjan, "Effect of dietary lipids and drumstick leaves (Moringa oleifera) on lipid profile and antioxidant parameters in rats," Food and Nutrition Sciences, vol. 3, pp. 141-145, 2012.

[141] L. Pari and N. A. Kumar, "Hepatoprotective activity of Moringa oleifera on antitubercular drug-induced liver damage in rats," Journal of Medicinal Food, vol. 5, no. 3, pp. 171$177,2002$.

[142] L. K. Mehta, R. Balaraman, A. H. Amin, P. A. Bafna, and O. D. Gulati, "Effect of fruits of Moringa oleifera on the lipid profile of normal and hypercholesterolaemic rabbits," Journal of Ethnopharmacology, vol. 86, no. 2-3, pp. 191-195, 2003.

[143] K. B. Saravillo and A. A. Herrera, "Biological activity of Moringa oleifera Lam. (Malunggay) crude seed extract," Philippine Agricultural Scientist, vol. 87, no. 1, pp. 96-100, 2004.

[144] S. G. Mahajan, R. G. Mali, and A. A. Mehta, "Protective effect of ethanolic extract of seeds of Moringa oleifera Lam. against inflammation associated with development of arthritis in rats," Journal of Immunotoxicology, vol. 4, no. 1, pp. 39-47, 2007.

[145] S. P. S. Khanuja, J. S. Arya, T. Ranganathan et al., "Nitrile glycoside useful as a bioenhancer of drugs and nutrients, process of its isolation from Moringa oleifera," United States Patent Number, US006858588B2, 2005.

[146] S. P. S. Khanuja, J. S. Arya, T. Ranganathan et al., "Nitrile glycoside useful as a bioenhancer of drugs and nutrients, process of its isolation from Moringa oleifera," European Patent Number, EP1611148B1, 2008.

[147] Y. Kiso, M. Tohkin, and H. Hikino, "Mechanism of antihepatotoxic activity of glycyrrhizin, I: effect on free radical generation and lipid peroxidation," Planta Medica, vol. 50, no. 4, pp. 298-302, 1984.

[148] M. Nose, M. Ito, K. Kamimura, M. Shimizu, and Y. Ogihara, "A comparison of the antihepatotoxic activity between glycyrrhizin and glycyrrhetinic acid," Planta Medica, vol. 60, no. 2, pp. 136-139, 1994.

[149] H. Akamatsu, J. Komura, Y. Asada, and Y. Niwa, "Mechanism of anti-inflammatory action of glycyrrhizin: effect on neutrophil functions including reactive oxygen species generation," Planta Medica, vol. 57, no. 2, pp. 119-121, 1991.

[150] Y. Fujisawa, M. Sakamoto, M. Matsushita, T. Fujita, and K. Nishioka, "Glycyrrhizin inhibits the lytic pathway of complement-possible mechanism of its anti-inflammatory effect on liver cells in viral hepatitis," Microbiology and Immunology, vol. 44, no. 9, pp. 799-804, 2000.

[151] S. Shibata, "Antitumor promoting and anti-inflammatory activities of licorice principles and their modified compounds," Food Phytochemicals for Cancer Prevention-II, vol. 31, pp. 308-321, 1994.

[152] T. Utsunomiya, M. Kobayashi, R. B. Pollard, and F. Suzuki, "Glycyrrhizin, an active component of licorice roots, reduces morbidity and mortality of mice infected with lethal doses of influenza virus," Antimicrobial Agents and Chemotherapy, vol. 41, no. 3, pp. 551-556, 1997.

[153] J. M. Crance, N. Scaramozzino, A. Jouan, and D. Garin, "Interferon, ribavirin, 6-azauridine and glycyrrhizin: antiviral compounds active against pathogenic flaviviruses," Antiviral Research, vol. 58, no. 1, pp. 73-79, 2003.

[154] S. P. S. Khanuja, S. Kumar, J. S. Arya et al., "Composition comprising pharmaceutical/nutraceutical agent and a bioenhancer obtained from Glycyrrhiza glabra," United States Patent Number, US006979471B1, 2005.

[155] S. P. S. Khanuja, S. Kumar, J. S. Arya et al., "Composition comprising pharmaceutical/nutraceutical agent and a bioenhancer obtained from Glycyrrhiza glabra," United States Patent Number, US20060057234A1, 2006.

[156] N. S. Iacobellis, P. Lo Cantore, F. Capasso, and F. Senatore, "Antibacterial activity of Cuminum cyminum L. and Carum carvi L. essential oils," Journal of Agricultural and Food Chemistry, vol. 53, no. 1, pp. 57-61, 2005.

[157] T. Malini and G. Vanithakumari, "Estrogenic activity of Cuminum cyminum in rats," Indian Journal of Experimental Biology, vol. 25, no. 7, pp. 442-444, 1987.

[158] S. Dhandapani, V. R. Subramanian, S. Rajagopal, and N. Namasivayam, "Hypolipidemic effect of Cuminum cyminum L. on alloxan-induced diabetic rats," Pharmacological Research, vol. 46, no. 3, pp. 251-255, 2002.

[159] M. Sayyah, A. Peirovi, and M. Kamalinejad, "Anti-nociceptive effect of the fruit essential oil of Cuminum cyminum L. in rat," Iranian Biomedical Journal, vol. 6, no. 4, pp. 141-145, 2002.

[160] M. Sayyah, A. Mahboubi, and M. Kamalinejad, "Anticonvulsant effect of the fruit essential oil of Cuminum cyminum in mice," Pharmaceutical Biology, vol. 40, no. 6, pp. 478-480, 2002.

[161] Gagandeep, S. Dhanalakshmi, E. Méndiz, A. R. Rao, and R. K. Kale, "Chemopreventive effects of Cuminum cyminum in chemically induced forestomach and uterine cervix tumors in murine model systems," Nutrition and Cancer, vol. 47, no. 2, pp. 171-180, 2003.

[162] L. Gachkar, D. Yadegari, M. B. Rezaei, M. Taghizadeh, S. A. Astaneh, and I. Rasooli, "Chemical and biological characteristics of Cuminum cyminum and Rosmarinus officinalis essential oils," Food Chemistry, vol. 102, no. 3, pp. 898-904, 2007.

[163] M. H. Boskabady, S. Kiani, H. Azizi, and T. Khatami, "Antitussive effect of Cuminum cyminum Linn. in guinea pigs," Natural Product Radiance, vol. 5, pp. 266-269, 2006.

[164] A. H. El-Ghorab, M. Nauman, F. M. Anjum, S. Hussain, and M. Nadeem, "A Comparative study on chemical composition and antioxidant activity of ginger (Zingiber officinale) and 
cumin (Cuminum cyminum)," Journal of Agricultural and Food Chemistry, vol. 58, no. 14, pp. 8231-8237, 2010.

[165] M. B. H. Pai, G. M. Prashant, K. S. Murlikrishna, K. M. Shivakumar, and G. N. Chandu, "Antifungal efficacy of Punica granatum, Acacia nilotica, Cuminum cyminum and Foeniculum vulgare on Candida albicans: an in vitro study," Indian Journal of Dental Research, vol. 21, no. 3, pp. 334-336, 2010.

[166] G. N. Qazi, K. L. Bedi, R. K. Johri et al., "Bioavailability enhancing activity of Cuminum cyminum extracts and fractions thereof," World Intellectual Property Organization, International Publication Number, WO03075685A2, 2003.

[167] G. N. Qazi, K. L. Bedi, R. K. Johri et al., "Bioavailability/bioefficacy enhancing activity of Cuminum cyminum and extracts and fractions thereof," United States Patent Number, US007514105B2, 2009.

[168] H. Toxopeus and H. J. Bouwmeester, "Improvement of caraway essential oil and carvone production in The Netherlands," Industrial Crops and Products, vol. 1, no. 2-4, pp. 295301, 1992.

[169] M. T. Khayyal, M. A. El-Ghazaly, S. A. Kenawy et al., "Antiulcerogenic effect of some gastrointestinally acting plant extracts and their combination," Arzneimittel-Forschung/ Drug Research, vol. 51, no. 7, pp. 545-553, 2001.

[170] M. Eddouks, A. Lemhadri, and J. B. Michel, "Caraway and caper: potential anti-hyperglycaemic plants in diabetic rats," Journal of Ethnopharmacology, vol. 94, no. 1, pp. 143-148, 2004.

[171] L. De Martino, V. De Feo, F. Fratianni, and F. Nazzaro, "Chemistry, antioxidant, antibacterial and antifungal activities of volatile oils and their components," Natural Product Communications, vol. 4, no. 12, pp. 1741-1750, 2009.

[172] S. Lahlou, A. Tahraoui, Z. Israili, and B. Lyoussi, "Diuretic activity of the aqueous extracts of Carum carvi and Tanacetum vulgare in normal rats," Journal of Ethnopharmacology, vol. 110, no. 3, pp. 458-463, 2007.

[173] A. Najda, J. Dyduch, and N. Brzozowski, "Flavonoid content and antioxidant activity of caraway roots (Carum carviL," Vegetable Crops Research Bulletin, vol. 68, pp. 127-133, 2008.

[174] M. R. Abyaneh, M. S. Ghahfarokhi, M. B. Rezaee et al., "Chemical composition and antiaflatoxigenic activity of Carum carvi L., Thymus vulgaris and Citrus aurantifolia essential oils," Food Control, vol. 20, no. 11, pp. 1018-1024, 2009.

[175] G. N. Qazi, K. L. Bedi, R. K. Johri et al., "Bioavailability enhancing activity of Carum carvi extracts and fractions thereof,' United States Patent Number, US20030228381A1, 2003.

[176] A. N. Makheja and J. M. Bailey, "Antiplatelet constituents of garlic and onion," Agents and Actions, vol. 29, no. 3-4, pp. 360-363, 1990.

[177] K. Prasad, V. A. Laxdal, M. Yu, and B. L. Raney, "Antioxidant activity of allicin, an active principle in garlic," Molecular and Cellular Biochemistry, vol. 148, no. 2, pp. 183-189, 1995.

[178] L. Y. Chung, "The antioxidant properties of garlic compounds: alyl cysteine, alliin, allicin, and allyl disulfide," Journal of Medicinal Food, vol. 9, no. 2, pp. 205-213, 2006.

[179] S. Ankri and D. Mirelman, "Antimicrobial properties of allicin from garlic," Microbes and Infection, vol. 1, no. 2, pp. 125-129, 1999.

[180] Y. Cai, R. Wang, F. Pei, and B. B. Liang, "Antibacterial activity of allicin alone and in combination with $\beta$-lactams against Staphylococcus spp. and Pseudomonas aeruginosa," Journal of Antibiotics, vol. 60, no. 5, pp. 335-338, 2007.
[181] K. Hirsch, M. Danilenko, J. Giat et al., "Effect of purified allicin, the major ingredient of freshly crushed garlic, on cancer cell proliferation," Nutrition and Cancer, vol. 38, no. 2, pp. 245-254, 2000.

[182] N. S. Kang, E. Y. Moon, C. G. Cho, and S. Pyo, "Immunomodulating effect of garlic component, allicin, on murine peritoneal macrophages," Nutrition Research, vol. 21, no. 4, pp. 617-626, 2001.

[183] J. K. Grover, S. Yadav, and V. Vats, "Medicinal plants of India with anti-diabetic potential," Journal of Ethnopharmacology, vol. 81, no. 1, pp. 81-100, 2002.

[184] A. Eidi, M. Eidi, and E. Esmaeili, "Antidiabetic effect of garlic (Allium sativum L.) in normal and streptozotocin-induced diabetic rats," Phytomedicine, vol. 13, no. 9-10, pp. 624-629, 2006.

[185] J. P. Anthony, L. Fyfe, and H. Smith, "Plant active components-a resource for antiparasitic agents?" Trends in Parasitology, vol. 21, no. 10, pp. 462-468, 2005.

[186] S. R. Davis, "An overview of the antifungal properties of allicin and its breakdown products - the possibility of a safe and effective antifungal prophylactic," Mycoses, vol. 48, no. 2, pp. 95-100, 2005.

[187] A. Ogita, K. I. Fujita, M. Taniguchi, and T. Tanaka, "Enhancement of the fungicidal activity of amphotericin B by allicin, an allyl-sulfur compound from garlic, against the yeast Saccharomyces cerevisiae as a model system," Planta Medica, vol. 72, no. 13, pp. 1247-1250, 2006.

[188] H. Borjihan, A. Ogita, K. I. Fujita, E. Hirasawa, and T. Tanaka, "The vacuole-targeting fungicidal activity of amphotericin $B$ against the pathogenic fungus Candida albicans and its enhancement by allicin," Journal of Antibiotics, vol. 62, no. 12, pp. 691-697, 2009.

[189] T. H. Tsai, P. J. Tsai, and S. C. Ho, "Antioxidant and antiinflammatory activities of several commonly used spices," Journal of Food Science, vol. 70, no. 1, pp. C93-C97, 2005.

[190] E. A. Wilson and B. Demmig-Adams, "Antioxidant, antiinflammatory, and antimicrobial properties of garlic and onions," Nutrition and Food Science, vol. 37, no. 3, pp. 178183, 2007.

[191] R. Naithani, L. C. Huma, L. E. Holland et al., "Antiviral activity of phytochemicals: a comprehensive review," MiniReviews in Medicinal Chemistry, vol. 8, no. 11, pp. 1106-1133, 2008.

[192] A. Ogita, K. Hirooka, Y. Yamamoto et al., "Synergistic fungicidal activity of $\mathrm{Cu}^{2+}$ and allicin, an allyl sulfur compound from garlic, and its relation to the role of alkyl hydroperoxide reductase 1 as a cell surface defense in Saccharomyces cerevisiae," Toxicology, vol. 215, no. 3, pp. 205-213, 2005.

[193] A. Ogita, K. I. Fujita, and T. Tanaka, "Enhancement of the fungicidal activity of amphotericin B by allicin: effects on intracellular ergosterol trafficking," Planta Medica, vol. 75, no. 3, pp. 222-226, 2009.

[194] A. Ogita, M. Yutani, K. I. Fujita, and T. Tanaka, "Dependence of vacuole disruption and independence of potassium ion efflux in fungicidal activity induced by combination of amphotericin B and allicin against Saccharomyces cerevisiae," The Journal of Antibiotics, vol. 63, no. 12, pp. 689-692, 2010.

[195] S. Patil, R. P. Dash, S. Anandjiwala, and M. Nivsarkar, "Simultaneous quantification of berberine and lysergol by HPLCUV: evidence that lysergol enhances the oral bioavailability of berberine in rats," Biomedical Chromatography, vol. 26, no. 10, pp. 1170-1175, 2012. 
[196] J. A. Vinson, H. Al Kharrat, and L. Andreoli, "Effect of Aloe vera preparations on the human bioavailability of vitamins $C$ and E," Phytomedicine, vol. 12, no. 10, pp. 760-765, 2005.

[197] G. R. Gokaraju and R. R. Gokaraju, "Bioavailability/bioefficacy enhancing activity of Stevia rebaudiana and extracts and fractions and compounds thereof," Date of Publication: 06/05/2010. United States Patent Number, US2010011 2101A1, 2010

[198] W. Zhang and L. Y. Lim, "Effects of spice constituents on P-glycoprotein-mediated transport and CYP3A4-mediated metabolism in vitro," Drug Metabolism and Disposition, vol. 36, no. 7, pp. 1283-1290, 2008.

[199] W. Zhang, T. M. C. Tan, and L. Y. Lim, "Impact of curcumininduced changes in P-glycoprotein and CYP3A expression on the pharmacokinetics of peroral celiprolol and midazolam in rats," Drug Metabolism and Disposition, vol. 35, no. 1, pp. 110-115, 2007.

[200] B. H. Pavithra, N. Prakash, and K. Jayakumar, "Modification of pharmacokinetics of norfloxacin following oral administration of curcumin in rabbits," Journal of Veterinary Science, vol. 10, no. 4, pp. 293-297, 2009.

[201] Z. Q. Liu, H. Zhou, L. Liu et al., "Influence of co-administrated sinomenine on pharmacokinetic fate of paeoniflorin in unrestrained conscious rats," Journal of Ethnopharmacology, vol. 99, no. 1, pp. 61-67, 2005.

[202] K. Chan, Z. Q. Liu, Z. H. Jiang et al., "The effects of sinomenine on intestinal absorption of paeoniflorin by the everted rat gut sac model," Journal of Ethnopharmacology, vol. 103, no. 3, pp. 425-432, 2006.

[203] J. D. Lambert, J. Hong, G. Y. Yang, J. Liao, and C. S. Yang, "Inhibition of carcinogenesis by polyphenols: evidence from laboratory investigations," The American Journal of Clinical Nutrition, vol. 81, no. 1, pp. 284S-291S, 2005.

[204] M. S. Kurzer and X. Xu, "Dietary phytoestrogens," Annual Review of Nutrition, vol. 17, pp. 353-381, 1997.

[205] X. Li and J. S. Choi, "Effect of genistein on the pharmacokinetics of paclitaxel administered orally or intravenously in rats," International Journal of Pharmaceutics, vol. 337, no. 1-2, pp. 188-193, 2007.

[206] J. D. Lambert, S. J. Kwon, J. Ju et al., "Effect of genistein on the bioavailability and intestinal cancer chemopreventive activity of (-)-epigallocatechin-3-gallate," Carcinogenesis, vol. 29, no. 10, pp. 2019-2024, 2008.

[207] H. C. Upadhyay, G. R. Dwivedi, M. P. Darokar, V. Chaturvedi, and S. K. Srivastava, "Bioenhancing and antimycobacterial agents from Ammannia multiflora," Planta Medica, vol. 78, pp. 79-81, 2012.

[208] L. Cruz, G. Castañeda-Hernández, and A. Navarrete, "Ingestion of chilli pepper (Capsicum annuum) reduces salicylate bioavailability after oral aspirin administration in the rat," Canadian Journal of Physiology and Pharmacology, vol. 77, no. 6, pp. 441-446, 1999.

[209] H. S. López, L. G. Olvera, R. A. Jiménez, C. G. Olvera, and F. J. Gómez, "Administration of ciprofloxacin and capsaicin in rats to achieve higher maximal serum concentrations," Arzneimittel-Forschung/Drug Research, vol. 57, no. 5, pp. 286290, 2007.

[210] A. Bouraoui, A. Toumi, H. Ben Mustapha, and J. L. Brazier, "Effects of capsicum fruit on theophylline absorption and bioavailability in rabbits," Drug-Nutrient Interactions, vol. 5, no. 4, pp. 345-350, 1988.

[211] R. J. Nijveldt, E. Van Nood, D. E. C. Van Hoorn, P. G. Boelens, K. Van Norren, and P. A. M. Van Leeuwen, "Flavonoids: a review of probable mechanisms of action and potential applications," American Journal of Clinical Nutrition, vol. 74, no. 4, pp. 418-425, 2001.

[212] S. L. Hsiu, Y. C. Hou, Y. H. Wang, C. W. Tsao, S. F. Su, and P. D. L. Chao, "Quercetin significantly decreased cyclosporin oral bioavailability in pigs and rats," Life Sciences, vol. 72, no. 3, pp. 227-235, 2002.

[213] J. S. Choi and X. Li, "Enhanced diltiazem bioavailability after oral administration of diltiazem with quercetin to rabbits," International Journal of Pharmaceutics, vol. 297, no. 1-2, pp. $1-8,2005$.

[214] S. C. Shin, J. S. Choi, and X. Li, "Enhanced bioavailability of tamoxifen after oral administration of tamoxifen with quercetin in rats," International Journal of Pharmaceutics, vol. 313, no. 1-2, pp. 144-149, 2006.

[215] J. S. Choi, Y. J. Piao, and K. W. Kang, "Effects of quercetin on the bioavailability of doxorubicin in rats: role of CYP3A4 and P-gp inhibition by quercetin," Archives of Pharmacal Research, vol. 34, no. 4, pp. 607-613, 2011.

[216] Y. H. Wang, P. D. L. Chao, S. L. Hsiu, K. C. Wen, and Y. C. Hou, "Lethal quercetin-digoxin interaction in pigs," Life Sciences, vol. 74, no. 10, pp. 1191-1197, 2004.

[217] J. S. Choi, B. W. Jo, and Y. C. Kim, "Enhanced paclitaxel bioavailability after oral administration of paclitaxel or prodrug to rats pretreated with quercetin," European Journal of Pharmaceutics and Biopharmaceutics, vol. 57, no. 2, pp. 313318, 2004.

[218] J. S. Choi and H. K. Han, "The effect of quercetin on the pharmacokinetics of verapamil and its major metabolite, norverapamil, in rabbits," Journal of Pharmacy and Pharmacology, vol. 56, no. 12, pp. 1537-1542, 2004.

[219] K. A. Kim, P. W. Park, and J. Y. Park, "Short-term effect of quercetin on the pharmacokinetics of fexofenadine, a substrate of P-glycoprotein, in healthy volunteers," European Journal of Clinical Pharmacology, vol. 65, no. 6, pp. 609-614, 2009.

[220] L. Xiuguo and J. S. Choi, "Effects of quercetin on the pharmacokinetics of etoposide after oral or intravenous administration of etoposide in rats," Anticancer Research, vol. 29, no. 4, pp. 1411-1416, 2009.

[221] A. Kale, S. Gawande, S. Kotwal et al., "Studies on the effects of oral administration of nutrient mixture, quercetin and red onions on the bioavailability of epigallocatechin gallate from green tea extract," Phytotherapy Research, vol. 24, no. 1, pp. S48-S55, 2010

[222] C. H. Yeum and J. S. Choi, "Effect of naringin pretreatment on bioavailability of verapamil in rabbits," Archives of Pharmacal Research, vol. 29, no. 1, pp. 102-107, 2006.

[223] H. S. Park, J. U. H. Oh, J. H. Lee, and Y. J. Lee, "Minor effects of the Citrus flavonoids naringin, naringenin and quercetin, on the pharmacokinetics of doxorubicin in rats," Pharmazie, vol. 66, no. 6, pp. 424-429, 2011.

[224] R. A. Dixon and C. L. Steele, "Flavonoids and isoflavonoidsa gold mine for metabolic engineering," Trends in Plant Science, vol. 4, no. 10, pp. 394-400, 1999.

[225] P. Hodek, P. Trefil, and M. Stiborová, "Flavonoids-potent and versatile biologically active compounds interacting with cytochromes P450," Chemico-Biological Interactions, vol. 139, no. 1, pp. 1-21, 2002.

[226] J. Dupuy, G. Larrieu, J. F. Sutra, A. Lespine, and M. Alvinerie, "Enhancement of moxidectin bioavailability in lamb by a natural flavonoid: quercetin," Veterinary Parasitology, vol. 112, no. 4, pp. 337-347, 2003.

[227] H. A. Bardelmeijer, J. H. Beijnen, K. R. Brouwer et al., "Increased oral bioavailability of paclitaxel by GF120918 in 
mice through selective modulation of P-glycoprotein," Clinical Cancer Research, vol. 6, no. 11, pp. 4416-4421, 2000.

[228] J. S. Choi and H. K. Han, "Enhanced oral exposure of diltiazem by the concomitant use of naringin in rats," International Journal of Pharmaceutics, vol. 305, no. 1-2, pp. 122$128,2005$.

[229] S. C. Lim and J. S. Choi, "Effects of naringin on the pharmacokinetics of intravenous paclitaxel in rats," Biopharmaceutics and Drug Disposition, vol. 27, no. 9, pp. 443-447, 2006.

[230] S. W. Cho, J. S. Lee, and S. H. Choi, "Enhanced oral bioavailability of poorly absorbed drugs. I. Screening of absorption carrier for the ceftriaxone complex," Journal of Pharmaceutical Sciences, vol. 93, no. 3, pp. 612-620, 2004.

[231] P. T. Kekuda, B. C. Nishanth, S. V. Praveen Kumar, D. Kamal, M. Sandeep, and H. K. Megharaj, "Cow urine concentrate: a potent agent with antimicrobial and anthelmintic activity," Journal of Pharmacy Research, vol. 3, pp. 1025-1027, 2010.

[232] A. Khan and V. K. Srivastava, "Antitoxic and bioenhancing role of kamdhenu ark (cow urine distillate) on fertilitty rate of male mice (Mus musculus) affected by cadmium chloride toxicity," International Journal of Cow Science, vol. 1, pp. 4346, 2005.

[233] J. A. Ganaie and V. K. Shrivastava, "Effects of gonadotropin releasing hormone conjugate immunization and bioenhancing role of Kamdhenu ark on estrous cycle, serum estradiol and progesterone levels in female Mus musculus," Iranian Journal of Reproductive Medicine, vol. 8, no. 2, pp. 70-75, 2010.

[234] J. A. Ganaie, V. Gautam, and V. K. Shrivastava, "Effects of kamdhenu ark and active immunization by gonadotropin releasing hormone conjugate (GnRH-BSA) on gonadosomatic indices (GSI) and sperm parameters in male Mus musculus," Journal of Reproduction and Fertility, vol. 12, no. 1, pp. 3-7, 2011.

[235] H. K. Han, "The effects of black pepper on the intestinal absorption and hepatic metabolism of drugs," Expert Opinion on Drug Metabolism and Toxicology, vol. 7, no. 6, pp. 721729, 2011. 

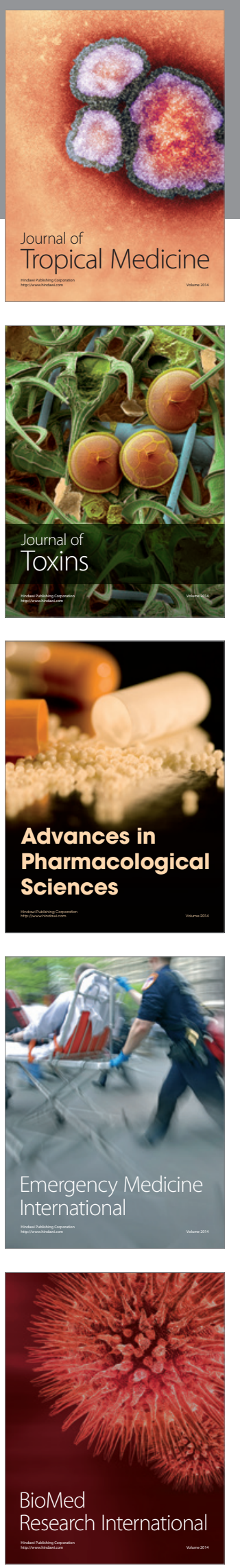
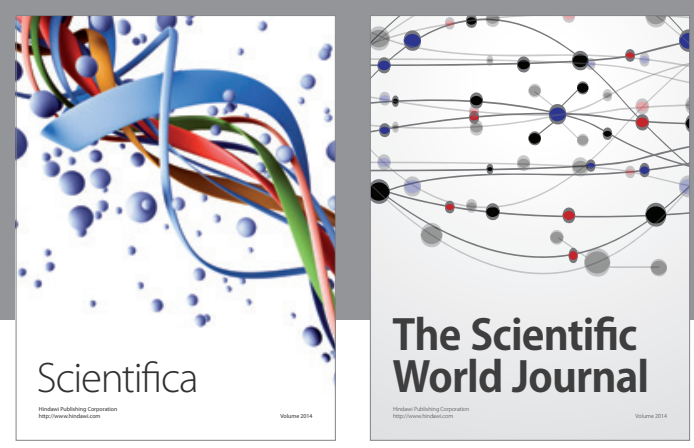

The Scientific World Journal
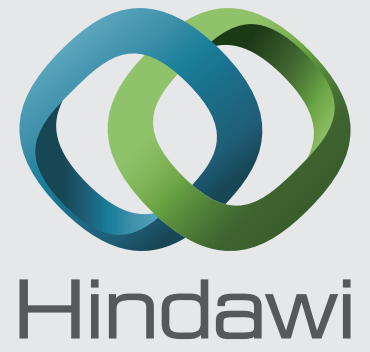

Submit your manuscripts at

http://www.hindawi.com
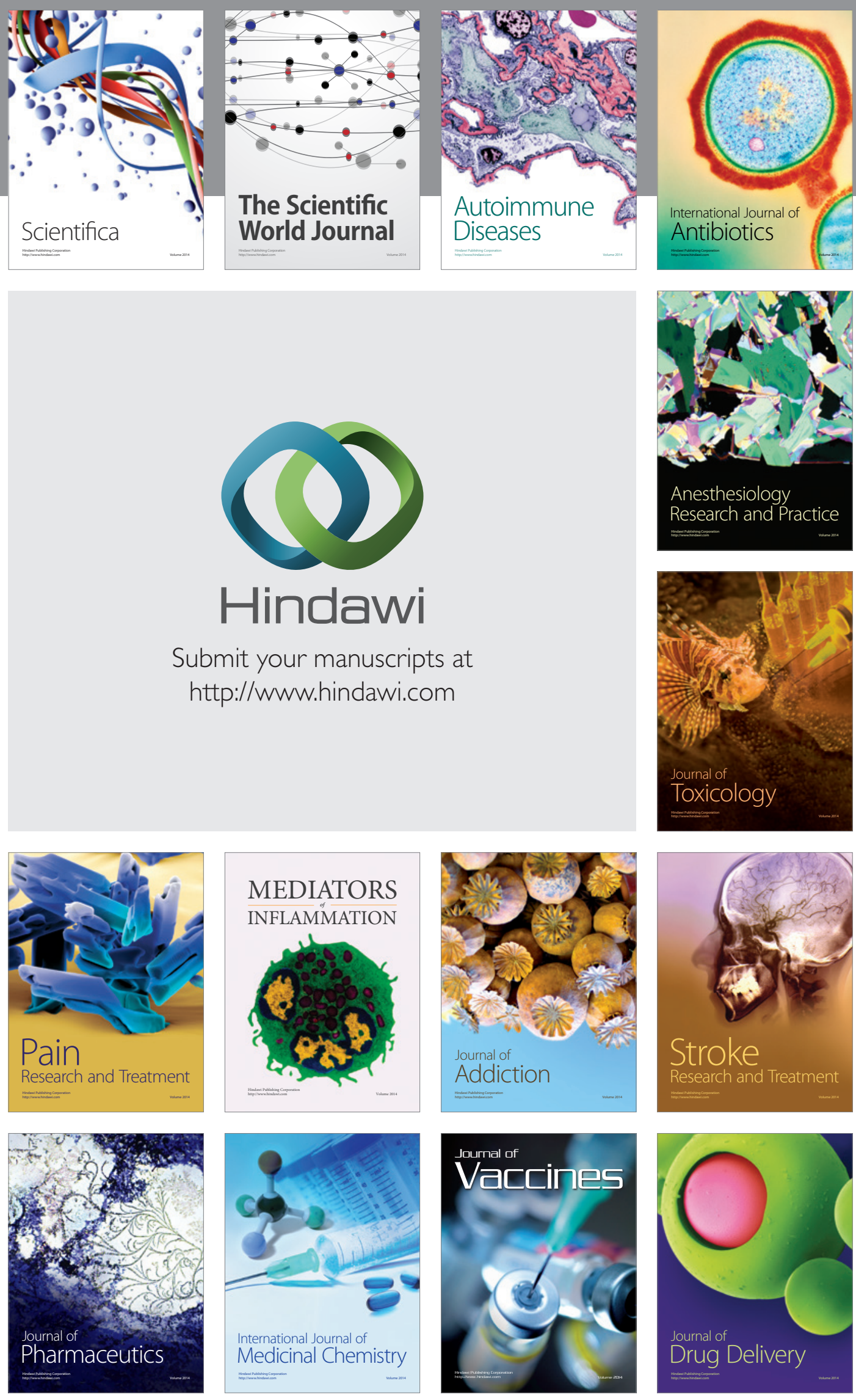